\title{
WestVirginiaUniversity
}

THE RESEARCH REPOSITORY @ WVU

Graduate Theses, Dissertations, and Problem Reports

2008

\section{Factors that affect college students' attitude toward mathematics}

Erin N. Goodykoontz

West Virginia University

Follow this and additional works at: https://researchrepository.wvu.edu/etd

\section{Recommended Citation}

Goodykoontz, Erin N., "Factors that affect college students' attitude toward mathematics" (2008).

Graduate Theses, Dissertations, and Problem Reports. 2837.

https://researchrepository.wvu.edu/etd/2837

This Dissertation is protected by copyright and/or related rights. It has been brought to you by the The Research Repository @ WVU with permission from the rights-holder(s). You are free to use this Dissertation in any way that is permitted by the copyright and related rights legislation that applies to your use. For other uses you must obtain permission from the rights-holder(s) directly, unless additional rights are indicated by a Creative Commons license in the record and/ or on the work itself. This Dissertation has been accepted for inclusion in WVU Graduate Theses, Dissertations, and Problem Reports collection by an authorized administrator of The Research Repository @ WVU.

For more information, please contact researchrepository@mail.wvu.edu. 
Factors that Affect College Students' Attitude toward Mathematics

Erin N. Goodykoontz

\author{
Dissertation submitted to the \\ College of Human Resources and Education \\ at West Virginia University \\ in partial fulfillment of the requirements \\ for the degree of
}

Doctor of Education

in

Curriculum and Instruction

\author{
Robert Mayes, Ed.D., co-chair \\ David Callejo-Perez, Ed. D., co-chair \\ Michael Mays, Ph.D. \\ Patricia Obenauf, Ed.D. \\ Jacqueline Webb-Dempsey, Ed.D.
}

Department of Curriculum and Instruction/Literacy Studies

\author{
Morgantown, West Virginia \\ 2008
}

Keywords: student attitudes, affect, mathematics, college attitudes

Copyright 2008 Erin N. Goodykoontz 


\title{
ABSTRACT \\ Factors that Affect College Students' Attitude toward Mathematics Erin N. Goodykoontz
}

\begin{abstract}
Many students have poor attitudes toward mathematics. This mixed methods study investigates factors that affect college students' attitudes toward mathematics as well as what may be done to reverse or prevent poor student attitudes in the future. Ninety-nine college algebra students completed a retorspective quantitative survey in order to amass numerical data and guide interview choices. Twenty-three of the ninetynine students were interviewed to gain in-depth knowledge of what factors affect their attitude as well as suggestions on improving these attitudes.
\end{abstract}

From this study, student attitudes are most affected by four external factors: the teacher, teaching style, classroom environment, and assessments and achievement. Additionally, one internal factor, individual perceptions and characteristics, also affect student attitudes. It is suggested that educators can affect the four external factors in order to influence the internal factor and, in turn, student attitudes. 


\section{DEDICATION}

For my husband, family, and friends, who keep me grounded and always support me. 


\section{ACKNOWLEDGEMENTS}

I would like to thank the Mathematics Department at West Virginia University for allowing me to conduct this study. Without their support, this study would not be possible. I would also like to thank them for supporting me as a part-time student in the College of Education and a full-time employee in their department. I appreciate their understanding in scheduling when trying to balance the classes I teach with the research and writing I was doing in order to obtain this degree. Also, thanks to many of the professors in the math department who have mentored me during various stages of the dissertation and my work as an undergraduate mathematics instructor.

Thank you to the college algebra students who agreed to participate in the study. I recognize how busy college students are and I appreciate them taking time to come and talk with me.

I would like to also thank my committee members for the guidance and support they have provided throughout this process. Thanks to Dave and Bob, who have read, edited, and guided me the whole way. Thank you also to Jaci, Mike, and Pat who provided suggestions and support. In addition to my committee members, I appreciate the support I have received from my friends in the doctoral program as we struggled together through this process. Special thanks to Sarah for the many conversations and suggestions she has given me.

Lastly, none of this would be possible without my husband, family, and friends. My oldest friends, Megan and Billie, have always provided me with complete support in all of my endeavors. I truly believe our friendship is one that many are not lucky enough to ever experience and I am thankful for them. My family is a constant in my life and my life is not complete without them. I am thankful for the closeness of our family and the unconditional love and support they give me in all areas of my life. I love you Mom, Dad, Becky, Jonathan, Mike, Amy and Elizabeth. Finally, eternal love and gratitude goes 
to my husband, Adam, who loves and supports all facets of me. He gives me stability, confidence and unwavering devotion. He accepts me in all ways, at all times and motivates me to succeed. Life would be empty without him. 


\section{TABLE OF CONTENTS}

Table of Contents ................................................................................................. vi

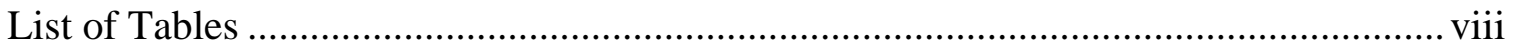

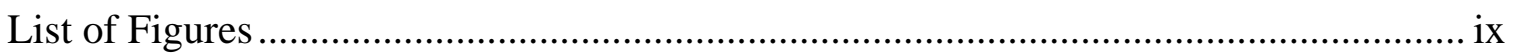

Chapter 1: Introduction ........................................................................................... 1

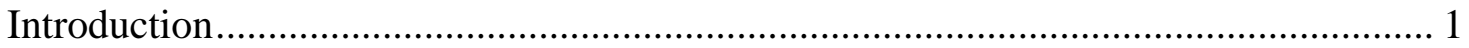

General Statement of the Problem .......................................................................... 1

Significance of Study ................................................................................................. 5

Why are college students' attitudes toward mathematics important?........................... 5

How will studying college students' attitudes toward mathematics advance knowledge in the realm of research in mathematics education?.................................. 7 How will studying college students' attitudes toward mathematics impact pedagogy?

Research Questions

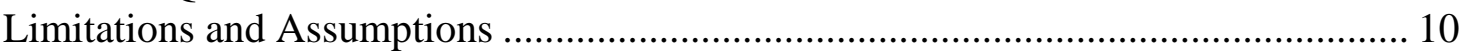

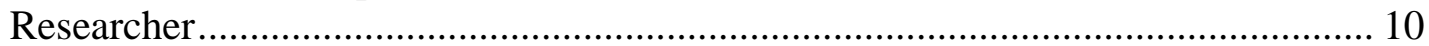

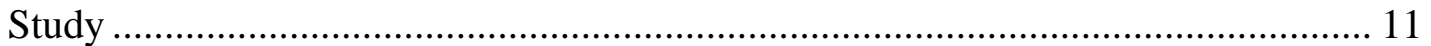

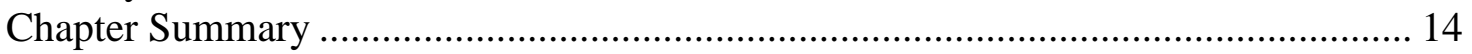

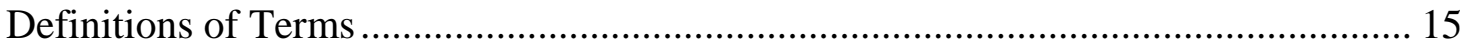

Chapter 2: Literature Review ............................................................................. 19

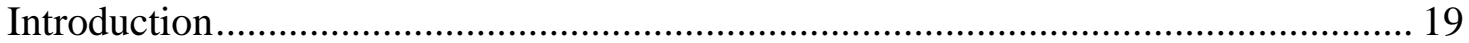

History of Mathematics Courses in Undergraduate Curriculum .................................. 20

Reform Movements in Undergraduate Mathematics Education...................................... 21

Calculus Reform Research..................................................................................... 22

Algebra Reform Research..................................................................................... 24

Implications of Undergraduate Mathematics Reform................................................... 27

Implications at Research Institution........................................................................ 28

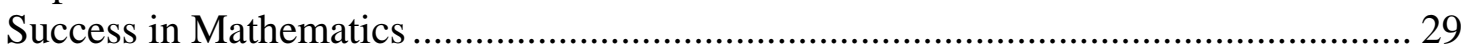

Affect, Attitude and Mathematics Education.............................................................. 30

Defining Affect, Attitudes, Beliefs, and Values …….................................................. 31

Affect, Attitude and Achievement ........................................................................... 35

Affect, Attitude and Instructional Factors …………..................................................... 38

Affect, Attitude and Instructional Style .......................................................................... 39

Affect, Attitude and Instructional Technique ............................................................. 41

Affect, Attitude and Teacher Beliefs ....................................................................... 44

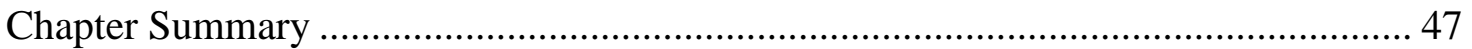

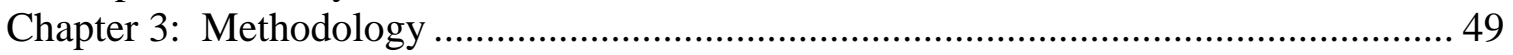

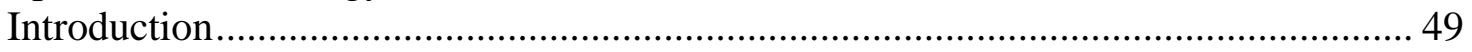

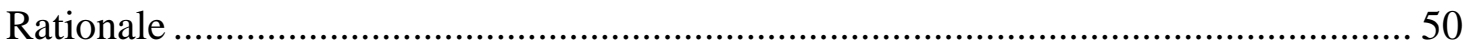

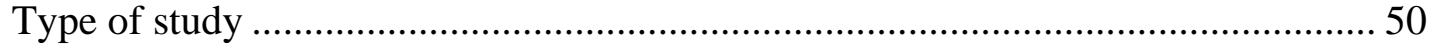

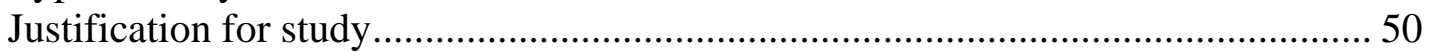

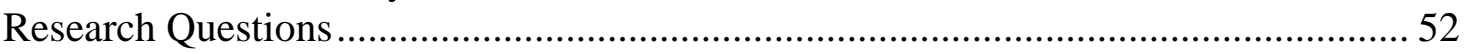

Research Design and Layout ................................................................................. 53

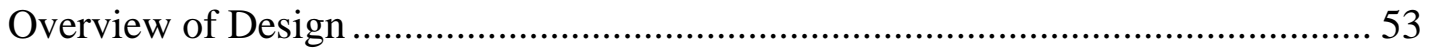




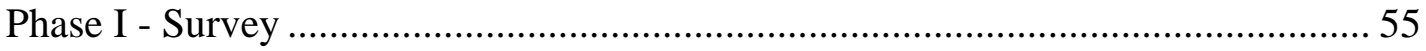

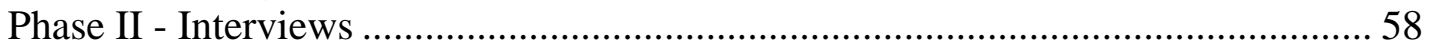

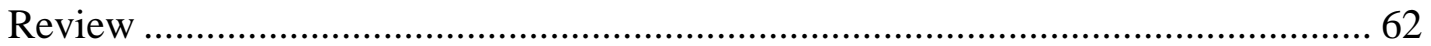

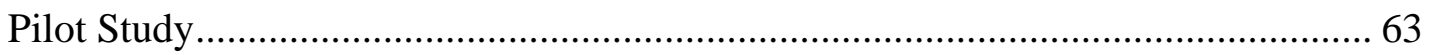

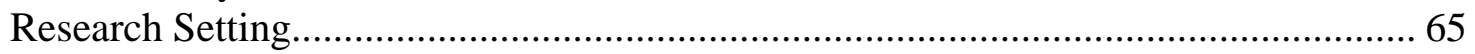

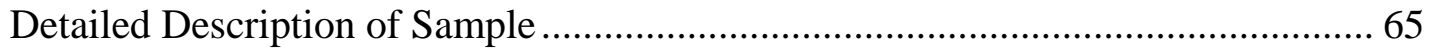

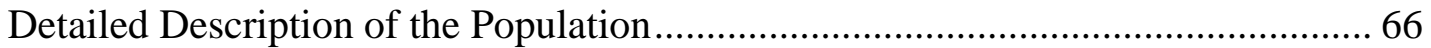

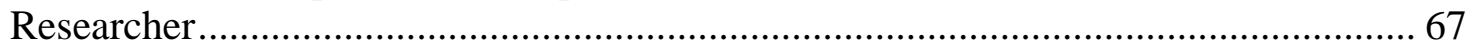

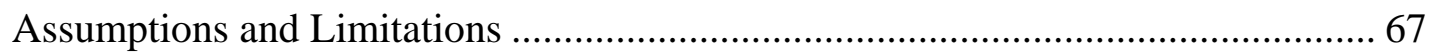

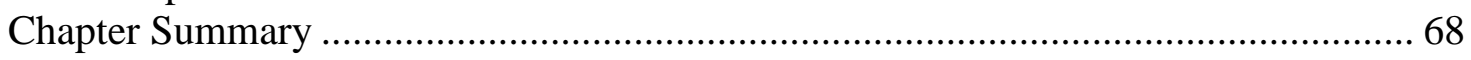

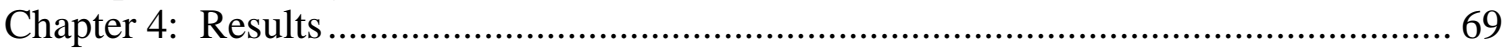

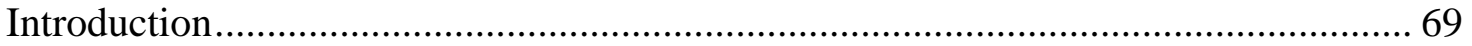

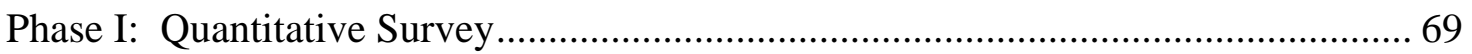

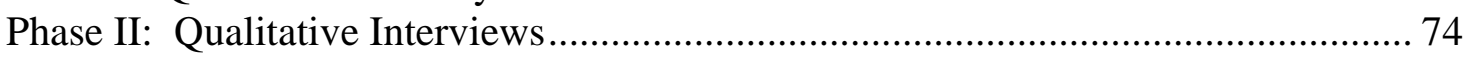

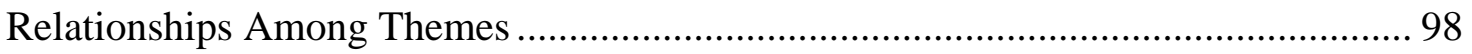

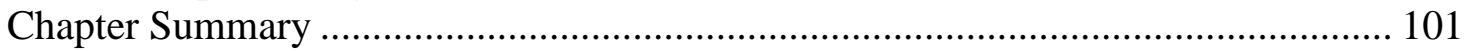

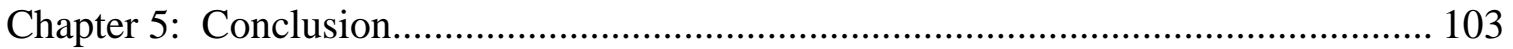

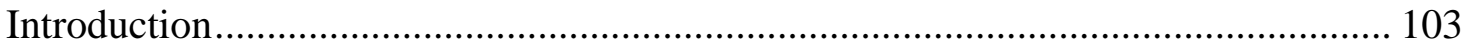

Comparisons with Previous Literature......................................................................... 103

Teacher Characteristics and Teaching Characteristics vs. Instructional Style and

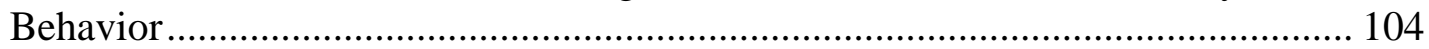

Teaching Characteristics vs. Instructional Techniques............................................ 106

Assessments and Achievement vs. Assessments and Achievement........................ 109

Classroom Characteristics vs. Instructional Style and Behavior ............................... 110

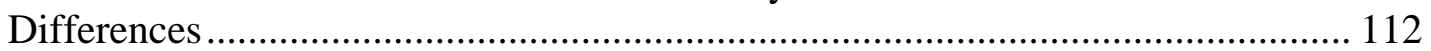

External and Internal Factors ....................................................................... 114

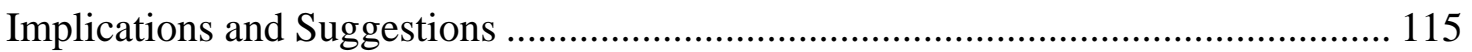

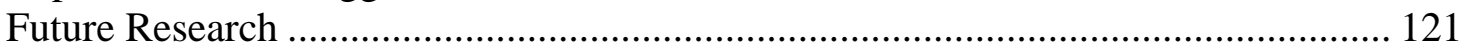

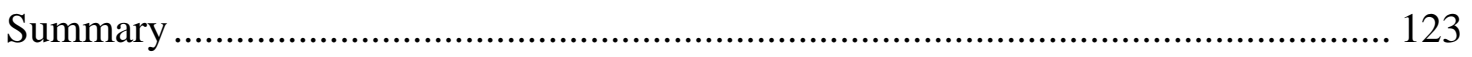

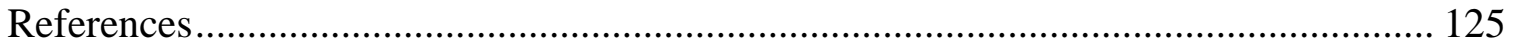

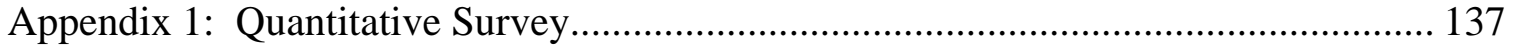

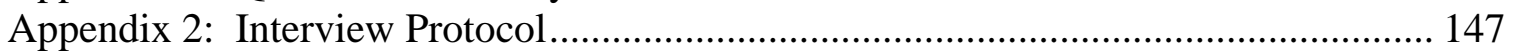

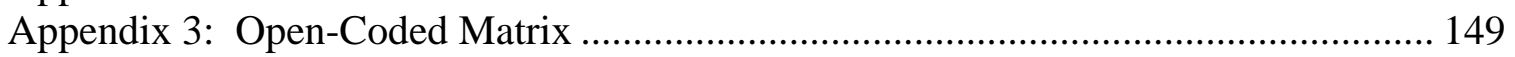




\section{I S T O F T A B L E S}

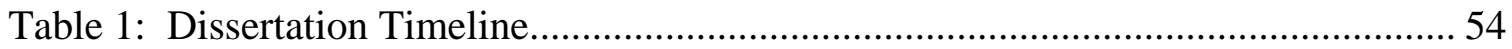

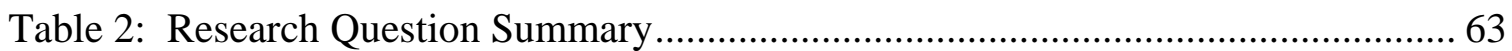

Table 3: Student Groupings by Grade and Trend ........................................................ 72

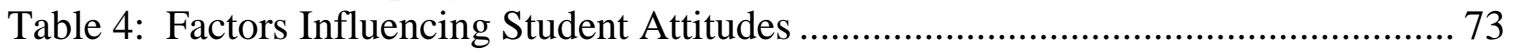

Table 5: Student Interview Groupings by Grade and Trend ......................................... 75 


\section{LIS T O F F I G UR E S}

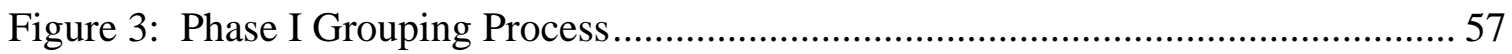

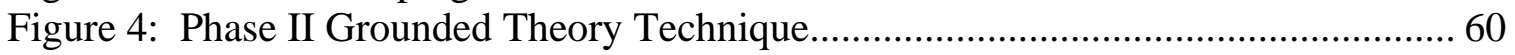

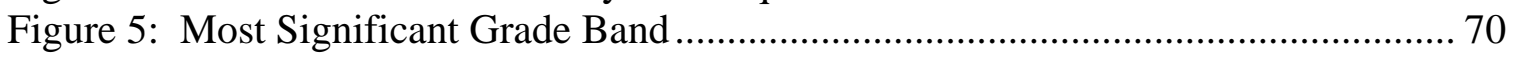

Figure 6: Attitude Trend ................................................................................... 71

Figure 7: Relationship between Factors that Affect College Students' Attitude toward

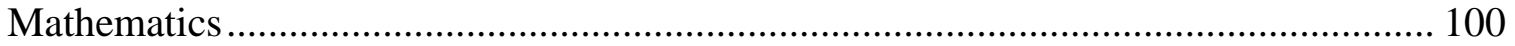




\section{CHAPTER 1: INTRODUCTION}

\section{Introduction}

It is the beginning of another semester and I open one of the doors at the back of the large lecture auditorium. As I make my way down the set of stairs for my last class of my first day, I still feel a little nervous as 200 sets of eyes are watching me. I put my bag down to get my books out and I hear a guy in the first row say to his friend, "Man, I hate math!” I look at him, smile and say, “I’m gonna try to change that this semester.”

This student's statement is one that I often hear, and it reminds me of the countless conversations that I have had in my office and after class with students as they recount why math is "not their thing”, a subject they have never been good at, or one they have never liked. Many of these conversations usually follow one of a few scripts. One familiar story is that the student has not liked math since (__ grade) because their teacher was incompetent for some reason. Another common account is that the student never properly understood some concept and has never recovered. A third is that math has never seemed applicable or useful and, hence, never appealed to the student. It is from many of these conversations and overheard comments that I wondered what factors contribute to a college student's attitude toward math and, furthermore, what kind of role could I play in affecting my students’ attitudes in a positive way.

\section{General Statement of the Problem}

Most people have heard the age-old saying, “attitude is the key to success”. Similarly, various quotes can be retrieved that subscribe to this philosophy. 
"For success, attitude is equally as important as ability”-Harry F. Banks.

In education, research suggests that student attitudes toward a subject lead to academic success (Popham, 2005; Royster, Harris, \& Schoeps, 1999). Generally speaking, mathematics is a subject that is often disliked, begging researchers to investigate how mathematics attitude affects mathematics learning. Further, I believe that student attitudes and achievement hold some implications concerning the types of mathematics courses offered and which department ultimately provides them for the students. Business and engineering majors are required to complete at least one semester of calculus at most universities. Currently, mathematics departments offer mathematics classes focusing on applications in specific areas and majors, such as business and engineering. If every other department wants a mathematics course that focuses on specific applications for their degrees, they may start offering their own mathematics courses. This, of course, could be detrimental to mathematics departments.

This study investigates college students' attitudes toward mathematics. While some of the student attitudes are positive or neutral, as an instructor of introductory mathematics courses in higher education, I have become increasingly concerned about the large number of unenthusiastic and/or poor attitudes that I have observed in many students.

It was mostly due to these firsthand experiences that I decided to investigate these attitudes further. I am most interested in college students who are enrolled in introductory college algebra courses. These courses are taught via large lectures at the University where the study is taking place. Specifically, I want to explore how college 
students' attitudes have changed over time and what factors have contributed to these attitudes.

This research examined what factors affect college students' attitudes toward mathematics. From these findings, suggestions will be made concerning ways in which the decline of student attitudes toward mathematics can be reversed or prevented at the college level. This qualitative study relies on survey methods to gain background information and group participants in order to choose interviewees that have had diverse mathematical experiences and attitudes throughout their life.

This dissertation consists of five chapters. The first three chapters describe why the study is important, its contribution, what other research has found, and how the study is structured. The fourth chapter describes the results and conclusions, while the fifth chapter interprets them as they pertain to the main research questions. Last, the fifth chapter also discusses implications of the study for math teachers and professors.

Chapter one focuses on introducing the reader to the topic at hand, while also discussing the importance of college students' attitudes toward math and the impact this study can have on mathematics pedagogy at all school levels. There are many studies that focus on student attitudes at a young age. This presents a gap in the research concerning college student attitudes. I do not believe the preponderance of studies on the attitudes of younger students is an indication that attitudes cannot be changed in college. It is important that we focus on attitudes at every age. This chapter also presents the research questions, the limitations of the study, and defines terms relating to affect and student attitudes. 
Chapter two is the literature review. I begin with a brief history of mathematics in the undergraduate curriculum and reforms that have been occurring in undergraduate mathematics courses over the past few decades. Reforms are often linked with student attitudes since changes tend to be met with initial resistance or acceptance. Research on affect and attitudes follows, along with what factors have been found to affect student attitudes toward mathematics. This review guided the development of the survey and interview questions for my study. I tried to ask questions about these factors while also leaving open opportunities to discover additional factors.

Chapter three describes the design of the study in detail. The research questions are revisited and the rationale for the mixed methods study is discussed. This study relies on preliminary quantitative surveys to guide the qualitative interviews and is split into two phases. The first phase is quantitative, while the second is qualitative. This chapter describes each phase in depth and also discusses reliability and validity for the qualitative phase. Once the phases and timeline for the study are covered, I will devise a matrix that displays how each phase and data collection technique will help answer the primary research questions and the three subsidiary questions. Overall, this chapter thoroughly covers how the study will be conducted.

Chapter four discusses the findings from the surveys and interviews. Since the interviews are the primary data collection method of this chapter, they are analyzed in depth. Details and quotes are given to support each of the major and minor findings.

Chapter five focuses on the interpretations and conclusions based on the findings from chapter four. The findings are summarized in order to arrive at conclusions. This is 
followed by a discussion of implications of the conclusions as well as suggestions for further research.

\section{Significance of Study}

\section{Why are college students' attitudes toward mathematics important?}

In reading literature on this topic, I have found that there exists a strong

relationship between student attitudes and achievement levels. In particular, some studies have suggested that achievement levels have a causal influence on student attitudes (Hannula, 2002; Tapia \& Marsh, 2001; Lopez, Lent, Brown, \& Gore, 1997; Midgley, Feldlaufer, \& Eccles, 1989), while other studies see the influence as reversed, that is, student attitudes affect achievement levels (Papanastasiou, 2002; Higbee \& Thomas, 1999). Rather than subscribing to a unidirectional relationship between the two, additional studies see the relationship as bidirectional (Williams, Williams, Kastberg, \& Jocelyn, 2005; Koller, Baumert, \& Schnabel, 2001; Cain-Caston, 1993). Therefore, by assuming this bidirectional relationship between achievement and attitude, it is essential that we consider ways to improve their attitudes toward the subject in order to make a difference in achievement levels of students in mathematics.

In addition, research has shown that a person's self-efficacy toward mathematics has a strong correlation to their choice of mathematics courses, their participation in math-related activities, and interest in pursuing careers in mathematics (O’Brien, Kopala, \& Martinez-Pons, 1999; Betz \& Hackett, 1983). Specifically, a student who has negative self-efficacy is less likely to enroll in higher level mathematics courses and therefore is more likely to choose a profession that does not require a strong background in 
mathematics. Therefore, we need to address the notion of improving self-efficacy among college students in order to promote interest in mathematical careers among a wide range of students. Although, this study focuses on perceptions and not self-efficacy, it is an aspect of affect that I may include in further research on college students’ attitudes toward mathematics.

Third, literature focusing on teachers' and parents’ attitudes toward mathematics suggests that these attitudes can have an effect on students' attitudes toward the subject (Beswick, 2006; Schoenfeld, 1985). Not surprisingly, literature suggests that negative mathematics teacher and parent attitudes toward mathematics can influence or play a role in the negative attitudes among their students and/or children (Uusimaki \& Nason, 2004). Therefore, in order to stop the cycle of negative attitudes toward mathematics, attention must be paid to reversing or preventing negative attitudes among students, especially preservice teachers. This may result in future students experiencing a more positive and enthusiastic atmosphere in future mathematics courses.

I believe student attitudes affect the development of mathematical knowledge and thinking. In turn, I think this development facilitates the growth of mathematical logical thinking. Logical thinking includes thought processes used in addressing every day scenarios. Mathematical logical thinking is only a piece of the total logical thinking skills that people possess and is used in mathematical problem solving scenarios in everyday life. Without developing this reasoning, I feel that students may have a more difficult time succeeding in common situations that require mathematical logical thinking. Therefore, an increase in positive attitudes toward mathematics may increase student achievement levels and student enrollment in mathematics courses. Assuming 
that these courses develop true mathematical understanding, I believe an increase in mathematical understanding and, in turn, mathematical logical thinking can result.

How will studying college students' attitudes toward mathematics advance knowledge in the realm of research in mathematics education?

Since my primary purpose is to determine what factors contribute to college students' attitudes toward mathematics, I believe the field of mathematics education will gain a great deal of insight into ways that we might motivate students at the college level. The in-depth interviews will bring to light the way students feel about mathematics and will suggest ways that teachers can improve college students' attitudes and views toward mathematics.

While there is a significant amount of literature on the topic of student attitudes toward mathematics and the factors that affect them, most studies focus on elementary or secondary school students (Smith III \& Star, 2007). This study is a beginning to address the need for more research dealing specifically with college age students. Additionally, the qualitative nature of this study will provide a more in-depth understanding of factors that affect student attitudes toward mathematics as well as possible relationships between these factors. This type of study is a much needed addition to research of affective issues in mathematics education since the majority of research is quantitative (McLeod, 1992).

\section{How will studying college students' attitudes toward mathematics impact pedagogy?}

Insight on students' past and present attitudes toward mathematics along with the factors that affect these attitudes may suggest ways in which negative attitudes toward mathematics can be prevented or reversed. From reviewing some of the literature of 
proposed factors, I believe many of these suggestions will alter the way that many topics and courses in mathematics are taught and the way in which concepts are approached by teachers in the classroom. Many of the proposed factors are related to teachers' attitudes, behaviors, and beliefs about teaching. Therefore, attempting to implement the suggestions may change teaching techniques and teacher behavior in the classroom.

Also, in reversing these attitudes among college students, we will be affecting the attitudes of future teachers and parents. Many pre-service teachers, especially elementary pre-service teachers, tend to hold negative attitudes toward mathematics and are often required to take a course in college algebra (Casa, McGivney-Burelle, \& DeFranco, 2007; Brady \& Bowd, 2005; Harper \& Daane, 1998). Changing pre-service teacher attitudes may affect the future teachers' instructional style. This may result in a modification of how these future teachers define and recognize high-quality mathematics instruction and pedagogy.

Research suggests that some students' attitudes are affected by the applicability, or lack thereof, of mathematics to their lives and future careers (Malmivuori, 2006; Elliott, Oty, McArthur, \& Clark, 2001). In fact, I also found this to be true in a pilot study I conducted (Goodykoontz, 2006). In response to this, many mathematics departments, including the one in which the study is taking place, offer algebra and/or calculus courses designed specifically for students of specific majors. If this trend continues and applicability emerges as one of the primary factors that affect college students' attitudes and achievement in mathematics, huge implications will result in the way in which mathematics is taught and, possibly, the department that offers mathematics courses. 


\section{Research Questions}

Taking into account personal experiences, my preliminary study, and other research described in chapter two, I have determined the following research questions:

1. What factors influence college algebra students' attitudes toward mathematics?

In-depth interviews of participants will suggest the factors that may contribute to college students' attitudes toward mathematics. While this is my primary research question, there are three subsidiary questions that have emerged and may actually become primary based on information obtained from the surveys and interviews.

2. Retrospectively, what were current college students’ attitudes toward mathematics in primary and secondary school?

3. Currently, what are college algebra students' attitudes toward mathematics?

A survey will investigate college students' current attitudes toward mathematics as well as what these students remember their attitudes to be in primary and secondary school. The results from the survey will aid in selecting the participants in order to answer the primary research question:

4. What are college algebra students' perspectives concerning how to reverse or prevent poor attitudes toward mathematics at the college level?

Once factors that contribute to the decline are suggested, further information from the in-depth interviews may provide suppositions regarding certain techniques that could help to reverse or prevent declining attitudes toward math among college students. 


\section{Limitations and Assumptions}

\section{Researcher}

I am the lead instructor of the course I am studying. Since this is the case, I will only be using the results and interviewing students that are not enrolled in classes I am instructing. However, since I have taught this class for a few years, I do have opinions and beliefs about the way the course is organized, the content of the course, the assessments in the course and the student attitudes in the course. I recognize these preexisting ideas and strive to remain open to other perspectives in order to gain the most complete understanding of factors that affect student attitudes toward mathematics. I will be open to the possibility that my opinions may not be correct and alterations to the course may be best for students.

Also, I am aware that my beliefs and attitudes about mathematics will probably be quite different from most students. I have always enjoyed mathematics and was raised in a house that emphasized the importance of mathematics in everyday life. Having undergraduate and graduate degrees in mathematics influences my view of math. I see math in most areas of life and feel as though I have an appreciation for its role in everything we do. I also truly enjoy teaching mathematics and work to open students’ eyes to the joy and usefulness of mathematics. I do realize that most students that I teach do not feel this way about mathematics. Hence, I will make every effort to consider all possibilities presented to me from the interviews and will not disregard ideas that are extremely different from my own. I realize that this will be a struggle, but I am excited 
about gaining multiple perspectives and trying to understand the students' view. As I see it, the more I can understand where my students are coming from, the better I will be at influencing their attitudes toward mathematics.

In general, since I am a mathematics educator in higher education, I have specific ideas and beliefs about college students' attitudes toward mathematics. From conversations and experiences with students, I have already formed opinions about what influences these attitudes. Each student is unique yet often has similar attitudes. I believe, as an educator, there is a way to work within some of the given constraints of the classroom to have an impact on student attitudes. It is necessary to understand and consider the student's point of view to accomplish this. Even though I have ideas about what can be done, I am open to the views and possibilities that students may present.

\section{Study}

As with all studies that are conducted with human participants, there are some limitations and assumptions. One limitation of the survey is the retrospective nature in which some of the attitude questions are asked. Research has highlighted some shortcomings and limitations concerning human recollection of events. In terms of recalling autobiographical events and experiences, Barclay (1993) found this recollection to be more reconstructive, meaning that people's recollection of past events were altered and influenced by subsequent events. In terms of students recalling academic experiences, Conway (1990) found that student recall of test preparation pre- and postexam was different as details seemed to be affected by the score that the student earned on the exam. A study by Brewer (1988) found human recollection to be less reconstructive, but discovered as repeated events become more alike, they can sometimes 
merge in a person's memory and reconstructive memory can result. This may hold true for a student who has had very similar experiences in mathematics classes their entire life. Many of these memories may merge into one. Other research found that a person's current emotional state can affect the recalling of events and experiences (Pernot-Marino, Danion, \& Hedelin, 2004; Thomas \& Diener, 1990). Thomas and Diener (1990) also found that people tend to recall negative times more readily than positive experiences. These are all factors and limitations that I am accepting and considering.

In this study, college students will be asked to report their attitudes toward mathematics at all grade levels. This will require the students to report their attitudes in primary and secondary school almost solely based on memory. This is a limitation since each student's memory of their mathematics attitude may not be identical to what their actual attitude was at the time they were in primary or secondary school. However, in order to truly gauge each student's current mathematics attitude throughout their entire schooling experience, a long-term longitudinal study would be required. For the time frame and purposes of this study, the assumption will be made that each student's memory is being reported as accurately as possible. This limitation of possible bias of each student is recognized and will be reported. As added incentive, every student in the class had the opportunity to receive five bonus points for completing the survey. This is a potential limitation since students may give answers that link more closely with what they think I want to hear than their actual opinions and experiences.

I plan to use this retrospective survey to select the participants. I hope that I will be able to choose a couple of students that have experienced a decrease followed by an increase in their attitude toward mathematics in college courses. This type of participant 
will give me great insight into how the decline of attitudes may be reversed. The limitation, of course, is that I may not be able to find a student that has experienced this reversal. If this is the case, I plan to select students who have had different attitudinal changes than other participants. For example, if I find a participant who has experienced a steady decline throughout their schooling experience in their attitudes toward mathematics, I would also select a student who has experienced an increase in positive attitudes toward mathematics at some time in their schooling experience. By comparing interviews of participants that have reported differing increases and decreases in positive attitudes toward math, I plan to suggest possible factors that affect students' attitudes. Hence, suggestions concerning how to reverse poor attitudes will also surface out of recommendations from these interviews.

As stated earlier, I am interested in studying college algebra students’ attitudes toward mathematics. Since my study will be conducted within a large university, the introductory courses that the participants will be enrolled in will be large lecture classes ranging from 80 - 220 students. Hence, there may be suggestions and factors that surface from the study that are unique to large lecture classes. Therefore, the results that emerge from the interviews may not be applicable to college algebra classes that have smaller enrollments. Also, the math classes that are the focus of this study have weekly laboratory sessions and include regular technological components. These elements also may affect the applicability of various factors and suggestions that emerge from the study to other math courses that do not share the same emphasis on technology that the courses in this study do. These are limitations that I do recognize. Since this is a qualitative study, the ability to generalize is usually limited. However, these limitations suggest 
additional studies that could be conducted focusing on college students' attitudes in math course with smaller enrollments or that do not have a strong emphasis on technology.

Furthermore, it is important that I recognize that I am not focusing on gender or ethnicity issues in terms of college algebra students’ attitudes toward mathematics. For example, some studies suggest that ethnicity can be a factor in student attitudes toward mathematics (Tsao, 2004; Birenbaum \& Nasser, 2006; Signer \& Saldana, 2001). Also, studies have found that female students tend to hold a lower self-concept and lack confidence in mathematics when compared to male students (Muzzati \& Agnoli, 2007; Orhun, 2007; Gasiorowski, 1998). While both of these topics are important to the field of affect and mathematics, I feel that it is beyond the scope of this study to focus on gender. Adding gender into the research questions would broaden the focus too much. Also, there is a great lack of diversity at the university where the study is taking place and I feel this would restrict my ability to focus on ethnicity. I also feel that we need to investigate the ideas and factors that cut across the boundaries of race, ethnicity, and gender before this issue becomes more specialized in these areas. This study will investigate the crucial, big questions that are relevant to all.

\section{Chapter Summary}

In this study, I plan to investigate college algebra students' attitudes toward math through a survey administered to a large group of students along with in-depth semistructured interviews with a few students. Through analyzing this data, I plan to suggest some factors that contribute to these attitudes as well as propose ways that may reverse or prevent negative attitudes. Before discussing the methodology for my study, it is 
important to review previous literature that exists concerning undergraduate mathematics education and students' attitudes toward mathematics. This will be discussed in the next chapter. However, before we move on to chapter two, certain terms need to be defined.

\section{Definitions of Terms}

For the purpose of this study, various terms need to be defined as well as the relationship among some of these terms. Listed below is a list of the terms along with the definition that will be adopted and used for this study.

- Affective Domain: a wide range of beliefs, attitudes, and emotions toward mathematics. This definition was created by Douglas McLeod. Many different definitions for affect exist in other studies. We will use McLeod's definition for this study.

- Attitudes: the positive, negative, or neutral feelings that a student has toward mathematics. Attitudes develop gradually, are slow to change, are of moderate intensity, and are of reasonable stability. This study will focus on the attitudinal portion of affect toward mathematics. i.e. like, dislike, boredom, curiosity, motivation.

- Beliefs: the ideas that students have concerning the purpose of math, their ability to succeed in mathematics, the teaching of mathematics, and "the context in which mathematics education occurs” (McLeod, 1992). Beliefs develop gradually, are slow to change, are of low intensity, and are of reasonable stability. i.e. self-efficacy, self-concept, confidence. 
- Confidence: a belief about one's competence in mathematics. Research has shown confidence to correlate positively with achievement in mathematics (Reyes, 1984).

- Emotions: the strong positive, negative or neutral feelings that a student experiences when learning mathematics. Emotions are more erratic than attitudes and beliefs and tend to lack stability. They are quick to develop, are quick to change, and are of high intensity. i.e. enjoyment, frustration, anxiety, panic, embarrassment, fear.

- Mathematics Anxiety: feelings of tension and anxiety that interfere with the ability to solve mathematical problems, to think logically, and to perform simple or complex mathematical manipulations and calculations. Research has shown that high levels of mathematics anxiety correlates with low achievement (Townsend, Moore, Tuck, \& Wilton, 1998)

- Problem Solving: problems that have non-routine solutions. Many studies involving various aspects of affect and mathematics focus on students solving these types of problems.

- Self-concept: a belief that is a "generalization of confidence in learning mathematics” (McLeod, 1992). One’s belief in their ability to learn and succeed in mathematics. Research has suggested a strong positive correlation between mathematics self-concept and achievement (Marsh, 1986).

- Self-efficacy: a variation of self-concept which focuses on the beliefs about one’s capabilities regarding mathematics performance. Research has found 
that self-efficacy can affect students' choice of mathematics courses and activities (Betz \& Hackett, 1983).

Figure 1.1 represents the relationship between the terms defined above in the affective domain:

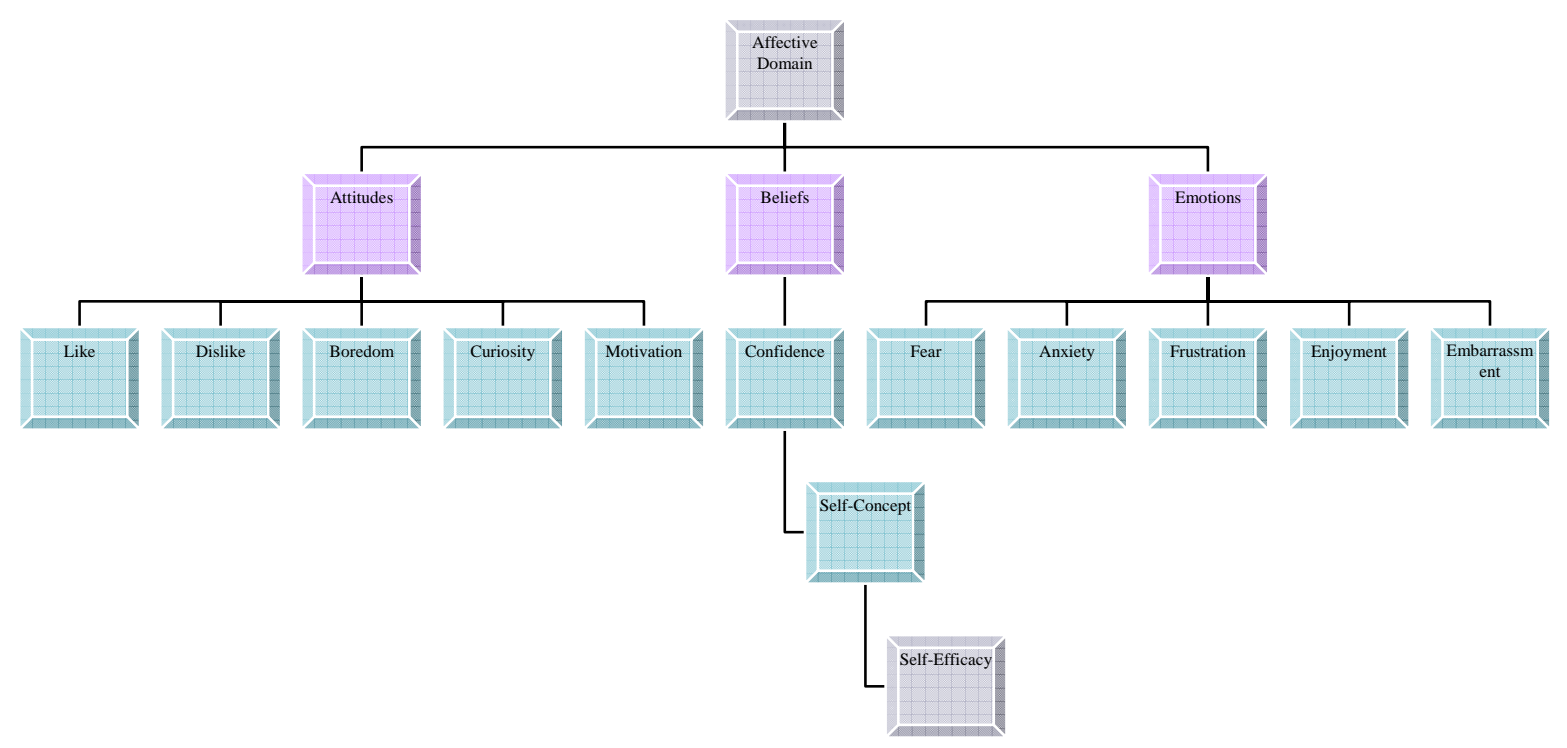

Figure 1: Relationships in Affective Domain

- Instructor Attitude and Beliefs: the non-visible personal feelings and ideas that a teacher has regarding mathematics. These can be feelings regarding the usefulness of mathematics, how mathematics is learned, or how mathematics is constructed. Literature suggests that the mathematical beliefs and attitudes of the instructor can affect their instructional style which, in turn, can influence student attitudes toward mathematics (Wilkins \& Brand 2004).

- Instructional Style and Behavior: the visible emotions, actions, and interactions with students of a teacher in the classroom. Instructional Styles and Behaviors are outward signs reflecting the instructor's attitudes and 
beliefs. Literature has found that instructor style can have an effect on student attitudes toward a subject (Thompson \& Thompson, 1989; Adams, 1989; Midgley, Feldlaufer, \& Eccles, 1989).

- Nonverbal Immediacy: an effort to make sustained eye contact, speak with vocal variety, make moderate gesturing, and use facial expressions when teaching or speaking. Related literature found that the lack of teacher nonverbal immediacy influences a decrease in student enjoyment of the subject (Cheseboro, 2003).

- Teacher Misbehaviors: behaviors of a teacher that are interpreted negatively by students. It is suggested that teacher misbehaviors influence the studentteacher relationship resulting in students' generating negative feelings toward the subject (Wanzer \& McCroskey, 1998). 


\section{CHA P T E R 2: L I T ERA T URE R E V I E W}

\section{Introduction}

The previous chapter introduced the topic of college students' attitudes toward mathematics and discussed how the topic may affect other areas and research. This section looks at previous literature to discover contributions that other research has made concerning undergraduate mathematics and student attitudes, and factors that may affect these attitudes. This chapter begins with a short history of the emergence of mathematics in the undergraduate curriculum. We see history repeating itself as we learn that mathematics was originally introduced into the undergraduate curriculum due to its applicability to the real world, and now there is a movement to return to applications as a focus in mathematics. The review then discusses changes and reforms that have been occurring in undergraduate calculus and algebra courses. Previous research has found that many of these reforms improve student understanding and student attitudes toward the course. Many of these changes are also an attempt to resurrect the applicability of mathematics. With increase emphasis on applicability, many articles arose discussing the place of mathematics in the university. Should it be housed in the mathematics department, should the mathematics department strive to meet the specific needs of every other department, or should each department teach their own mathematics course?

After covering background issues relating to undergraduate mathematics curriculum, the literature review discusses the importance of positive student affect in success in mathematics courses. Various researchers' definitions of affect, attitude, beliefs, emotions, and values are covered in order to increase the understanding of this 
complex topic. Following definitions, several research studies are presented that investigate certain factors that may affect students' attitude toward mathematics. Achievement, instructional factors, instructional style, instructional technique, and teacher beliefs were found to be main factors according to previous research. This research guided the creation of the survey and interview protocol for this study.

\section{History of Mathematics Courses in Undergraduate Curriculum}

There have been various changes and reforms to undergraduate mathematics courses in the United States for centuries. We often see that history repeats itself and the history of math curriculum in the American higher education system is no exception. Of course, the pioneers of higher level mathematics can include Socrates, Plato, Aristotle, Pythagoras, Euclid, and Archimedes (Houghton \& Dawson-Threat, 1999). Many of these pioneers viewed mathematics as the search for pure truth and wisdom. However, it was then discovered by many that various concepts in mathematics are applicable to other areas such as astronomy, trade, and navigation (Houghton \& Dawson-Threat, p.22).

As a result, mathematics was first introduced into the undergraduate curriculum in 1726 by Yale, and became an entrance requirement in 1745 . It was viewed as an important subject for future leaders of the world, not only for its obvious applicability, but also for its ability to strengthen logical thinking skills (Houghton \& Dawson-Threat, 1999, p.23). However, in the late 1800's, the emergence of varying educational philosophies caused a rift between educating the common man and teaching the classics. One of the results was the separation of mathematical theory from its various applications. The rise of technology and increased specialization of research areas in the 
early $20^{\text {th }}$ century furthered this division. Finally, in the later parts of the $20^{\text {th }}$ century, there was a call to return to the connection between mathematics and its applications.

\section{Reform Movements in Undergraduate Mathematics Education}

The Mathematical Association of America’s (MAA) Committee on the Undergraduate Program in Mathematics (CUPM) published a report calling for a major educational reform of undergraduate calculus courses (Bressoud, 2001). This report was published in 1989, and followed a decade of increasing concern for calculus courses, culminating in the 1987 conference Calculus for a New Century. At this time, the National Science Foundation (NSF) “launched a calculus initiative” (Bressoud, p. 578). Various funds were made available to support this reform, which became known as the Calculus Reform Movement (Bressoud, p.578). Some of the primary focus areas of the movement were: an increased use of application, modeling and interdisciplinary projects, multiple representations of key ideas, cooperative learning activities, and writing about mathematics (Bookman \& Friedman, 1998; Yerushalmy \& Schwartz, 1998; Hurley, Koehn, \& Ganter, 1999). The reform movement started in some of the larger academically challenging institutions. Using the funds from the NSF, some of these schools produced new curriculum materials for other undergraduate institutions to implement. Duke University produced ProjectCALC and Harvard created Harvard Calculus Consortium (Smith III \& Star, 2007). Smaller institutions followed the movement, and finally large state schools got involved (Cipra, 1993).

Of course, there were and still are proponents and opponents of the movement. Some educators were and still are concerned that skills would be lost in the non- 
traditional calculus courses, especially with the integration of technology (Cipra, 1988 \& 1996). Many were also concerned that the reform was watering down the subject and the true nature of calculus was being lost (Hurley, et.al, 1999). On the other hand, proponents believed that the need for a deeper understanding and connection to other disciplines was necessary in order to aid students in applying calculus to their careers and life (Hurley, et al., p.800). Barry Cipra (1988, 1993, \& 1996) has written a few informational articles that discusses what he views as the current thoughts toward the movement. His 1988 piece reviews the history behind the emerging reform and states other's positions on the movement. In 1993, as the reform became more widespread, Cipra reports on the popular curriculum and educational steps adopted by the larger state institutions. Finally, in 1996, Cipra addresses the 'backlash' that had emerged in the calculus community, as some educators became very concerned that the reform was creating a watered down version of calculus; a claim that proponents of the reform denied.

\section{Calculus Reform Research}

Various studies have been conducted throughout the years in order to support or deny claims from opposing camps (Smith III \& Star, 2007; Bookman \& Friedman, 1998; Yerushalmy \& Schwartz, 1999; Narasimhan, 1993; Roddick, 2001; Hurley et.al., 1999).

Smith III \& Star (2007) review some previous literature on student achievement and affect in $\mathrm{K}-12$ standards-based reform as well as higher education calculus reform. They noticed that most research seems to focus on student achievement, rather than student attitudes, although there is a shortage of both (Smith III \& Star, p.5).

Additionally, there are virtually no studies that investigate the relationship between 
achievement and affect. Also, even after a few decades, the implementation of the Calculus Reform Movement is still spotty. Traditional calculus courses are still taught in many institutions. Hurley et al. (1999) took a local and national look at calculus reform. In their longitudinal study at the University of Connecticut they found that on average the reform calculus students scored higher than those in the traditional course on a common final examination containing both procedural and conceptual questions. They also tracked many of the students from both types of courses and found that on average more post-calculus technical courses were completed by students from the reform course. The researchers also reported results of similar studies conducted around the nation. Studies from Dartmouth, the United States Naval Academy, Baylor University, the United States Merchant Marine Academy, Purdue, University of Illinois at Chicago, SUNY Stony Brook, University of Michigan, Duke, and Oklahoma State University found that student achievement in reform courses were higher or the same in the calculus course and/or subsequent mathematics courses than those from the traditional courses. Additionally, University of Michigan and Duke also found a positive increase in student attitudes toward the subject (Hurley et al., p.807). Narasimhan (1993) compared a calculus reform course implemented with Harvard's Calculus Consortium materials with the traditional business calculus course at DePaul University. After instructing both types of courses, the author believes that the reform calculus course is a better fit for students in nonscience disciplines (Narasimhan, p.255). While the business calculus did show how calculus is applied in the business world, the author thought the course lacked an explanation of why the calculus is used. Yerushalmy and Schwartz (1999) also compared two types of calculus courses, both labeled as reform courses. One course emphasized 
informal understanding while the other focused more on formal modeling approaches and use of technology. The researchers suggest the ideal would be a balance between these two areas of reform, a marriage between formal and informal understanding. A study by Roddick (2001) also compared two differing calculus courses. She investigated the procedural and conceptual understanding of students enrolled in a reform calculus course sequence with those from a traditional calculus course. Overall, she found the reform students approached calculus problems more from a conceptual point of view than those from the traditional course (Roddick, p.175). While most studies focus on student understanding and achievement, Bookman \& Friedman (1998) studied student attitudes toward a calculus reform course. The research consisted of three studies that spanned three years and compared the attitudes of students in a traditional calculus course with those in a reform calculus course based on Duke’s ProjectCALC materials (Bookman \& Friedman, p.118). Initially, students in the reform course disliked and resisted the course since it was markedly different from any mathematics class they had previously. However, after the first few months of opposition, attitudes seemed to gradually improve. Two years after the course, students in the reform course felt they better understood the applicability of math and appreciated the challenging nature of the course (Bookman \& Friedman, p.121).

\section{Algebra Reform Research}

As the Calculus Reform Movement expanded, the ideas began to trickle down to more introductory mathematics courses in higher education, such as College Algebra and Intermediate Algebra. Since College Algebra is one of the first collegiate mathematics courses many undergraduates take, many were concerned about the lack of academic 
preparedness and level of true mathematical understanding of many incoming students (Berry, 2003; Carroll, 2004; Parker, 2005; Carlson, 1997). These studies found that even students who were high achieving high school students were struggling to truly understand and succeed in college algebra courses. Many of the same ideas from the calculus reform were implemented in college algebra courses (Hobson-Panico, Hoard, \& Romero, 1999). Of course, research followed this implementation in order to gauge the effectiveness of new strategies and projects (Adams, 1997; Herman, 2007; Yarborough, 1999; Fox \& West, 2001;Chappell \& Hardy, 1999). You can see many of the same reform techniques from the Calculus Reform Movement in these studies. It is also important to note that most of these studies also focused more on student achievement and understanding than on student attitudes to the changes. Adams' (1997) study focused on integrating technology via graphing calculators into a college algebra classroom and the impact it had on problem solving ability and oral discourse in the classroom. Not surprisingly, through observations, the researcher saw an increase in oral discourse from student to student as well as from student to teacher. Also, students worked in groups with the calculators and were more likely to attempt to find alternate solutions to problems when using the calculators. Herman (2007) also studied the impact of graphing calculators in a college algebra classroom. She was interested in the type of strategy and representation students would choose to solve algebra questions. Students were given a pre- and post-test consisting of algebra word problems that can be solved symbolically, graphically, or by using a table. Ultimately, she found that more students were able to solve the problems graphically or using a table once they completed the course that used graphing calculators. However, she also noted that the primary method chosen by 
students on both tests was symbolic (Herman, p.35). After interviews, it was suggested that many students believe the symbolic representation is "a more mathematically correct way to solve problems” than the other two (Herman, p.27). This raises questions on how we can change students' core beliefs about mathematics that have been formed years ago. Yarborough (1999) reflects on the effect that a discovery approach to teaching college algebra had on his students. He argues that in teaching this way for the past ten years, he has found that students are able to gain a deeper understanding of mathematics and are able to succeed, compared to memorizing facts and rules with no true understanding. He does note that student attitudes are not always positive with this method. Some types of learners appreciate his methods, while others do not. Chappell and Hardy (1999) also experienced both opposing attitudes toward a class taught for deeper understanding. The instructor here taught an experimental college algebra course called College Algebra in Context which focused on fewer algebra topics. The goals of the course were for students to be able to apply the concepts to other areas, truly understand why they apply these concepts to certain problems, use multiple strategies to solve problems, and be able to effectively communicate their understanding. The implementation was viewed as effective in obtaining these goals, but the student reactions to the course were polarized. After some interviews, it was noted that some of the students gained an appreciation for the course and had a positive attitude toward it. Others were extremely frustrated with the new approach to algebra and did not have a positive outlook on the course. I believe this is mostly due to the fact that the style of the course goes against most students' basic ideas of what mathematics is about. Fox and West (2001) also investigated student attitudes and feedback on an experimental college algebra course focusing on modeling 
and applications at Francis Marion University. The students were given large projects to complete in order to motivate students and stress the mathematical topics at hand. These projects were completed in groups of 2 or 3 and focused on multiple representations. Students were surprised that multiple answers could be accepted since this idea went against many of their previous beliefs about mathematics. Through student feedback, it was found that initially they were apprehensive about the projects, but most gave positive comments about the projects (Fox \& West, p.95). As a result, this course has been added to the curriculum.

In summary, various studies have found that implementing reform ideas into an undergraduate mathematics course seem to not only affect student achievement and understanding, but also play a role in student attitudes toward the course. Since many of these reform methods tend to contradict students’ beliefs about mathematics, initial resistance and dislike is not uncommon. However, ultimately it seems as if students' attitudes can improve and an appreciation toward mathematics and the reform methods can develop.

\section{Implications of Undergraduate Mathematics Reform}

As reforms in higher education introductory mathematics courses continue to evolve and focus on applications, people are seeing the necessity for the mathematics department to form a stronger partnership with their clientele departments, such as engineering, business, and physics (Peterson, 1987; Wilson, 2000; Bressoud, 2001; Hurley et al., 1999). At the beginning of the Calculus Reform Movement, Ivars Peterson (1987) discussed the possibility of physics and engineering departments teaching their 
own calculus courses if their needs are not met through the mathematics department. Similarly, Wilson (2000) discusses the new wave of national calculus reform and quotes Don Small, a professor at West Point, who predicts that calculus may someday not be a separate course at many institutions. Calculus topics will just be integrated into courses as needed. When reflecting on the national impact of higher education mathematics reform, Hurley et al. (1999) discusses the spread of the reform. They also see many institutions implementing programs that "eliminate the traditional boundaries between" various disciplines "by means of an integrated teaching approach" in an attempt to connect mathematics to its applications (Hurley et al., p.808). These highlight the need for increased collaboration amongst all disciplines in order to achieve a mathematics course that will address the needs and concerns of most college students and their future careers. It also raises some concern relating to the future of mathematics in the collegiate setting. Will mathematics departments need to meet each specific need of every other discipline in order to keep their courses or will the other subject areas decide to teach their own courses, resulting in the demise of introductory mathematics courses in the mathematics department?

\section{Implications at Research Institution}

The state University on the eastern side of the United States where this study takes place has also seen modifications to its mathematics curriculum. Mathematics was part of the undergraduate curriculum since its inception in 1867. However, there have been recent developments within the curriculum and the department emphasizing applicability of mathematics and implementing ideas from the Calculus Reform Movement to many undergraduate courses. In 2001, the Mathematics Department 
created a subset unit called the Institute for Mathematics Learning (IML), which, along with additional projects and goals, implements many of the ideas from the Calculus Reform Movement in introductory mathematics courses. These courses range from a Mathematics in Society course to Introduction to Calculus. Each course has a laboratory component, which emphasizes applications and modeling, multiple representations, cooperative learning, and writing. I teach and have taught various courses with this format. The College Algebra course is the focus of this study. This course is an IML course and the students do participate in these weekly laboratory activities. Also, while the Mathematics Department does offer a traditional calculus course, in 2004 an Engineering Calculus course that focuses on engineering applications in a calculus setting was created. The Mathematics and Engineering departments work collaboratively in order to make this course a success. Hence, this university is and has been experiencing collaboration across departments, as well as implementing calculus reform methods into their introductory mathematics courses.

\section{Success in Mathematics}

As we have seen, many math educators are attempting to implement reform ideas in order to increase student understanding and success. However, in many studies, success is only measured by achievement on exams or answers to certain mathematical questions. I believe that success in any subject requires many aspects joining together in a certain way. Each student's background knowledge, learning style, and ability to understand instruction are just a few of these elements. An element that each student brings with him or her is their affect toward the subject. Many theories propose that 
affect plays a large role in a student's ability to become successful in a certain subject (Popham, 2005; Royster et al., 1999).

\section{Affect, Attitude and Mathematics Education}

Affect toward mathematics has been a topic of interest for many years (McLeod, 1994). A review of literature that covers the years 1970 to 1994 conducted by Douglas McLeod discussed many of the approaches and studies that have been completed in the past and made suggestions for increased amounts of qualitative research in this area. Earlier research produced mostly quantitative results.

In the current mathematics reform movement, there is a call for an improvement in student dispositions toward mathematics (NCTM, 1989). In 1989, The National Council for Teachers of Mathematics (NCTM) produced a set of standards for mathematics curriculum, teachers, and assessment. This was followed by the Principles and Standards for Mathematics Education that emerged in 2000. There was much emphasis on improving student and teacher attitudes and beliefs about mathematics, especially in the 1989 document, Professional Standards for Teaching mathematics. These standards cover various aspects for educators and a few of the standards discuss

some factors that may affect students' attitudes and beliefs (NCTM, 1989). The 2000 Principle and Standards document also comments on the importance of student dispositions toward mathematics and their beliefs about mathematics (NCTM, 2000). 


\section{Defining Affect, Attitudes, Beliefs, and Values}

McLeod is one of the staples for research concerning affect in mathematics. He first focused on the role that affect plays with students and their ability to problem solve in mathematics (McLeod, 1988). In this study, problem solving denotes problems that have non-routine solutions. Students often experience strong emotions and attitudes when attempting to solve these types of problems. In later work, McLeod (1992) introduced the idea of defining affect as involving beliefs, attitudes, and emotions toward mathematics. Beliefs and attitudes are believed to gradually develop and are slow to change while emotions are seen as more dynamic and extreme. Beliefs are those ideas that students have concerning the purpose of math, their ability to succeed in math, the teaching of mathematics, and "the context in which mathematics education occurs" (McLeod, 1992). In their study on the beliefs of students in grades $7-10$ concerning the amount of mathematics involved in everyday activities, Edwards and Ruthven (2003) suggest that students did view many everyday activities as involving mathematics. However, the students tended to believe that mathematics was involved when the activity had a single or limited solution. These beliefs are believed to gradually develop through different experiences that students have with mathematics throughout their life (D’Andrade,1981). This is highlighted by a study conducted by Tsao (2004) comparing the differences in the math perception of American fifth grade students and Taiwanese fifth graders. Unlike Taiwanese, American students tended to view mathematics as mostly involving numbers that have right or wrong answers and saw memorization as the key to succeeding in mathematics. Also, American students were more influenced to learn by positive motivation such as wanting to succeed in the class or impressing their 
teacher, while Taiwanese students were more influenced by negative motivation like fear of being punished (Tsao, p.211).

Often times, attitude is difficult to separate from beliefs. Attitude can be referred to as the positive or negative feelings that a student has toward mathematics. These are the feelings that are relatively stable throughout various experiences with mathematics (McLeod, 1992). These fairly stable attitudes also develop gradually and therefore are slow to change. While this idea is more universally accepted by most, a study by Liljedahl (2005) found that many college students noted a change in their beliefs and attitudes about mathematics as a result of an AHA! experience, in which a concept is suddenly understood by the student. This AHA! experience is viewed as an emotion which influences student attitudes and beliefs. It is important to note that most research on affect and mathematics tends to focus on attitudes and/or beliefs, since it is often difficult to distinguish the two. Emotions, on the other hand, have been studied less than attitudes and beliefs (McLeod, 1992). This could be due to the fact that they lack stability and therefore are more difficult to measure, especially using questionnaires, the popular measuring instrument of the past. In fact, recently there has been a call for more studies dealing with emotions, since many believe that they play a large role in the formation of attitudes and beliefs toward the subject (Zan, Brown, Evans, \& Hannula, 2006; DeBellis \& Goldin, 2006). In their study, DeBellis and Goldin (2006) suggested using natural emotions, like frustration and fear toward a subject, in a positive way. They propose educators and researchers focus on fostering positive feelings about these expected emotions, rather than trying to eliminate them (DeBellis \& Goldin, p.137). 
Affect and terms related to affect can hold a variety of definitions (Hart, 1989). In McLeod and Adams' (1989) book dealing with affect and problem solving, Hart discusses the different definitions that affect, attitudes, beliefs, and emotions have for various mathematics educators as well as for social psychologists. Often times, these educators and psychologists are using common terms, but with differing definitions. The basic definitions that McLeod uses for attitudes, beliefs, and emotions toward mathematics are also adopted by Hart (1989). However, she discusses the differences in affect as well as the differences in the relationship between all of the terms. She tends to define affect as dealing primarily with the emotions of mathematics, such as math anxiety and other strong, but temporary feelings. She sees attitudes toward mathematics as having three facets: the emotional reaction to math, the behavior toward math, and the beliefs about math (Hart, 1989). In this way, she tends to see beliefs as a part of attitudes toward mathematics. It is important when studying affect, attitudes, beliefs, and emotions toward mathematics that the terms are properly defined for the scope of the study. Zan et al. (2006) also discusses this disparity in defining terms and even expanded McLeod's three main concepts of affect. They state that more recently a fourth concept, values, has been added to definitions of affect (Zan et al., p.116). For DeBellis and Goldin (2006), values can be viewed as the ethics, morals, and “deep personal truth" that a person holds regarding mathematics (DeBellis \& Goldin, p.135). In this way, values are a deeper version of beliefs. Of course, even these four concepts do not cover the entire gamut of terms used when studying affect. Motivation has also been receiving increased attention in some of the latest research, along with the role that cognition plays in affective responses (Hannula, 2006; Schweinle, Meyer, \& Turner, 2006). Specifically, 
Schweinle et al. (2006) tackles the vital relationship between motivation and affect as well as the importance of instructor attitude and teaching practices to aid in balancing challenge and frustration. The researchers believe this can ultimately affect a student's affect toward mathematics (Schweinle et al., p.289).

One of the most agreed upon findings concerning mathematics and affect is the decline of positive affect over time. Studies seem to agree that as students progress through school, there is a decline of positive beliefs, attitudes, and emotions toward mathematics (Wilkins and Ma, 2003; Royster, Harris, \& Schoeps, 1999; Edwards \& Ruthven, 2003; Hallam \& Deathe, 2002; Muzzati \& Agnoli, 2007). Wilkins and Ma (2003) suggest in their study that there is a larger decrease in positive affect during secondary school than in middle school. However, even though positive affect declined, it was found that students' beliefs about the social importance of mathematics did not seem to change from their beliefs in seventh grade. This finding suggests that the decline of these beliefs occurs sometime prior to seventh grade. The study by Royster et al. (1999) focused on the attitudes and beliefs among college students. Not all types of college students experienced a decrease in positive affect for mathematics. However, a decline was noticed amongst humanities majors. Not surprisingly, the study found that mathematics majors had the most positive affect for the subject. This finding can lend support to Wilkins' study in that the major decline seems to be occurring at a younger age than college. Similarly, in surveys of students in $7^{\text {th }}, 8^{\text {th }}, 9^{\text {th }}$, and $10^{\text {th }}$ grades, Edwards et al. (2003) found that there was a decline in the mathematics attitudes of $10^{\text {th }}$ graders compared to the mathematics attitudes of $7^{\text {th }}$ graders. An additional study by Hallam and Deathe (2002) suggested that there is a decline of mathematics self-concept, as well as 
general and school self-concept between years 9 and 10 of high school. Also, mathematics self-concept was significantly lower among all grade levels as compared to school and general self-concept. Lastly, Muzzatti and Agnoli (2007) studied belief and attitude differences based on gender. Among other results, they found that selfconfidence in math decreased for both genders as they increased from grades 2 to 8 (Muzzatti \& Agnoli, p.753).

While there does seem to be some agreement over the decline of positive affect and attitudes concerning mathematics, there is some discrepancy over what factors contribute to this decline. It is my belief that if we can determine what factors are promoting this decline, we can work to reverse the decline. Some of the proposed factors that contribute to student attitude are student achievement, instructional style, instructional techniques, and teacher attitudes and beliefs about mathematics. While this is not an exhaustive list, it does include some of the common factors.

\section{Affect, Attitude and Achievement}

Student achievement is linked to student affect in many studies. However, there is a type of 'chicken-egg' disagreement. Some studies claim that student affect and attitude is formed and influenced by poor, average or excellent achievement in mathematics (Hannula 2002, Tapia \& Marsh 2001, Lopez, Lent, Brown, \& Gore 1997, Midgley, Feldlaufer, \& Eccles 1989). In an ethnographic case study on an eighth grade girl, Hannula (2002) found that an increase in understanding, possibly brought on by a high score on an exam, resulted in an increase in positive attitude toward mathematics. In this case, it is suggested that an increase in achievement was a factor in the increase in 
positive affect. Tapia and Marsh (2001) studied attitudes for 7th through 12th graders using the Attitudes Toward Mathematics Instrument. After various statistical analyses, it was found that "achievement levels influenced value, motivation, and enjoyment at all grade levels” (Tapia \& Marsh, p.14). The study conducted by Lopez et. al. (1997) focused on self-efficacy of high school students. Various relationships were found between self-efficacy, interest, previous performance, and grades. Among other conclusions, results suggest that prior performance in mathematics influences selfefficacy. A 1989 study by Midgley et.al. investigated various relationships between student achievement, student attitudes, and student and teacher relations as a result of students transitioning to junior high school. One finding proposes that lower achieving students' attitude toward mathematics is more effected by their relationship with their teachers. This suggests that achievement level, along with teacher-student interaction does play a role in student attitudes.

On the other hand, other studies suggest that poor, average or excellent achievement occurs as a result of student affect toward a subject (Papanastasiou, 2002; Higbee \& Thomas, 1999; House, 1995; House, 1993). Papanastasiou (2002) conducted a quantitative study using a structural equation model on middle school students in Cyprus and found that, statistically, student achievement could not be predicted by student attitudes and beliefs, although the results do suggest that these attitudes and beliefs do have some impact on mathematics outcomes. Higbee and Thomas (1999) investigated student attitudes and achievement in some developmental mathematics college courses. Various student attitudes toward mathematics were measured using quantitative surveys and instruments. Student achievement was also measured using exams. It was found that 
student attitudes were related to student achievement. It was suggested that once students gain interest in the mathematics course, they may be likely to surpass initial achievement expectations. Hence, a student's attitude can affect their achievement in mathematics. Additionally, House (1995) studied student achievement and attitudes among 218 college students at a large United States university. Before beginning their first semester, they completed an attitude survey, mostly focusing on self-concept. Then the grade each student earned in a college calculus course was recorded at the end of the semester. It was found that three of the items on the attitude survey, self-ratings of overall academic ability, self-ratings of mathematics ability, and expectation of graduating with honors, were significantly correlated with later achievement in calculus. Hence, it is suggested that a student's attitude can contribute and have an effect on their achievement. This study follows a similar study by House (1993) where he focused on students that were not academically prepared for college algebra. He concluded that "academically underprepared students with a high academic self-concept earned higher grades in college algebra than academically underprepared students with a low academic self-concept” (House, p.111).

A third idea is that the effect that the one has on the other is cyclical. That is, affect is influencing achievement and achievement is influencing affect (Williams et al., 2005; Koller et al., 2001; Cain-Caston, 1993). The international study by Williams et al. (2005) used quantitative analysis to show some support for this bidirectional relationship between affect and achievement, specifically in the subject area of reading. It is important to note that the strength of this finding differed among nations. Some of the nations seem to reflect the bidirectional relationship. Others, however, seemed to support 
more of a unidirectional relationship. In fact, the data for the United States did not reach statistical significance for the bidirectional relationship, although the analysis of the data seems to lend support to that relationship (Williams et al., p.531). Another study (Koller et al., 2001) conducted in Germany found that this cyclical relationship seems to exist in high school students. It was found that student interest in mathematics at the end of tenth grade directly and indirectly influenced student achievement, while it was also suggested that student achievement also affected student interest from grades 7 to 10 . However, even with all three of these scenarios on the relationship between affect and achievement, there are studies which do not believe there is any relationship between the two (CainCaston, 1993). Therefore, while there may be some relationship between achievement and student attitudes, beliefs, and emotions toward mathematics, these are just one of many proposed factors.

\section{Affect, Attitude and Instructional Factors}

National reports by the National Council for Teachers of Mathematics have suggested that instructional factors can contribute to student affect toward mathematics (NCTM, 1989). There are three standards in the 1989 Professional Standards for Teaching Mathematics that highlights the important role that the teacher may play in affecting and assessing student beliefs and attitudes toward mathematics. One standard discusses the importance of promoting mathematical disposition. It is suggested that using real-world applications and the teacher showing his/her love for mathematics are two ways of accomplishing this. Positive feedback and responses are also deemed important. Another standard stresses the importance of properly assessing a student's true understanding of mathematics. This means having a deep understanding of each 
student, their abilities, and perceived confidence toward mathematics. A third standard suggests that teachers work to develop "mathematical power" in each student (NCTM, p.21). This standard discusses the importance of developing a learning environment that will promote mathematical power and help to develop students' positive dispositions toward math. A supportive, encouraging environment that incorporates various participation activities is suggested. In summary, this standard encourages knowing each student well enough to create the best learning environment to foster mathematical power. An updated version of the Standards emerged in 2000 and combined many of the above principles into The Teaching Principle to stress the importance of instruction and student attitudes. The Teaching Principle in the 2000 Standards states, "effective mathematics teaching requires understanding what students know and need to learn and then challenging and supporting them to learn it well” (NCTM, p.370). This involves keeping students engaged, improving students’ confidence, and supporting students’ learning.

\section{Affect, Attitude and Instructional Style}

Various studies have been conducted suggesting that the instructional style, as well as the environment nurtured by the instructor, can both have an effect on student affect toward the teacher and toward the subject (Chesebro, 2003; Wanzer et al., 1998; Thompson \& Thompson, 1989; Adams, 1989; Midgley, Feldlaufer, \& Eccles, 1989; Harkness, D’Ambrosio, \& Morrone, 2006; Stage, 2000; Schweinle, Meyer, \& Turner, 2006). Chesebro (2003) found that instructor clarity and nonverbal immediacy both played a part in influencing student affect for the course. Nonverbal immediacy is defined in this study by "the degree of perceived physical or psychological closeness 
between people” (Chesebro, p.141). Teachers in this study used eye contact, vocal variety, gestures and facial expressions to vary their nonverbal immediacy. Additionally, they used the order of topics, transitions between main points, previews and reviews to vary teacher clarity. It was suggested that increased clarity and nonverbal immediacy resulted in an increase of positive affect for the course or topic (Chesebro, 2003). Similarly, Wanzer (1998) looked at teacher communication style by studying what was termed as teacher 'misbehaviors'. These misbehaviors were defined as negative classroom behaviors that may distract or irritate students. While defining these misbehaviors will vary depending on each student, research suggests that a teacher that is not highly assertive or responsive tends to exhibit misbehaviors. Some examples may be "showing up late to class, giving unfair tests, giving too much or too little information, and showing favoritism” (Wanzer, p.44). Among other relationships, the data supported the conclusion that students seem to like the material less as teachers exhibited these misbehaviors (Wanzer, 1998). Hence, it seems as if these misbehaviors contribute to the decline of positive affect for a course. Adams (1989) investigated the important role that teachers may play in student affect. She reflected on her teaching style and the instructional decisions that were made in response to the affective responses of students. Adams' study highlights the large role that teaching style can have on student affect. A study by Thompson \& Thompson (1989) focused on one fifth grade mathematics teacher who regularly conducts problem solving activities with cooperative learning. It was suggested that one of the primary factors in the improvement of students' attitudes and persistence toward mathematics was his overall tolerant and patient demeanor, coupled with his teaching style of accepting student responses without question. Similarly, 
Midgley et al. (1989) found that the perceived support level of instructors at the junior high school level influenced students’ attitudes toward mathematics. Specifically, students who perceived their teacher to be unsupportive tended to experience a decline in their attitudes and beliefs about mathematics. A study by Harkness et.al. (2006) also found that students, specifically pre-service elementary teachers, believed that their instructor's support and patience was one of the many factors that motivated them to work through the struggle of problem solving in their mathematics class. Schweinle et.al. (2006) conducted a study of the relationship between motivation and affect in elementary students. Overall, they found that teacher support and finding the right balance between challenge and skill for students can aid in increased motivation and student affect.

\section{Affect, Attitude and Instructional Technique}

Often times, specific instructional techniques were found to have an effect on student affect and attitude toward a subject or toward part of a course (Anderson, 2005; Townsend et. al., 1998; Higgins, 1997; Pearce et. al., 1999; Mitchell, 1999; Kinney, 2001; Yusof \& Tall, 1999; Elliott et. al., 2001; Raymond \& Leinenbach, 2000; Whitin, 2007). Anderson (2005) found that the particular way that college level students were put into groups for a collaboration activity played a role in the attitudes that the students had toward the activity. Groups were formed to take part in a simulation game for a business course. The relationships and dynamics between the team members had an effect on students' feelings toward the simulation game. Hence, the technique of group work affected student attitudes toward part of the course. A second tertiary study also focused on the implementation of co-operative learning activities as well as increased class discussions in order to increase student self-concept in mathematics and decrease 
anxiety (Townsend et al., 1998). While a decrease in anxiety was not found, the study did support a slight increase in mathematics self-concept. The attitudes of middle school students were studied with respect to two different instructional techniques (Higgins, 1997). A problem solving approach to learning mathematics was compared to a traditional instructional approach. Those students who received the problem solving instruction were found to view mathematics as more useful and tended to exhibit more perseverance in solving problems. Also, these students showed a more positive attitude toward mathematics. In the elementary school, a study was conducted concerning the effect that two curriculums had on first graders' attitudes toward math (Pearce et. al. 1999). This study found that it is important for teachers to assess student attitudes and that the two curriculums used in teaching mathematics did seem to have a positive effect on student affect toward mathematics. One curriculum, Mathematics Their Way, highlights lessons using manipulatives, games, and concrete materials. The second curriculum is titled Silver, Burdett, and Ginn which focuses on lessons with hands-on independent work and problem solving. Another study was conducted by Mitchell (1999) at the elementary level. This action research investigated teaching practices that could be used to change the negative attitudes toward math that were observed among first and second graders. Some strategies such as discussions, observations, games, feedback, and weekly student comments were implemented to alter student enjoyment, motivation, and evaluation. It was found from surveys that these strategies increased positive attitudes toward math. Kinney (2001) conducted a study which compared two different types of instructional techniques in college developmental math courses. One technique utilized computer-mediated instruction while the other used traditional lecture. 
Interestingly enough, most test scores did not show a significant difference. However, students in the computer-mediated course reported an increase in confidence in mathematics as well as a more drastic increase in their attitudes toward mathematics. A similar study (Yusof \& Tall, 1999) altered the instructional techniques in a college mathematics course. Problem solving and reflective sessions with little direction and instruction were implemented into a mathematics course. This consisted of a two hour small group problem solving session with little direction, followed by a one hour lecture and discussion that focused on some aspects of the problem. Following an initial resistance, it was found that eventually students experienced an increase in positive attitudes toward mathematics. A third study by Elliott et.al. (2001) compared a traditional College Algebra course with an interdisciplinary course called Algebra for the Sciences. This non-traditional course used science topics and modeling to lead to math topics (Elliott, p.812). A significant increase in positive attitudes was found in the group that completed the Algebra for the Sciences course when compared to the traditional College Algebra course. Raymond \& Leinenbach (2001) conducted action research in order to investigate the results and reactions from implementing manipulatives in order to teach solving equations in an eighth grade classroom. The classroom teacher (Leinenbach) collaborated with a university professor (Raymond) and used the 'HandsOn Equation’ program which uses the idea of a balance to solve algebraic equations. While it was unclear whether this technique affected subsequent student achievement, after interviewing students, it did seem to improve their outlook and attitude toward algebra in a positive way. Lastly, Whitin (2007) discusses the creation of an instrument to assess student attitudes toward mathematics and how the results of the survey can 
guide alterations in teaching techniques. A survey was created and administered to fourth grade students. The results of the surveys were then used to change some of the teaching techniques, such as implementing more group activities and problem solving projects that related to other subject areas, as well as altering the discourse in the classroom. The survey was given again at the end of the year and the results suggest that these changes in teaching techniques resulted in an improvement of student attitudes. While these studies have been conducted in different environments and using various instructional techniques, all lend support to the idea that certain instructional strategies will have an impact on student affect and attitude.

\section{Affect, Attitude and Teacher Beliefs}

Similar to instructional factors, there are various studies that investigate the effect that the beliefs and attitudes of pre-service and/or in-service teachers have on student affect and attitudes (Uusimaki \& Nason, 2004; Beswick, 2006; Wilkins \& Brand, 2004; Swan, Bell, Phillips, \& Shannon, 2000; Grouws \& Cramer, 1989; Schoenfeld, 1985; Beswick, 2007). A study of pre-service teachers by Uusimaki and Nason (2004) found that an overwhelming majority of the future teachers' dislike of mathematics was believed to be a result of poor experiences with a teacher. However, in their responses to a survey in which they ranked factors that influenced them, it seemed as if these preservice teachers recognize the important role that the attitude of the teacher can play on the subsequent attitudes of students since these factors were highly ranked by many students. Similarly, a study conducted by Beswick (2006) found that pre-service teachers noted the influence that a teacher can have on their students. These pre-service teachers ranked the importance of certain elements from two mathematics units that they took. 
Three of the top five aspects that were valued most by the pre-service teachers related to their perceptions of the lecturer of the course. Both of these results are important since there exists some literature which suggests that teachers’ beliefs may affect their instructional methods (Wilkins \& Brand, 2004). If this is the case, then a concerted effort needs to be made in courses taken by pre-service teachers to improve attitudes so that a cycle of poor attitudes is not constructed. Wilkins \& Brand (2004) saw an improvement in pre-service teacher beliefs following a mathematics methods course which emphasized an "investigative approach to teaching mathematics” (Wilkins \& Brand, p.226). With respect to teacher beliefs about mathematics, a study by Swan et al. (2000) suggests that often times the teacher's beliefs concerning the primary purpose of a task is different from the students' beliefs. Swan et al. found this to be particularly true when the tasks were more open-ended. Grouws and Cramer (1989) observed six teachers who seemed to be creating great classrooms with respect to mathematical problem solving. They identified some teaching practices that seemed to be causing an increased student enjoyment of mathematics, specifically in problem solving. Some of the main practices were the enthusiasm of the teacher, the rapport that the teacher had with his/her students, and the warm atmosphere of the classroom. This study lends support to the idea that the outward attitude of the teacher influences the attitudes of the students. A study conducted by Schoenfeld (1985) suggests that the techniques students find to be most useful on assessments conflict with concepts that are verbally emphasized by instructors. This discrepancy causes confusion among students’ attitudes and beliefs. Specifically, in class, teachers stress the importance of students deeply understanding the mathematics. However, they also suggest memorizing as one of the best ways to succeed on the test. It 
was found that students tend to accept this contradiction and often answer questionnaires accordingly. They tend to indicate that understanding is important, but that memorization is essential to succeeding in mathematics.

As stated previously, the factors responsible for reinforcing and strengthening declining positive attitudes toward mathematics are important to determine so that we can work to reverse these poor attitudes or even prevent these attitudes. As McLeod (1992) states, these beliefs and attitudes are slow to form and hence are slow to change. Of course, the longer that these attitudes and beliefs are reinforced, the more difficult it will become to reverse the negative effect. Because of this, reversing negative attitudes and beliefs among adult students poses a unique problem that is particularly challenging. This is even more apparent since many of the studies have focused on students in elementary, middle, or secondary schools. Figure 2.1 represents many of the factors that previous literature suggests as having an effect on students' attitudes toward mathematics. 


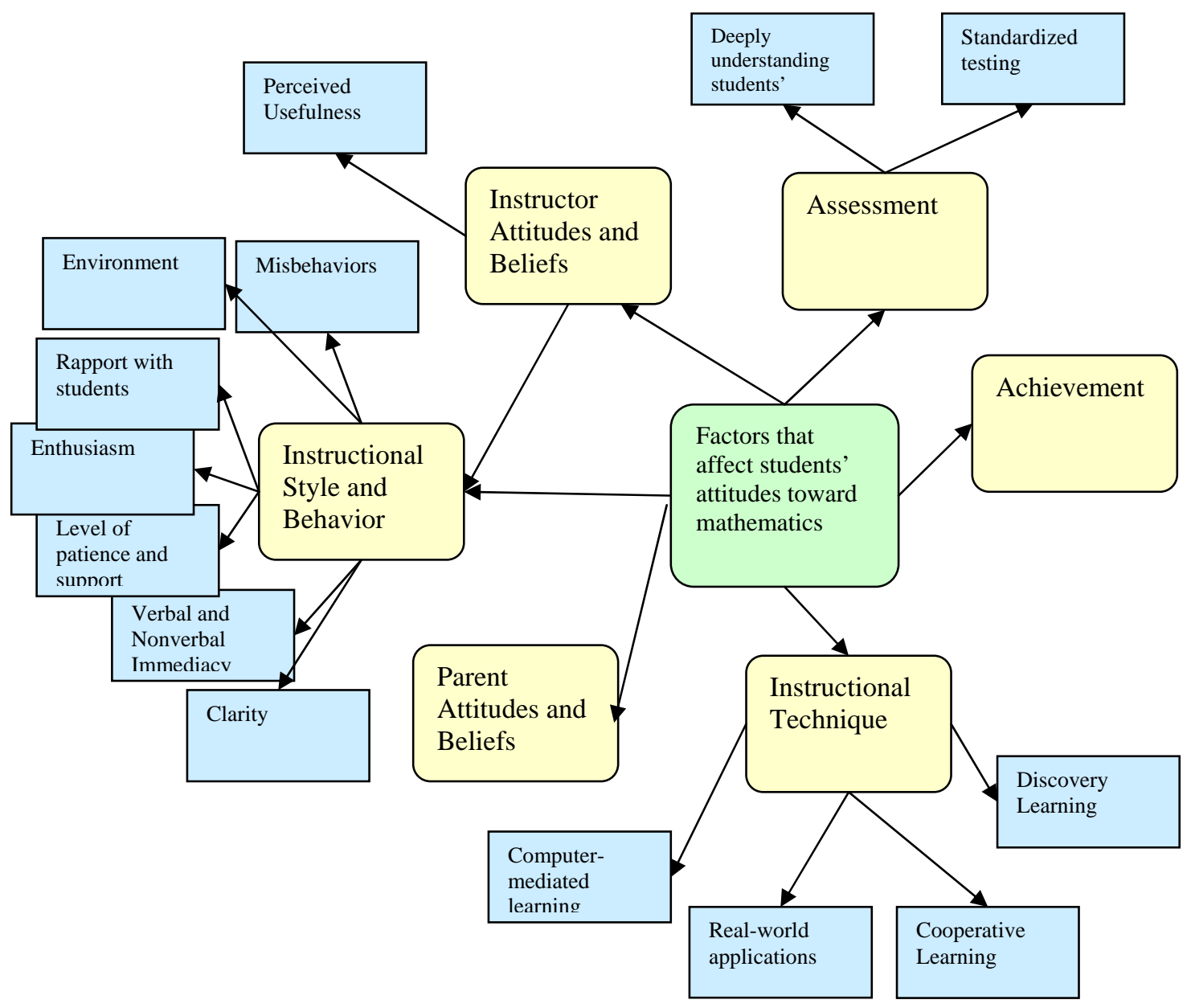

Figure 2: Factors that Affect Student Attitudes toward Mathematics

\section{Chapter Summary}

This review has taken the reader through the history of math education in the American undergraduate curriculum, the history and research of reforms that have occurred in this curriculum, the role that affect and attitude can play in mathematics, and what factors have been found to contribute to and possibly influence student affect and 
attitudes toward mathematics. The history of math education highlights the importance of the applicability of mathematics. We see many changes that have taken place in the undergraduate mathematics curriculum and realize that many of the reform ideas were found to promote student understanding and positive student attitudes. Finally, the research on affect, attitude and mathematics emphasizes the significant role that various factors can have on student attitudes. This study will investigate students' perceptions of what factors contribute to their attitudes.

Sometimes research can occur in a vacuum, in my opinion, often not taking into account the contexts of the world around them. For this study I want to be sure to recognize two larger curriculum paradigms and their impact on student attitudes toward math: 1) First, the social and policy impact on the math curriculum we teach in higher education and 2) the social and policy impact of the curriculum on the students we teach. In other words, the curriculum we teach may affect student attitudes, but it is important to realize that the curriculum has been affected by social and political factors throughout history. Similarly, by the time we teach students in undergraduate mathematics classes, their attitudes toward mathematics have been affected by social forces and years of mathematics classes. This chapter engenders the need to explore and understand the contexts from which our students, their perceptions, and our curriculum evolved. The historical and research perspective of this literature review is important to investigate college student attitudes toward mathematics. The next section describes the methods that will be used to answer the main research question; what factors affect college students' attitude toward mathematics? 


\section{CHA P T E R 3: M E THO D O L O G Y}

\section{Introduction}

This section describes the design of this study in detail. We begin with a broad explanation of the type of study and the large stages of the study. Justification for the mixed methods design with a focus on qualitative methods is covered and a review of the research questions is visited once again. The chapter moves on to a more detailed description of the two major phases of the study, in order to give the reader a better understanding of exactly how the study was conducted. Reliability and validity for the qualitative phase is highlighted, since it is the primary method of data collection. For increased clarity, a timeline of actions and diagrams of the phases are also presented. Once each phase is described thoroughly, the research questions are revisited and aligned with the data collection methods in a matrix in order to show how each phase and data collection technique contributed to answer the research questions. An explanation and description of the pilot study follows the description of the current study in order to shed some light on revisions that have been made to the survey and interview protocol, along with some expected results. The chapter concludes by revisiting the limitations and with a detailed description of the sample and the population, with the understanding that many of these results may not be generalized for the entire population. 


\section{Rationale}

\section{Type of study}

This study is a mixed methods study. Phase I consisted of a quantitative survey and served as the secondary data source. This survey allowed me to gain quantitative data from a large number of students. It also helped to give context to each person's attitude about mathematics, as well as helped influence purposefully selecting a smaller group of students for the qualitative portion of the study.

Phase II was comprised of a qualitative interview which was the primary data source. These interviews followed the quantitative surveys. Information from the interviews helped me gain a deeper perspective than the original quantitative survey. Even though the qualitative part consisted of fewer participants, the information was richer and hence a more thorough understanding of these students' attitude toward mathematics resulted. In short, the quantitative surveys give breadth to my study by reaching a large number of students, while the interviews provide depth to my study by deeply exploring a smaller number of students’ perspectives.

\section{$\underline{\text { Justification for study }}$}

Previous literature has shown that a student's attitude toward a subject may affect their achievement and understanding in that subject, deeply held beliefs about the subject, and even influence career choices. These are only a few of the reasons why it is important to study student attitudes. Also, since mathematics tends to have larger numbers of poor attitudes, it is an important subject on which to focus. 
In general, studies that are largely qualitative attempt to give us a more in-depth understanding of the complexities of human beings. Each person is unique and complex and they possess various experiences, backgrounds, and points of view. In an educational setting, all of these unique features have contributed to and molded every student's individuality and learning style. These all are nearly impossible to measure with numbers alone. Quantitative studies can effectively measure if one numerical variable has an effect on other numerical variables. However, it often fails to answer the questions 'how' or 'why'. Why do these variables affect each other? What else is playing a role? Real life is complicated and there are so many external and internal factors, numbers could never represent it all.

Qualitative studies attempt to understand other's point of view, to delve into these complicated matters and try to arrive at some common answers to 'how' and 'why' (Patton, 2002, p.14). To me, it is similar to two different understandings of mathematics. Many will tell you that math is a static subject with one right answer and everything is very black and white. In fact, several people who have strong attitudes toward math find that this perspective strongly influences their attitude. This can be similar to quantitative studies: either there is significance or there is not. However, most people who have taken a number of mathematics courses, like me, will tell you that mathematics is very far from static and black and white. Mathematicians want to know the why: why does this work? It is even sometimes determined that old mathematical theories and concepts are changed and even proven incorrect over time. As mathematics educators, we want our students to know why: why am I doing this? This is more like a qualitative study to me: 
not just searching for the black and white answer, but searching for the why lying beneath it all.

Studies on affect and mathematics are lacking, especially those that focus on qualitative interviews (McCleod, 1992; Smith III \& Star, 2007). Most studies tend to take place in the $\mathrm{K}$ - 12 environment and most focus on comparing attitude surveys to test scores in an attempt to link attitude and achievement. While it is important to compare these two quantitative measures, these studies do not seem to uncover why these student attitudes are what they are and how they influence (or do not influence) students' achievement. I feel it is as important to gain a deeper understanding of as many factors as possible that are contributing to student attitudes toward mathematics so that we can work to improve student attitudes and increase true student understanding.

\section{Research Questions}

The overall purpose of my research is to investigate adult/college students’ attitudes toward mathematics. Specifically, I would like to explore the factors that contributed to their attitudes toward the subject.

My research questions are as follows:

1. What factors influence college algebra students' attitudes toward mathematics?

2. Retrospectively, what were current college students' attitudes toward mathematics in primary and secondary school?

3. Currently, what are college algebra students' attitudes toward mathematics?

4. What are college algebra students' perspectives concerning how to reverse or prevent poor attitudes toward mathematics at the college level? 
The first and second questions are considered secondary. Finding out what student attitudes are and were like can help educators, parents, and students recognize the impressionable times in which student's attitudes form and can focus on pedagogical practices during these times. The third question is my primary question and is the main focus of the study. I want to thoroughly understand all the factors that can play a role in student attitudes. The answers to this primary question influences the fourth question. Once I determine factors that affect student attitudes, I can then investigate student ideas for action that can be taken to make a lasting change in college students’ attitudes.

\section{Research Design and Layout}

\section{Overview of Design}

This study consisted of both a quantitative and a qualitative component. Essentially, it can be classified as quan $\rightarrow$ QUAL. The quan (Phase I) is represented first and is not capitalized because this component was not the focus of the study, was administered first and influenced the larger part of the study, the qualitative component $(Q U A L)$. The quantitative component is a survey that was administered to large groups of college students enrolled in an introductory mathematics course. The quantitative component served as a guide to aid in selecting a smaller group of these students to participate in the larger part of the study, the qualitative component (Phase II). This smaller group of students was interviewed based on responses from the surveys and on their responses to the interview questions. The semi-structured open-ended interviews were analyzed within each interview as well as compared across interviews. A timeline below summarizes these actions. The fall 2007 semester was when most data was 
collected and therefore the timeline is broken down into the sixteen week semester in

\section{Table 3.1.}

\begin{tabular}{|c|c|}
\hline Time & Actions \\
\hline $\begin{array}{l}\text { Summer } \\
2006\end{array}$ & $\begin{array}{ll}\text { - } & \text { Prepare rough draft of Introductory Chapter } 1 \\
\text { - } & \text { Prepare rough draft of part of Literature Review Chapter } 2 \\
\text { - } & \text { Prepare preliminary comparison survey } \\
\text { - } & \text { Prepare preliminary interview protocol } \\
\text { - } & \text { Apply for IRB approval for pilot study for surveys and interviews }\end{array}$ \\
\hline $\begin{array}{l}\text { Spring } \\
2007\end{array}$ & $\begin{array}{ll} & \text { Pilot the comparison survey on small group } \\
\text { - } & \text { Revise surveys based on feedback and results of pilot study } \\
\text { - } & \text { Pilot the interview protocol } \\
\text { - } & \text { Revise interview protocol based on feedback and results of pilot interviews } \\
\text { - } & \text { Work on and defend Comprehensives }\end{array}$ \\
\hline $\begin{array}{l}\text { Summer } \\
2007\end{array}$ & $\begin{array}{ll}\text { - } & \text { Prepare complete rough draft of Literature Review Chapter } 2 \\
\text { - } & \text { Prepare complete rough draft of Methodology Chapter } 3 \\
\text { - } & \text { Revise Chapters } 1,2 \text { and } 3 \text { and prepare to defend Prospectus } \\
\text { - } & \text { Defend Prospectus } \\
\text { - } & \text { Apply for IRB approval for Dissertation Study }\end{array}$ \\
\hline $\begin{array}{l}\text { Fall } \\
2007\end{array}$ & $\begin{array}{l}\text { - Week 1-4: Prepare online version of comparison survey and upload } \\
\text { - Week 5-7: Administer comparison survey to sections of } 126 \\
\text { - Week: 8-9: Analyze data and group students for interview selection } \\
\text { - Week 9: Contact students for interviews } \\
\text { - Week 10-15: Administer interviews and send for transcription } \\
\text { - Week 16: Begin coding and categorizing data from interviews; Create } \\
\text { matrix to organize data; Begin code book }\end{array}$ \\
\hline $\begin{array}{l}\text { Winter } \\
2007\end{array}$ & $\begin{array}{l}\text { - } \\
\text { - }\end{array}$ \\
\hline $\begin{array}{l}\text { Spring } \\
2008\end{array}$ & $\begin{array}{ll}- & \text { Prepare rough draft of Results Chapter } 4 \\
\text { - } & \text { Prepare rough draft of Discussion Chapter } 5 \\
\text { - } & \text { Finalize revisions and defend dissertation }\end{array}$ \\
\hline
\end{tabular}

Table 1: Dissertation Timeline 


\section{Phase I - Survey}

The quantitative survey was administered during the first half of the 2007 fall semester. This survey was a comparison survey that asked questions concerning student attitudes, experiences, and feelings from grade school through college life. The survey was separated into five different grade band sections: Kindergarten to Second Grade, Third to Fifth Grade, Sixth to Eighth Grade, Ninth to Twelfth Grade, and post High School. Similar questions were asked in each of the grade bands so that the responses can be compared during each grade band. I chose the separations based on the grade groupings suggested by the NCTM and the standards based mathematics reform currently in elementary, middle, and high schools. A copy of the survey is in Appendix 1. I created the survey largely based on the literature concerning factors that may play a role in student attitudes toward subjects, specifically mathematics. From this review, I found achievement, teacher attitude, instructional technique, and teacher beliefs to be the primary factors to contribute to student attitudes. I constructed questions that ask students to rate the influence these factors had on them through use of a Likert scale. I also conducted a pilot study in the fall semester of 2006 in order to test and revise the survey. As a result, I shortened the survey and reworded some of the questions.

The survey was available online for all students enrolled in Math 126 during the 2007 fall semester. The survey was available for a couple weeks in order to gain maximum participation. As an added incentive, students received 5 bonus points for completing the survey. I was able to track each student's responses while also allowing them to remain anonymous by giving each student's survey an identification number. 
Since I taught three of the four sections of the course, only the results from the course that I did not instruct were used in the study.

Once the surveys were closed, I exported the data from the section that I did not instruct and ran some simple statistical tests. In order to classify students with varying attitude shifts, I compared the difference between the student's mean response from each grade band with the overall mean response from the remaining grade bands. Each student was grouped into the grade band whose mean score lies the farthest from the mean of the remaining scores. These calculations allowed me to group students according to their most positive or least positive attitude experiences by grade band. For example, all students who had the most significant attitude score in middle school were in one group, while those with the most significant attitude score in high school were placed in another. From these initial groupings, I investigated the overall attitude trends throughout each student's school experience, by simply comparing the mean responses for each grade band. Then, I further grouped the students from each initial group into subgroups according to overall trend. For example, students who experienced initial positive attitudes, followed by a decline in attitudes, ending with an increase in positive attitudes were grouped together, while those who experienced a steady decline in positive attitudes were grouped in another. Students with mean values that do not fit a specific trend or whose mean values are very close together were grouped together. Overall, the grouping process was an emergent design. The groupings emerged based on the results of the survey. I attempted to interview participants from each of these groupings to gain varying perspectives. Figure 3.1 illustrates Phase I and the grouping process. 
Figure 3: Phase I Grouping Process

**Select students from each group to interview

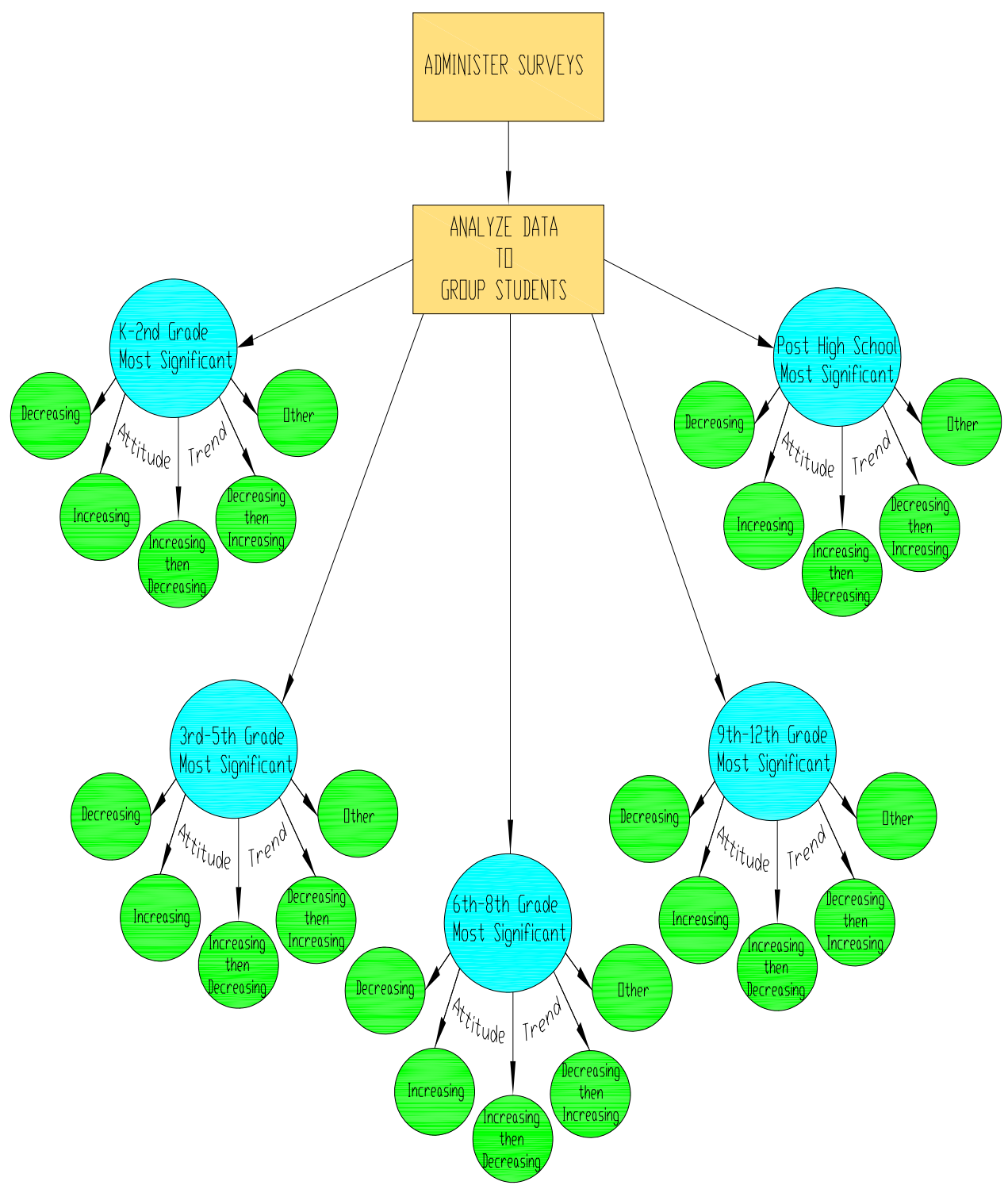




\section{Phase II - Interviews}

Once the surveys were completed and all groupings were made, students were contacted and asked to participate in the audio-taped, semi-structured, open-ended interviews. I contacted the students around the ninth week of the fall semester. Originally, I planned to obtain a set percentage from each group so as to retain a representative collection of students with a range of attitudinal experiences in mathematics. For example, if half of the students fell into one category, I planned to attempt to pool fifty percent of my interviewees from this category. The interview protocol is attached in Appendix 2 and was created largely based on previous literature. The interview protocol was piloted with the survey in the fall 2006 study. As a result, some questions were added and rearranged to the semi-structured, open-ended format.

I interviewed all participants between the tenth and fifteenth weeks of the fall semester 2007. Each interviewee was read an introductory explanation of their rights, anonymity, and decided if they would allow the interview to be audio-taped. I also took notes during every interview in case of tape malfunction or a decline for taping. Each interview lasted between 15 and 30 minutes and was transcribed for analysis. Once transcribed, I adopted many of the coding and analyzing techniques from Harry, Sturgis, and Klingner (2005). Many of these techniques and concepts are drawn from Glaser and Strauss's Grounded Theory (1967), meaning that the data is constantly compared and the results are grounded in the data and emerge from the data. On an initial read-through, I open-coded each transcript in order to gain an idea of the main elements in each interview. Open-coding is the first step in grounded theory in which "the researcher 
names events and actions in the data and constantly compares them with one another to decide which belong together” (Harry, Sturgis, and Klingner, 2005, p.5). This was the initial attempt at comparing the interviews to look for similarities and differences. I then created a matrix that contained each of the main codes from open-coding for each interview. In this case, each row represented a student and every column contained codes for each interview. This matrix helped organize all the interviews into one construct to compare all of the open codes and collapse the codes into broader categories. This is often referred to as axial coding (Harry, Sturgis, and Klingner, 2005, p.5). Once these categories began to emerge from the open codes, I created a code book that defined the categories. The code book defined each category completely as I saw them emerge from the open code matrix. For example, as in the pilot study, I noticed many codes pertaining to the teaching style of the instructor while other codes described the personality or actions of the instructor in the classroom that did not necessarily pertain to the teaching style of the instructor. When collapsing these codes into categories, it was important to properly define the categories so as to avoid mistakes. The next step was to compare the categories in order to collapse categories into themes. The themes were defined in the code book so as to ensure consistency. I also tested each theme by revisiting all of the interviews to make sure that the themes are apparent in each of the interviews. Once the themes emerged, I attempted to find relationships and interactions among the themes. From these interactions, I began to arrive at conclusions regarding what factors affect college students' attitudes toward mathematics and how these factors relate to each other. Figure 3.2 illustrates the coding process of Phase II. 
Figure 4: Phase II Grounded Theory Technique

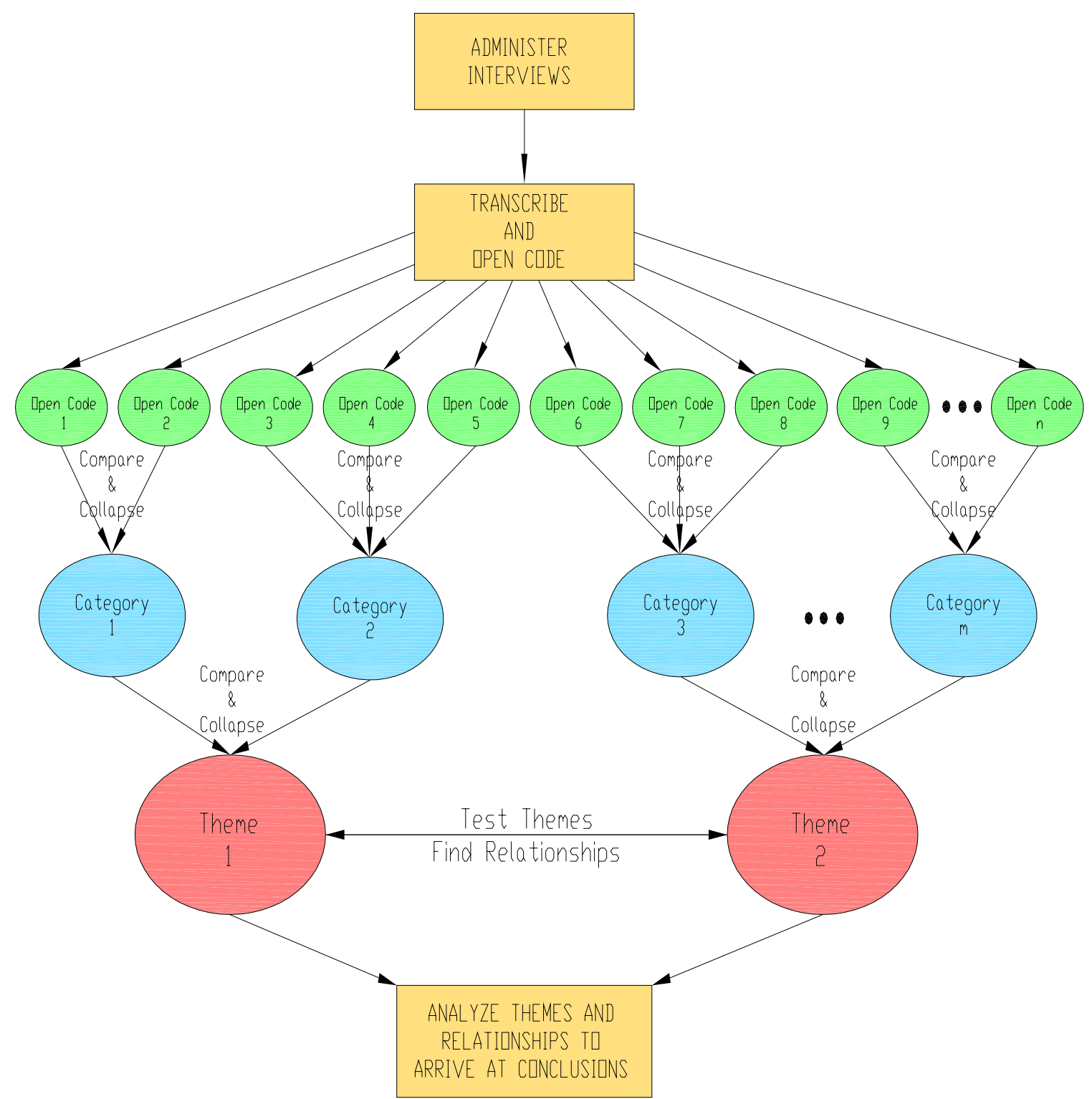




\section{Phase II Reliability and Validity}

In order to ensure reliability and validity, I incorporated various strategies. First, triangulation will be used between the data from the surveys, the findings from previous literature, and the interview themes. Triangulation is a technique in qualitative research which compares multiple data sources or multiple collection methods (Patton, 2005, p.247). I was able to compare the survey responses and interview responses of each student. From the pilot study, I also expected many student responses to be similar to those from previous studies, but also expected variations from prior literature. Second, I incorporated member checks with each of the interview participants. Member checks involve providing a short summary and interpretations of each interview to the interviewee in order to gain their opinion of its plausibility (Merriam, 2002, p.31). I wanted each interviewee to confirm the basic ideas that I had deduced from each interview. Third, I interviewed enough students so I felt the data was saturated, meaning no new perspectives are being discovered (Merriam, 2002, p.31). This helped to confirm a true understanding of student attitudes toward math. Finally, by attempting to purposefully select my interviewees, I was remaining open to various ideas and increasing the range of application of the results of the study. Students from a variety of backgrounds, majors, and attitudes were interviewed to ensure a wide range of viewpoints. 


\section{$\underline{\text { Review }}$}

I will now revisit my research questions and the research methods used in order to summarize how analyzing the survey and the interviews helped answer my primary and secondary research questions. The questions are:

1. What factors influence college algebra students' attitudes toward mathematics?

The survey determined some factors that may contribute to the students' attitude. However, qualitative interviews delved more deeply into the students' perspectives concerning their attitudes toward mathematics.

2. Retrospectively, what were current college students' attitudes toward mathematics in primary and secondary school?

3. Currently, what are college algebra students' attitudes toward mathematics?

A quantitative retrospective survey designed by the researcher administered to college students inquiring about past and present mathematical experiences suggested a grade level in which this decline began. Interview questions also asked students to recall past and present experiences in mathematics.

4. What are college algebra students' perspectives concerning how to reverse or prevent poor attitudes toward mathematics at the college level?

In-depth case interviews on students who have experienced a change in attitudes investigated what factors contributed to this change. Interview questions also probed into what advice each student would give for change.

The following matrix, table 3.2, summarizes how each instrument will affect each research question: 


\begin{tabular}{|c|c|c|c|c|}
\hline & $\begin{array}{l}\text { RQ\#1: What factors } \\
\text { influence college } \\
\text { students' attitudes } \\
\text { toward mathematics? }\end{array}$ & $\begin{array}{l}\text { RQ\#2: } \\
\text { Retrospectively, what } \\
\text { were college students' } \\
\text { attitudes toward } \\
\text { mathematics in } \\
\text { primary and secondary } \\
\text { school? }\end{array}$ & $\begin{array}{l}\text { RQ\#3: Currently, } \\
\text { what are college } \\
\text { students' attitudes } \\
\text { toward } \\
\text { mathematics? }\end{array}$ & $\begin{array}{l}\text { RQ \#4: What are } \\
\text { college algebra } \\
\text { students' } \\
\text { perspectives } \\
\text { concerning how to } \\
\text { reverse or prevent } \\
\text { poor attitudes } \\
\text { toward } \\
\text { mathematics at the } \\
\text { college level? }\end{array}$ \\
\hline $\begin{array}{l}\text { Quantitative } \\
\text { Comparison } \\
\text { Survey }\end{array}$ & $\begin{array}{l}\text { The comparison } \\
\text { questions also asked } \\
\text { students to rate how } \\
\text { the proposed factors } \\
\text { affected them } \\
\text { throughout their } \\
\text { schooling } \\
\text { experiences. }\end{array}$ & $\begin{array}{l}\text { Students rated their } \\
\text { experiences in } \\
\text { mathematics } \\
\text { throughout their } \\
\text { schooling career. }\end{array}$ & $\begin{array}{l}\text { Students took into } \\
\text { account and rated } \\
\text { their previous } \\
\text { schooling } \\
\text { experiences as } \\
\text { well as their } \\
\text { current college } \\
\text { mathematics } \\
\text { experiences. }\end{array}$ & \\
\hline $\begin{array}{l}\text { In-depth } \\
\text { Interviews }\end{array}$ & $\begin{array}{l}\text { Most of the } \\
\text { interview questions } \\
\text { focused on students' } \\
\text { overall experiences } \\
\text { with mathematics as } \\
\text { well as their ideas as } \\
\text { to what factors may } \\
\text { contribute to their } \\
\text { attitudes toward } \\
\text { mathematics. }\end{array}$ & $\begin{array}{l}\text { Based on survey } \\
\text { responses, interview } \\
\text { questions explored the } \\
\text { attitudes that students } \\
\text { remember } \\
\text { experiencing in } \\
\text { primary and secondary } \\
\text { school as well as what } \\
\text { factors they felt } \\
\text { contributed to these } \\
\text { attitudes. }\end{array}$ & $\begin{array}{l}\text { Based on survey } \\
\text { responses, } \\
\text { interview } \\
\text { questions further } \\
\text { investigated } \\
\text { students' current } \\
\text { attitudes toward } \\
\text { mathematics. }\end{array}$ & $\begin{array}{l}\text { Some interview } \\
\text { questions } \\
\text { addressed student } \\
\text { opinions and } \\
\text { advice for math } \\
\text { educators and on } \\
\text { the ideal format of } \\
\text { mathematics } \\
\text { courses. }\end{array}$ \\
\hline
\end{tabular}

Table 2: Research Question Summary

\section{$\underline{\text { Pilot Study }}$}

As stated previously, I conducted a pilot study in the spring semester 2007 in order to test and ultimately revise the comparison survey and the interview protocol (Goodykoontz, 2007). The quantitative survey asked students to recall and rate their mathematical experiences throughout their entire educational life. I created the questions based on a review of literature concerning factors that effect student attitudes toward content areas, specifically mathematics. A graduate student administered the surveys to a small section of a College Algebra class. The surveys also consisted of four open-ended 
questions in order to obtain student opinions of the survey along with gathering volunteers willing to be interviewed.

I received 32 responses to the survey and eight students gave an email address for the possibility of an interview. I entered the survey responses and conducted simple statistical tests in order to gain some information concerning attitudes toward mathematics during different grade levels. Just by computing and comparing each student's mean response at every grade level, I noticed that most students had at least one grade level in which the responses were much higher or much lower than the other grade levels. Upon closer inspection, I found that 12 of the 32 respondents seemed to have their highest or lowest ratings at the high school level. This is not a particularly surprising result since high school memories are the most recent for beginning college students. Also, none of the respondents appeared to have their highest or lowest rating in the $\mathrm{K}-2^{\text {nd }}$ grade, and only 2 had those in the $3^{\text {rd }}-5^{\text {th }}$ grade level. These findings guided my ideas concerning grouping the students in order to gain a wide range of student perspectives during the interview process.

The open-ended questions at the end of the survey provided opinions and suggestions with respect to the survey. I summarized the responses to the three suggestion questions in a matrix in order to see any themes or major findings. From this, I noticed three primary findings which may result in modifications to the survey: the survey was seen as too long, too repetitive and many students had difficulty recalling experiences from kindergarten or first grade. It is from these responses that I revised and shortened the survey. 
The survey also asked for volunteers to participate in piloting the interview protocol that I devised in order to investigate students' past and present attitudes toward math in greater depth and detail. After a struggle to find four students to interview, I transcribed and open-coded the interviews in order to discover major themes. I also used a matrix to organize the themes with the purpose of discerning primary conclusions. I found that the students I interviewed attributed their attitude toward mathematics to the teacher, the size of class, the type of class, and the assessments of the class. These results did seem to coincide with much of the previous literature.

One of the major complications that arose was the difficulty in finding willing participants. This is one reason that the pool of students will be much larger for the dissertation study. In terms of revising the interview protocol, students seemed to have difficulty recalling some experiences, so I will try to conduct the interviews closely after administering the surveys. I also rearranged some interview questions so as to investigate the student's memory in a more logical way. I am thankful for this pilot study, as I truly believe it has strengthened the larger study.

\section{Research Setting}

\section{Detailed Description of Sample}

The sample for this study consisted of college algebra students of a large land grant institution research university in the Appalachia region of the United States. The quantitative surveys were administered to students enrolled in large lecture sections of Math 126, College Algebra, during the Fall 2007 semester. This math course typically holds the highest enrollment of all introductory math courses at the University. The 
course is a basic algebra course that consists of two 50 minute lectures per week in a large auditorium and one 50 minute laboratory class per week in an 80 seat computer lab. The topics covered mostly consist of various types of functions, their graphs, and applications. The class begins with a chapter on solving equations then moves through linear, quadratic, polynomial, rational, exponential, and logarithmic functions. The course is taught in large lecture halls and normally has 160 - 220 students per section. With 3 or more sections per semester, roughly 480 - 660 students enroll in Math 126 each semester. Students usually take this course as their first mathematics course unless another course is needed for their degree or they place into a remedial or advanced course. Currently, students are eligible to take Math 126 based on ACT or SAT scores or as a result of a placement exam score. Each student must have a math ACT score of at least 23, a math SAT score of at least 540 to take the course, or a satisfactory score on the placement test. Most students tend to be of freshman or sophomore status, with the traditional student age being 18 or 19 . Since Math 126 is a common course recommended by a large number of departments, typically there is much variety in the majors of the students. This course tends to be a representation of the average lower division undergraduate college student. A smaller group of students will be selected from this sample to participate in the qualitative semi-structured interviews. These students were chosen based on their responses on the surveys.

\section{Detailed Description of the Population}

Since the bulk of the study is qualitative, I do not necessarily expect to be able to generalize my findings to a larger population. However, based on the sample, the population would be all college students enrolled in introductory mathematics courses. 
Ultimately, the qualitative interviews provided a more in depth understanding of a small group of student attitudes than that of purely quantitative surveys. My hope is that other higher education mathematics instructors are able to relate to the findings of my research and may use some of the suggestions to try to reverse or prevent declining student attitudes toward mathematics. Also, other college students may be able to relate to the attitudes and responses of the college students in the sample of the study as well as reflect on their own attitudes toward mathematics.

\section{Researcher}

\section{$\underline{\text { Assumptions and Limitations }}$}

There are some assumptions and limitations that I am accepting as initially stated in chapter 1 . In qualitative research, the researcher is the primary instrument and I realize that there is an unavoidable lens that I bring to the data and research. I will revisit the limitations that are specifically linked to the fact that I was acting as the primary instrument. Since I am the lead instructor of the course I studied, I do have opinions and beliefs about the way the course is organized, the content of the course, the assessments in the course and the student attitudes in the course. To account for this, I only used the results and interviewed students that were not enrolled in classes I was instructing and I strived to remain open to other perspectives in order to gain the most complete understanding of factors that affect student attitudes toward mathematics.

I am also aware that my beliefs and attitudes about mathematics were quite different from most students. My enjoyment of and experiences with mathematics could challenge my ability to relate to their experiences and feelings. Hence, I made every 
effort to consider all possibilities presented to me from the interviews and did not disregard ideas that are extremely different from my own. This was a challenge, but I was excited to gain multiple perspectives and truly try to understand the students' view. As I see it, the more I can understand where my students are coming from, the better I will be at influencing their attitudes toward mathematics.

\section{Chapter Summary}

This chapter describes the design of the study, the data collection process, and the way in which the data will be analyzed. The design is quan $\rightarrow Q U A L$, with the emphasis on the qualitative interviews. A comparison survey will collect attitudinal data from a large number a students, with the primary purpose of grouping students so as to purposefully select interviewees. The bulk of the study is qualitative. Interviews will be coded and analyzed in order to truly understand factors that can contribute to these students' attitudes toward math. As a mixed methods study, I am looking forward to gaining depth and breadth concerning factors that affect college students' attitudes toward mathematics. The next chapter describes the results I have collected from implementing the design explained above. 


\section{CH A P T E R 4: R E S UL T S}

\section{Introduction}

This chapter reports the results of the two data collection techniques used in the study. First, the groupings that emerged from the quantitative surveys are displayed and discussed. This is followed by a detailed discussion of the five themes that emerged from the qualitative interviews. The connections and relationships among these themes are proposed in order to answer the primary research question: what factors affect college algebra students' attitudes toward mathematics? Ideal classroom conditions from the students' perspectives are discussed to highlight these relationships. Finally, the research questions and answers are revisited.

\section{Phase I: Quantitative Survey}

The retrospective quantitative survey was available online to all students of Math 126 during the fifth, sixth, and seventh weeks of the fall semester 2007. Students were asked to rate their mathematics attitude throughout their schooling career. They also were asked to select which factor most influenced their attitude during each grade band, along with an open-ended question at the end of the survey. Since I was the instructor of three sections of this course, I was only able to use the results from the one section I did not instruct, consisting of roughly 140 students. This section produced 99 completed, usable surveys resulting in approximately a 70.71\% return. Most results and groupings from the quantitative surveys give some general answers to two of the subsidiary research 
questions concerning student attitudes during primary and secondary school as well as current student attitudes.

In order to group each student into the grade band where he or she experienced the most significant attitude toward mathematics, the mean response for each grade band was compared to the overall mean of the remaining grade bands. Figure 4.1 below illustrates this grouping:

\section{Most Significant Grade Band}

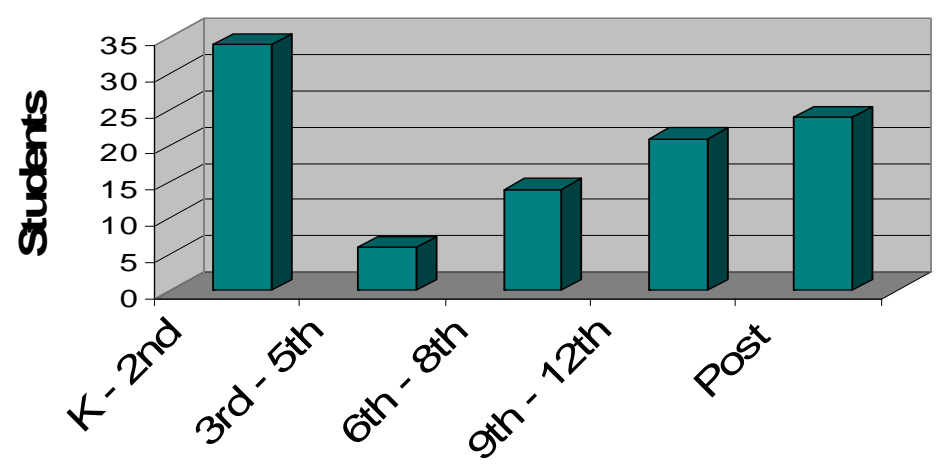

Figure 5: Most Significant Grade Band

As you can see, the kindergarten to second grade band had the highest number of students, followed by the post high school band. I believe there are a few reasons why the first grade band had the highest number of significant experiences. Since this survey was retrospective in nature, students would have a more difficult time recalling specific experiences in kindergarten, first, and second grade. Since this time is usually less grueling academically, I think most students have overall fond memories of the time spent in these grades. Also, after the pilot study, I did revise the survey and shortened the amount of questions for this grade band. Again, this was because of the increased difficulty, as stated by the students, in recalling feelings from this time. In order to investigate this further and account for the differences in the number of questions presented for each grade band, I did recalculate the groupings without using the 
kindergarten to second grade band. In this scenario, the post high school grade band absorbed all of the students from the kindergarten to second grade band, with the exception of two students who fell into the third to fifth grade band. This grouping would put the post high school band numbers well above any other. Since this band is the current band, the memories and feelings are more accessible and strong. The retrospective nature of the survey is a limitation of my study that I accept and hope to improve on in future research.

I also visually compared each student's mean response as they progressed through school in order to discern the attitude trend of each student. Figure 4.2 below illustrates this grouping:

\section{Attitude Trend}

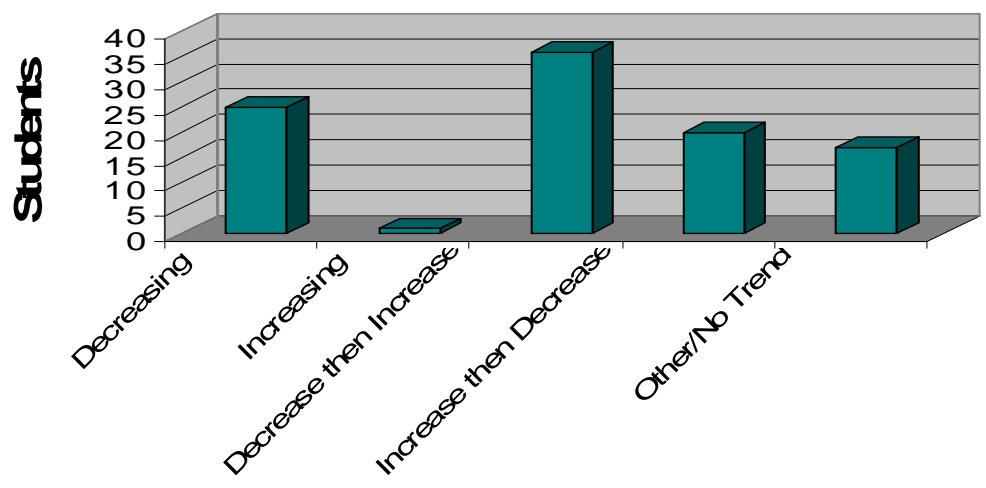

Figure 6: Attitude Trend

Not surprisingly, most students experienced a decrease in their attitude toward mathematics at some point in their life and only one student experienced an increase with no decrease in his attitude toward mathematics. On a positive note, many students did experience an increase in their attitude toward mathematics during sometime in their schooling career. This is encouraging and suggests student attitudes can be improved. 
Lastly, students were grouped first by their significant grade band and then further by their attitude trend. Table 4.1 below illustrates this grouping:

\begin{tabular}{|c||c|l|c||c|c|}
\hline GRADE & Decreasing & Increasing & $\begin{array}{c}\text { Decreasing } \\
\text {-Increasing. }\end{array}$ & $\begin{array}{c}\text { Increasing } \\
\text {-Decreasing. }\end{array}$ & Other \\
\hline \hline $\mathrm{K}-2$ & 12 students & & 11 students & 3 students & 8 students \\
\hline $3-5$ & & & 2 students & 2 students & 2 students \\
\hline $6-8$ & & & 11 students & 2 students & 1 student \\
\hline $9-12$ & 3 students & & 10 students & 5 students & 3 students \\
\hline Post & 10 students & 1 student & 2 students & $\mathbf{8}$ students & 3 students \\
\hline
\end{tabular}

Table 3: Student Groupings by Grade and Trend

The table above represents the grouping explained in detail in chapter 3 and in Figure 3.1.

The last question in each grade band was to select which factor most influenced his or her attitude during that specific time and contributed to answering the primary research question regarding what factors influence college algebra students' attitude toward mathematics. The choices were: teacher, grade in class, content, classroom environment, tests, or other. Since the kindergarten to second grade band was shortened, this question was not included. Therefore, the results are only available for third to fifth grade, sixth to eighth grade, ninth to twelfth grade, and post high school. Table 4.2 shows the results of this question: 


\begin{tabular}{|c|c|c|c|c|}
\hline Factor & $3^{\text {rd }}-5^{\text {th }}$ & $6^{\text {th }}-8^{\text {th }}$ & $9^{\text {th }}-12^{\text {th }}$ & Post \\
\hline Content & 15 & 22 & 14 & 19 \\
\hline Teacher & 30 & 34 & 49 & 13 \\
\hline $\begin{array}{c}\text { Tests and } \\
\text { Assessments }\end{array}$ & 10 & 12 & 10 & 15 \\
\hline $\begin{array}{c}\text { Classroom } \\
\text { Environment }\end{array}$ & 9 & 8 & 5 & 10 \\
\hline Grade & 11 & 19 & 17 & 30 \\
\hline Other & 4 & 22 & 4 & 9 \\
\hline $\begin{array}{c}\text { not } \\
\text { answered }\end{array}$ & $\begin{array}{c}\text { Teacher, } \\
\text { Grade, } \\
\text { Content, } \\
\text { Other, } \\
\text { Tests, } \\
\text { Environment }\end{array}$ & $\begin{array}{c}\text { Teacher, } \\
\text { Content, } \\
\text { Grade, } \\
\text { Tests, } \\
\text { Environment }\end{array}$ & $\begin{array}{c}\text { Teacher, } \\
\text { Grade, } \\
\text { Content, } \\
\text { Tests, } \\
\text { Environment }\end{array}$ & $\begin{array}{c}\text { Grade, } \\
\text { Content, } \\
\text { Tests, } \\
\text { Teacher, } \\
\text { Environment }\end{array}$ \\
\hline
\end{tabular}

\section{Table 4: Factors Influencing Student Attitudes}

It is interesting to note that the teacher received the most votes in increasing numbers, until post high school, where it received the fourth most votes. In fact, about half of the students felt that the teacher had the most influence on their attitude toward mathematics in high school, compared to only thirteen students in post high school. This is probably the most surprising result from my perspective, especially being a mathematics instructor in higher education. From a personal point of view and past experience, I do believe the teachers can influence student attitudes, even at the college level.

After speaking with students in the interview portion of this study, I have a few ideas concerning the decline of teacher influence post high school. Students seemed to be realizing that, as an adult, they need to succeed in these classes in order to obtain a 
degree and eventually a career. As you can see from the table, nearly one third of the students in post high school felt that their grade was the most influential factor. This also suggests that students could be more goal-oriented at this stage in their life and may view mathematics as a means to an end. On the other hand, it could also be that since students were taking this survey in a college mathematics class, they worried their teacher may have access to the results and did not want to blame the teacher for what might have been their poor attitude. The students were told that the survey responses would remain anonymous, but they still may have been reserved. It could also be due to the large lecture format that this class assumes, making relationships with the teacher more challenging. In any event, I think this is a topic that warrants more investigation.

\section{Phase II: Qualitative Interviews}

Once the quantitative surveys were completed and analyzed, I contacted students for an in-depth, semi-structured, open-ended interview. Initially my hope was to gain a representative number from each grouping. However, after I contacted all 99 students and received four responses for interviews, I realized I should just focus on gaining as many interviews as possible. After three rounds of emails, I was able to interview 23 students, with each grade band represented. Further, the only attitude trend not represented was the Increasing attitude trend, which only contained one student. I did attempt to email this student a fourth time, to no avail. Table 4.3 illustrates from which group each of the interviews belonged: 


\begin{tabular}{|c|c|c|c|c|c|}
\hline GRADE & Decreasing & Increasing & $\begin{array}{l}\text { Decreasing } \\
\text {-Increasing. }\end{array}$ & $\begin{array}{l}\text { Increasing } \\
\text {-Decreasing. }\end{array}$ & Other \\
\hline $\mathrm{K}-2$ & 2 & - & 4 & 1 & 4 \\
\hline $3-5$ & - & - & 1 & 0 & 0 \\
\hline $6-8$ & - & - & 4 & 2 & 0 \\
\hline $9-12$ & 0 & - & 2 & 0 & 0 \\
\hline Post & 2 & 0 & 0 & 1 & 0 \\
\hline
\end{tabular}

Table 5: Student Interview Groupings by Grade and Trend

As you can see, I was able to interview students with a wide range of attitudes and ideas about mathematics. Each interview was audio taped and transcribed so that grounded theory techniques could be utilized in order to analyze the data. Any quotes used in reporting the results were taken verbatim from the transcriptions in order to uphold the integrity of the student response and to give the reader the most accurate representation of each student. All names used when referencing students are fictional. I am also using footnotes to cite my interview so as to not disrupt the flow of the results and quotes.

I began open coding and created a large matrix to represent these codes. Appendix 3 is the open-coded matrix constructed from keywords attached to each answer of every interview. The matrix is 24 rows by 16 columns. Each row represents an interview, while each column represents a question in the interview. Once the matrix was created, these open-codes were collapsed into broader categories. The 24 categories were defined in a code book to ensure consistency. ${ }^{1}$

\footnotetext{
${ }^{1} 24$ categories: Understanding, Usefulness, Time, Level of Difficulty, Achievement, Personal Attention, Teacher Explanation, Multiple Representations, Examples, Placement, Collaborative
} 
After considering each category, five themes emerged that answer my main research question: What factors affect college algebra students' attitudes toward mathematics? The five themes are: 1 . Teacher characteristics, 2 . Teaching characteristics, 3. Classroom characteristics, 4. Assessments and achievement, and 5. Individual perceptions and characteristics. There are many relationships among these five themes. Primarily, I see these first four characteristics as external to the student, while the last one is internal and based on each student's perceptions that have been building and been influenced throughout their lives.

\section{Teacher Characteristics}

Students discussed various characteristics of the teacher they felt affected their attitude toward the subject. When considering external characteristics that have an impact on student attitudes, I believe the teacher characteristics are the most important. Teachers hold a position of perceived power over students in a classroom and often have some control over the other external factors like teaching characteristics, classroom characteristics and the assessments in math courses.

The demeanor of the teacher was frequently referenced. Students seemed to talk about two different types of demeanor: one being the teacher's personal demeanor that did not have a direct affect on their ability to learn mathematics, whereas the other was more of a professional demeanor which did have a direct impact on their ability to learn and understand mathematics. Descriptions of a nice, mean, or funny teacher would be attributes of personal demeanor, while a patient, devoted or boring teacher would be 
attributes of professional demeanor. I recognize these characteristics are interrelated. For example, being devoted could be considered part of being nice. However, in the interviews, some students recognized the differences as well. For example, a teacher could be very funny but also be a poor teacher. Resa is an 18 year old communications major who has a pretty neutral attitude toward math. She remembered a male teacher who would joke around a lot but also was not very respectful of students. She said, "I really liked the guy. He was like always joking. If you asked a dumb question, he would make fun of you...I feel uncomfortable with that."2 In fact, the combinations of these teacher characteristics differed slightly for many students. However, most teachers that were considered nice tended to possess characteristics like patience or care. Students typically felt a nice, funny, relaxed teacher who was patient and supportive influenced their attitude in a positive way. Carly, a 24 year old psychology major has always struggled with math and feels the teacher plays a pivotal role in her attitude. She recalls a positive experience with her high school teacher, "I had a teacher in high school that really, really tried to do everything she could to make me understand. She met me after class. That would be the most positive thing. I knew she was doing everything she could to help me.”3 Resa also noted the difficulty in learning and liking mathematics if the teacher did not possess these attributes. She said, "She was really mean. I was happy I never had a real mean teacher for the whole year. Because I can’t work whenever teachers are not nice or not approachable or if they are really difficult."4

In addition to the demeanor of the teacher, students often discussed the importance of the relationship and interaction between the students and the teacher. This

\footnotetext{
${ }^{2}$ Interview with Resa

${ }^{3}$ Interview with Carly, November 14, 2007

${ }^{4}$ Interview with Resa, November 2, 2007
} 
is related to the perceived demeanor of the teacher. Students felt better about a class where there was a lot of relaxed interaction with the teacher. Doug is an 18 year old computer engineering major who views math mostly as a requirement. Doug expressed the importance of a teacher that respects student ideas;

I think attitudes would change along with other things, like how you are teaching. I keep going back to the pre-cal teacher. Like the entire class would laugh and throw in suggestions and talk and throw around ideas because they knew he would go with it, take it seriously, where my trig teacher no one really talked because we knew she wouldn't do anything with it, and just get mad and give us more homework or something. ${ }^{5}$

On the other hand, a lack of respect and poor interaction with students can have a lasting effect on a student's attitude toward the subject. When asked to recall a negative memory from mathematics, a few stories emerged concerning the way a teacher treats students. Zack is a 29 year old Multidisciplinary Studies major who remembers an especially vivid interaction with his fifth grade teacher;

I took a test on my own not having had a chance to study it too well, took it, didn't do well, and the teacher calls me up to the desk and shows me it and pretty much belittled me. And then I go to take the test off of her to see how bad I did and she just looks at me and rips it in half and says, 'You don't get this back' and throws it in the trash. ${ }^{6}$

\footnotetext{
${ }^{5}$ Interview with Doug, November 9, 2007

${ }^{6}$ Interview with Zack, November 15, 2007
} 
Most students also expressed the need for personal attention in order to not only increase their level of understanding, but also to increase their positive attitude toward the course. Zack, along with Greenlee and Kendall, conveyed this feeling. Zack felt that he needed “more one-on-one help”, , while Greenlee, a 25 year old graduate elementary education student who has always struggled with math said, "I think teachers maybe need to make the effort to do more one-on-one time."8 Kendall echoed their thoughts when thinking about the positive aspects of high school mathematics classes. The 18 year old general studies major states, "During my high school years, there was less lecture and more looking at examples and more one-on-one.”9

I believe the teacher can affect the internal characteristics of the student, which ultimately influences their attitude. Patient teachers who are willing to give one-on-one time with each student help to increase student motivation, self-efficacy, and selfconcept. I believe this results in increased understanding and improved student attitudes.

\section{Teaching Characteristics}

Directly related to the characteristics of the teacher is the way in which the teacher instructs the classroom. Students often give examples of instructional techniques or explanations they feel supported or failed to support their understanding in the class, which ultimately affects their attitude toward the class. Students want to enjoy the class and also understand the class. Some students seemed to, in general, talk about the teacher's ability to explain a concept. Students often referred to good teaching and bad teaching in general, while others gave more specific examples of good teacher

\footnotetext{
${ }^{7}$ Interview with Zack

${ }^{8}$ Interview with Greenlee, October 31, 2007

${ }^{9}$ Interview with Kendall, November 2, 2007
} 
explanation. Resa recognized the importance of teacher explanation and discussed how her current college instructor explains concepts;

She actually goes through it and explains it before people asks questions in front of 200 people. She explains like each step like whenever she first goes over something she first explains each and every step to it and then the next time she goes over the same kind of example...she will skip a couple steps but she will still go back and say what she did. ${ }^{10}$

Similarly, Loretta, a Business major who has always liked math, spoke of the importance of teacher explanation. She gave advice to teachers to improve student attitudes. She said, “explain things a lot better because if kids know what they're doing their attitudes are going to be positive toward math." ${ }^{\text {11 }}$ Becky agrees on the positive aspect of good teacher explanation. The 18 year old Child Development major said, "instead of being so complex, they break it down and going through each step every time you do it."12

In terms of explanation and teaching techniques, students expressed the importance of multiple explanations and multiple representations for different types of learners. Some students saw the benefit of a deep, thorough explanation and the effect that may have on student attitudes. Susan, an 18 year old Journalism major often does not like mathematics because she fails to see the usefulness in the real world. Speaking to the importance of multiple representations, she said, "the teacher explains it overall in a way everyone could get it. Maybe in like five different ways and everyone can take some

\footnotetext{
${ }^{10}$ Interview with Resa

${ }^{11}$ Interview with Loretta, October 29, 2007

${ }^{12}$ Interview with Becky, November 1, 2007
} 
kind of grasp on it.”13 An 18 year old English major named Elizabeth concurs with this idea. She gives a suggestion to teachers, "explain how it works and why it works...my teacher does things algebraically and then she'll go 'if you're a graphic learner, here it is’, and she'll sketch a graph and stuff.”" Adam agrees with Susan and Elizabeth. He is an 18 year old Criminology major who has experienced a positive increase in his attitude toward mathematics. He gave teachers this advice to improve student attitudes, "explain to students why things work. Some students are going to complain about it but the students who are there to really learn, they'll appreciate it. Also, give a good mix of the visuals and the algebraic part of it."15

Many students also felt their attitude is affected by each student’s perceived usefulness of the mathematics material. Students want to see how mathematics will affect them and also the role it plays in everyday life and the real-world. From the students' point of view, more of an effort should be made to highlight the usefulness of mathematics for everyone. Obviously, students seem to be missing the connections that mathematics has in daily life, along with the connections among various topics in mathematics. Students such as Elizabeth, Carly and Holden talked about what teachers may want to do or have done in the past to connect mathematics to everyday life. Elizabeth said, "If you're positive and willing to take time to teach and connect with the kids and bring it into a real life scenario, I think that is going to help kids learn math better and have a better time with math in the long run.”16 When asked what might improve her attitude toward mathematics, Carly wished that teachers "had a way to show

\footnotetext{
${ }^{13}$ Interview with Susan, November 6, 2007

${ }^{14}$ Interview with Elizabeth, October 25, 2007

${ }^{15}$ Interview with Adam, October 25, 2007

${ }^{16}$ Interview with Elizabeth
} 
you a way how this was going to be useful or you will need this to understand this class." ${ }^{17}$ Holden, a 23 year old who has never liked math, agreed with this notion and remembers an experience from high school; "I had a high school teacher...she always had some way to connect the information to real life and that is what really counted...give me a reason to know. If there were no reason to know it then I didn't really care. It doesn’t affect me.”18

Others also talked about how the perceived usefulness of mathematics affects their attitude toward mathematics. Students felt that seeing the usefulness of mathematics creates a connection between them and the subject. Rami, an 18 year old Journalism major does not believe mathematics is very interesting. He thinks teachers should try to teach "something that appeals to you or how you can relate to it and how you can use it later on."19 Dave is a 19 year old Social Studies major who agrees with Rami. He summarizes his attitude toward mathematics. He said, “I really don’t like it [mathematics] because I don't see any point to have it related to real life.”20

Students talked about working collaboratively, either with other peers or with tutors. This was another teaching technique that affected the way they felt about the class and about learning in the class. When asked what could support a student's learning, Loretta said,

\footnotetext{
${ }^{17}$ Interview with Carly

${ }^{18}$ Interview with Holden, November 12, 2007

${ }^{19}$ Interview with Rami, November 1, 2007

${ }^{20}$ Interview with Dave, November 5, 2007
} 
More time spent working in groups and with another person because if you work with someone else, you're more likely to come up with...or see how other people learn. $^{21}$

On the other hand, Carly discussed the emotional issues that can occur when working in groups. She said,

I really find it difficult to work in groups in math classes. Because I am so selfconscious about my level...in my case, I am paired with two people who are really good in math so it is really embarrassing for me to work in a group with them and provide no input. ${ }^{22}$

The issue of time also emerged in various ways from multiple students. Often, students thought that teachers needed to take time with each student to be sure that everyone understood the material. Ultimately, this seemed to improve their attitude toward the mathematics class. A few students spoke on this idea. John is a 19 year old Business Law major who has lost interest in mathematics recently. He gave this advice to teachers; "just make sure all the students understand the material. Ask frequently if they're stuck on anything, if any minor things are holding them back from finishing a problem. And to try to find ways to make it a little more interesting, maybe like better examples.”23 Jonathan, a 19 year old Business Management major, recalls how a previous teacher always made time for students. He remembered, "if you didn’t understand you asked her [the teacher] and if you still didn't understand after that she

\footnotetext{
${ }^{21}$ Interview with Loretta

${ }^{22}$ Interview with Carly

${ }^{23}$ Interview with John, October 29, 2007
} 
would make time for you to come in after class for some time to make sure you understand., 24

This brings up the issue of time and pacing in mathematics in general. I can relate to this idea as a teacher. So often, the dictated pace does not allow time for everyone to understand. I believe this is a paradox that teachers deal with: the need to get through the material that will be asked on an assessment or that students will need for the next class, while also trying to go slow enough to not leave anyone behind. I feel the underlying issue is that of breadth versus depth. There are many factors in the educational system that convey the idea that breadth is more important. Standardized testing has a specific number of requirements that teachers need to cover prior to testing. This often results in teachers focusing on trying to cover all the topics in the amount of time allotted. In higher education, there are many sequences of courses, such as the calculus sequence, which require that certain topics and concepts are covered prior to the next course in the sequence. Again, the focus is on the breadth of topics rather than the depth of understanding. A shift toward depth should allow teachers to spend more time on difficult concepts and topics.

\section{Classroom Characteristics}

It is clear through these interviews that some characteristics of the classroom are affected and created by the teacher. Other classroom characteristics directly affect the characteristics of the teacher and the teaching. In other words, I see the relationship between teachers and teaching with the classroom as bidirectional. Each one influences

\footnotetext{
${ }^{24}$ Interview with Jonathan, November 12, 2007
} 
the other. Most students discussed the effect that class size had on the overall classroom environment, as well as their attitude to the class and their ability to understand the concepts. Large classes, in general, make certain teacher and teaching characteristics harder to express. Students overwhelmingly expressed the desire for a smaller classroom, making many ideal teacher and teaching characteristics more plausible. Various students discussed the relationship between class size, personal attention, and overall classroom environment. Greenlee described the positive aspect of a small math class. She said, It [a previous college math class] just seemed more on a personal level and it was a smaller class - there was only probably 25 kids in it and I think that really helps with math classes. When you don't feel overwhelmed by the student population as well as the concepts....and I think at the college level your classes are so huge and so you feel just swept under the rug anyway...so it’s hard to kind of stay ahead of the game in that environment. ${ }^{25}$

Elizabeth agrees with Greenlee and feels the class size affects the level of interaction. She said, "smaller class size. I think that's a big factor. When a teacher asks us for answers, there's not a lot of response. She can't hear something...so if there were smaller class sizes there would be better interaction." ${ }^{26}$ Similarly, Dave points out the problems with a large class. He said, "there's a lot of kids in the class, so there's like 150 or whatever so it seems like it's not very personal. You're just learning with a whole bunch of people. I guess like making smaller classes so that you feel like you're actually part of a group learning instead of just a big lecture hall.,27 Amy is an 18 year old

\footnotetext{
${ }^{25}$ Interview with Greenlee

${ }^{26}$ Interview with Elizabeth

${ }^{27}$ Interview with Dave
} 
Psychology major who has not liked mathematics since high school. She agrees with Dave and said, "I feel almost overwhelmed when the teacher's down there and she has this small little voice...but when someone's standing there and they can look at me faceto-face, that would be my ideal class."28 Zack noted the issues of asking for help in a large classroom. He said, “do you really want to be the one out of 300 people to raise your hand saying, 'I don’t understand it'?”29 Carly also recognizes the problems with a large class but realizes that it is not solely the teacher's fault. She said, "it is not fair to say they [the teachers] don't care, it's just there is so many students it is impossible for them to reach out to everybody.

For Billie, a Business Management major who resents math classes and her lack of understanding, size was crucial,

I'd be very happy if there were only 30 people and the teacher was writing on the chalkboard...it's much less intimidating than a huge screen that if you're sitting anywhere near the side of the class or the teacher then you're breaking your neck to sit there and watch this huge screen. I find the screen to be very impersonal and the chalkboard for some reason I still associate with elementary school, middle school, high school, and I find it much more personal, much easier to approach. $^{31}$

Students also discussed how teachers can affect the overall classroom environment. Students seem to be more comfortable in a relaxed environment. Becky remembered a teacher that created this type of environment, "she [the teacher] wouldn't

\footnotetext{
${ }^{28}$ Interview with Amy, November 15, 2007

${ }^{29}$ Interview with Zack

${ }^{30}$ Interview with Carly

${ }^{31}$ Interview with Billie, November 1, 2007
} 
be uptight about things. I like classes where you can speak out whenever you want to instead of raising your hand. ${ }^{\text {32 }}$ Bryce agrees with Becky. The 18 year old Journalism and Psychology major has experienced a decline in mathematics attitude over time and wishes his math classes had "fun learning environment. Fun teaching. More enthusiasm. Laugh with each other." ${ }^{\text {,3 }}$ When describing their ideal math course, some students wanted a more interactive class with games or activities. Jonathan said, "make it handson and make it kind of fun."34 Mike added, "they [students] should have math puzzles— something like Sudoku or some way to incorporate the math equations into an everyday thing. I think that would be so cool. To come in and play games.”35 One reason some students wanted activities in a mathematics course was introduce variety and to break up the monotony of daily lectures. Kendall said, "Less repetition and more new subjects. Like we do the lab...so that it's not the same every class. I would do various activities, too, like the lab maybe. I don’t love the labs but they’re a switch from lecture.”36 Doug added, "keep it dynamic and keep it interesting, not just the same old thing day after day and class after class. Mix it up a little bit." ${ }^{37}$ Students desired a more interactive environment, possibly with the teacher walking around the classroom to help students. Jonathan said an ideal teacher "would always be walking around helping, always giving advice and helping without giving the answers. ${ }^{, 38}$ Clearly, according to these statements, smaller classes in a relaxed, interactive environment are ideal conditions for student understanding and positive student attitudes toward mathematics.

\footnotetext{
${ }^{32}$ Interview with Becky

33 Interview with Bryce, November 6, 2007

${ }^{34}$ Interview with Jonathan

${ }^{35}$ Interview with Mike

${ }^{36}$ Interview with Kendall

${ }^{37}$ Interview with Doug

${ }^{38}$ Interview with Jonathan
} 


\section{Assessments and Achievement}

Students also linked their attitude toward mathematics with their success in the course. Success is a difficult concept to define since it carries different meanings for everyone. People also have varying ideas on how to measure success. In a schooling environment, many might say that success is measured through scores and grades. After all, a passing grade is usually how students pass courses. Others might say that success is measured by the level of understanding that a student possesses. As a teacher, I recognize that the student who scores the highest on an assessment is not always the one who truly understands the concepts the best. This leads to a broader question: what does this say about our testing and grading system?

Often times and understandably so, students felt success was measured by their scores on assessments and their achievement in the course. The idea of success was discussed by most students. Students often saw their attitude toward a class decline as their success (often defined by grades) in the class declined and vice versa. Amy pointed out the effect a poor score can have on her attitude, especially if she put forth effort. "My attitude toward math is probably influenced by my grades. If I put forth a pretty good effort where I think I should get a B on a test and I get an F it's going to really just make me not stand math even though it doesn’t really have to do with math.”39 Other students concurred that the effort they put into the course should be reflected in their scores. Speaking to this idea, when asked what influences her attitude toward math, Carly said, "I would say probably my scores. I know I put the time into it. If things were reinforced

\footnotetext{
${ }^{39}$ Interview with Amy
} 
by better grades I would have a different attitude." ${ }^{40}$ Sabini and Monterosso (2003) investigated the relationships that college students see between effort and grades.

Overall, the research examined whether or not students saw grading as a moral domain. Students in this study felt that a substantial amount of effort and hard work should be rewarded by raising a student's grade based solely on this effort in preparing for the assessment. Students were also less likely to support lowering a student's grade due to lack of effort. In general, the study discusses a balance between effort and talent. This is a source of frustration among many students. As a mathematics educator, I know there are students who score higher with less effort than other students. Students who do not see their efforts pay off with high achievement, tend to resent the course and the subject.

John reflected on how his ability in mathematics affects his attitude in this sports analogy: "If you do something and you do it good you're going to like it a lot better than if you're failing something. Compared to like sports. You feel like if you're good at basketball that means you like to do it. And if you're pretty terrible you don't want to go out there and play all the time."41 Zack agrees with John and said, "The thing that I liked about math would be just the times I was actually able to accomplish it and I was able to do well and that kind of changed your attitude. Kind of give you something good you're going to like it more. And then once you start doing bad again you start disliking it., ${ }^{42}$ Megan, an 18 year old Occupational Therapy major who has always earned good grades

\footnotetext{
${ }^{40}$ Interview with Carly

${ }^{41}$ Interview with John

${ }^{42}$ Interview with Zack
} 
in math, echoes this notion and plainly states, “[My attitude is influenced by] how well I’m doing in it."43

Students also hypothesized why other students seem to not like mathematics. Megan and Becky both felt that poor achievement was the primary reason. Megan also said, “they [other students] don't like it [mathematics] just because they can’t do it...they think they’re bad at it and they don’t like it.”44 Similarly, Becky added, "I know a lot of students get a negative attitude when they don't get a good grade.”45

Kendall looked back on her high achievement in mathematics classes, "I felt pretty good about it [mathematics]. I always did well in math in high school. I took the honors levels of most courses...was able to understand."46 Carly offers the opposite perspective on the effect that poor achievement and lack of understanding have on her attitude; “I have never been very good at math. I still don't understand math. I don’t have a very good attitude because I just can’t do it.”47 Kendall also noted the importance success has on attitude; “Like if you're able to be successful and learn the material, I that makes it...that's the liking factor of it. And I like math too because I understand it and I can teach it to other people."48

Students were also specific on the types of assessments that are most helpful to them and influence their ability to succeed in the course, which, in turn, can affect their attitude in the class. Most students requested low-risk, required, frequent assessments similar to homework and quizzes. Students also felt feedback on these assessments

\footnotetext{
${ }^{43}$ Interview with Megan, November 1, 2007

${ }^{44}$ Interview with Megan

${ }^{45}$ Interview with Becky

${ }^{46}$ Interview with Kendall

${ }^{47}$ Interview with Carly

${ }^{48}$ Interview with Kendall
} 
would be beneficial. Commenting on the need for feedback, Carly said, "I think it would also help if you collected more homework because I do the homework and I do wrong homework."49 Billie emphasized the importance of low-risk assessments. She said, "I don't like tests. I like how there’s other things contributing toward your grade just as much as tests are. Like the quizzes and the labs...I don't like classes where you have four tests and that's your grade.”50

\section{Individual Perceptions and Characteristics}

While students often discussed external factors that affect their attitude, such as the classroom, their teachers, the teaching style, and their achievement, they also recognized that some internal factors also influence their attitude. As stated earlier, most of these internal factors have been affected by external aspects. Many of these individual factors are beliefs and perceptions that the student holds or has held throughout their school life, while others are connected to the student's background and family. Some students felt their attitude was initially affected by their family and exposure to mathematics when they were young. Karen, an 18 year old Exercise Physiology major has always had a good attitude toward mathematics. She recalled how her father influenced her positive math attitude at a young age,

Ever since I was really, really young like even before I started school, my dad was always interactive because I guess he liked math too. He started me out on it. Giving me little math problems to do. Like the riddles in math. He would always make me do them. ${ }^{51}$

\footnotetext{
${ }^{49}$ Interview with Carly

${ }^{50}$ Interview with Billie

${ }^{51}$ Interview with Karen, November 1, 2007
} 
On the other hand, Greenlee noted the influence her family had on her negative feelings toward math. She said,

But my mother was a math teacher and that was always kind of a stigma almost. You should be good at it, or so. ${ }^{52}$

A third student attributed most of her attitude toward math to her family and, specifically, her upbringing. This University is in the Appalachia area of the United States so many students are from rural backgrounds and do not have a family lineage of higher education. When asked what affects her attitude toward math, Susan said,

Off the top of my head I would say my parents and their background. Neither one of them graduated from high school. Neither of them really applied themselves which makes me feel eager to do better than that. I am the first person in my family to go to college. I think it [my attitude] has a lot to do with my background and family and what has been exposed to me. Plus my grandma, I live with her, she doesn't know math or anything about math so she could never help me and it was frustrating when I didn't get it. ${ }^{53}$

The above quote also highlights the role that frustration and challenge level can play in student attitudes toward mathematics. Students often expressed the need to be challenged, but at an appropriate level. Students who found a mathematics class too difficult or challenging experienced frustration that seemed to cause their attitude toward the class to decline. In addition, the sense of accomplishment that students felt when able to work through challenging concepts seemed to affect student attitudes in a positive way.

\footnotetext{
${ }^{52}$ Interview with Greenlee

${ }^{53}$ Interview with Susan
} 
Speaking to this, Doug describes why he likes challenging problems better than easy problems:

I like the harder one if I can actually get the answer and I know it's right because it’s kind of an achievement. 'Yeah, I got it!' I’ve had some hard problems that I've done like 600 times and keep getting the wrong answer-it's so frustrating. ${ }^{54}$

The perceived level of difficulty also affected student frustration and student attitudes. Students discussed the way a difficult math class or math concept often frustrates them. Elizabeth explained, "like if it was something hard and if it took me really long to figure out and my grades would drop. I didn’t understand things then it was more frustrating so if I understood it faster I felt better." ${ }^{55}$ Megan sees this happen with many students. She said, “they [students] get too frustrated and they just don't want to do it [mathematics].,56

Elizabeth also discusses how she worked through frustration to realize that there are times when she may struggle with mathematics. She felt this is the primary reason that her attitude toward mathematics improved after elementary school:

If I didn’t get it the first time I was not going to get it and I didn’t care... as I got away from that it got easier to accept I'm not going to get this the first time and it got easier to deal with math. ${ }^{57}$

Motivation and its role in student attitudes emerged in many different ways throughout the interviews. Students spoke of ways that they could be motivated through

\footnotetext{
${ }^{54}$ Interview with Doug

${ }^{55}$ Interview with Elizabeth

${ }^{56}$ Interview with Megan

${ }^{57}$ Interview with Elizabeth
} 
their teachers, their grades, and their connectedness to the concepts in mathematics. Bryce credited a caring teacher as a source of motivation: "My one teacher, she was really devoted and made you want to try harder."58 Rami simply recognized the motivation that often is a result of achievement. "If you get good grades, you get rewarded"59 Other students spoke of motivation being directly linked with each student feeling some type of connection to mathematics. Holden said, “Give me a reason to know. If there were no reason to know, then I didn't really care. It doesn’t affect me.”60

Similarly, when asked what teachers could do to improve their students attitude toward math, Mike simply stated, "give them a reason why they should be in math.”61 To me, achieving this balance of challenge and frustration is a key element to a successful class with motivated students. Students need to be challenged so that they are not bored, but should not be too discouraged and frustrated from too much challenge. There are many studies that discuss this idea of challenge and frustration and its connection to motivation. Students can be motivated intrinsically or extrinsically. According to Eccles and Wigfield (2002), intrinsic motivation occurs when students are engaged in an activity "because they are interested in and enjoy the activity" (112). On the other hand a student is motivated extrinsically when the reason for engaging in an activity is because of a reward that may result. I believe most students can see the extrinsic reward of engaging in mathematics at the college level: they pass the class so they can earn the degree. However, it seems this is often not enough motivation for many students. In my opinion, educators need to consider how students can be intrinsically motivated in order to

\footnotetext{
${ }^{58}$ Interview with Bryce

${ }^{59}$ Interview with Rami

${ }^{60}$ Interview with Holden

${ }^{61}$ Interview with Mike
} 
increase student understanding, attitudes, and success. Mihaly Csikszentmihalyi developed flow theory, which focuses on an appropriate balance between challenge and the skills needed to meet those challenges (Shernoff, Csikszentmihalyi, Schneider, \& Shernoff, 2003). According to this theory, appropriate challenges need to be provided to students so that their skills are "neither overmatched nor underutilized" (160). In the 2003 study, Shernoff et. al (2003) surveyed high school students to see how they spend the majority of their time in school and what activities keep them engaged. They found that subjects such as math were viewed as academically intense and relevant, but students had negative feelings toward the subject. In the end, teachers need to create activities that are challenging and relevant, but also cultivate a positive emotional response, possibly by giving students more control over their learning environment. Schweinle, Meyer and Turner (2006) agree with the importance of balancing challenge and frustration. Their study concluded that "emphasizing the balance of challenge and skill, supporting self-efficacy and value for mathematics, and fostering positive affect can enhance student motivation in the classroom” (Meyer and Turner, 2006, 271).

In order to motivate students and properly balance challenge and frustration, students need to be correctly placed in their math courses. This will help to prevent overmatching or underutilizing students' abilities. Students often felt overwhelmed and behind in many math classes. This is usually due to poor placement and the level of challenge being too high for the ability of the student. Two students below discuss how falling behind affects their attitude toward mathematics. Billie feels she is always behind in mathematics. She said, "The fact that I am already falling behind and I find it hard to catch up and it makes me even more antsy about it and I just feel like I'm constantly, 
constantly falling behind."62 Carly agrees; "In math, if you start out on a bad foot it is hard to get ahead because you are always playing catch up. I think that is why a lot of students don't like it because they feel they are always behind.”63

On the other hand, Resa recognizes that being ahead of other students affects their self-confidence and, in turn, attitude toward mathematics. She said, "I liked being ahead. I liked feeling smart." ${ }^{64}$ Carly also recognizes the issues that arise when students in a math class have varying levels of ability; "Where you have so many different levels in one class...that's what makes it difficult for somebody who is a little lower level or the people right in the middle, they get lost.",65

While many students recognized external factors that affect their attitude and understanding of mathematics, others noted the importance of personal effort and responsibility. Adam and Resa both recognized that they must also put in enough effort to earn grades in mathematics. Adam had recently discovered the importance of personal responsibility in college and said, "when it comes down to it my success in math will be based on whether or not I have worked hard enough to get the right grade in the math class.”66 After reflecting on what might help to improve her attitude and understanding in math, Resa said, "math has always been so easy and maybe that is why I had so much trouble with calculus, too because I had to apply myself more...I don’t try to understand it more...I guess if I tried a little harder.”67

\footnotetext{
${ }^{62}$ Interview with Billie

${ }^{63}$ Interview with Carly

${ }^{64}$ Interview with Resa

${ }^{65}$ Interview with Carly

${ }^{66}$ Interview with Adam

${ }^{67}$ Interview with Resa
} 
Finally, when discussing individual perceptions that affect a college algebra student's attitude toward mathematics, an ability to understand was referenced more than any other idea. Basically, most students said their attitude toward mathematics was affected by their understanding in the class. Again, it varied how each student measured their level of understanding. Some referenced high scores on assessments, while others just spoke about being able to understand the material in general. Even when students referenced understanding in general, their definition of understanding is not completely clear and could be quite different than other students and the instructor. It is possible that they just want to understand how to complete the problems and implement algorithms and are not alluding to truly understanding the concepts. When asking students with a positive attitude why they like mathematics, Resa said; “I think because I understood it most of the time and I am good at it and I get good grades in it I liked it."68 Adam was in agreement with Resa. He said, "I enjoy math the most when I understand what is going on."69 When asked what could be done to improve attitudes toward mathematics, John suggested, “just a better understanding of it rather than just trying to remember stuff just for a test or just for a quiz. Understanding it for a long period of time.”70

In general, many students felt that understanding is one of the main factors that influences their attitude as well as other students' attitudes. Amy ties together the ideas of motivation and understanding. She said, “if I'm doing it because I want to do it because I know how to do it, that's what makes people have a positive attitude, is when they know how to do something."71 Others saw the connection between understanding

\footnotetext{
${ }^{68}$ Interview with Resa

${ }^{69}$ Interview with Adam

${ }^{70}$ Interview with John

${ }^{71}$ Interview with Amy
} 
and frustration. Becky and Susan both found their attitude improved if their understanding came easily. Susan recognizes that she often struggles with mathematics. When asked what could help to improve her attitude, she said, “it doesn't come easy to me and it still doesn't come easy for me...probably if I understood it quicker." ${ }^{, 72}$ Becky agrees and believes positive attitudes are a result of "understanding it [mathematics] and being able to do it without struggling., ${ }^{, 73}$ Jonathan also agrees that frustration can play a role in understanding and attitudes. He said, "the more I understand the better I like it and I don’t understand from the beginning it makes it frustrating, ${ }^{\text {,74 }}$

Others agreed with the importance of understanding mathematics. Billie sees that she struggles with math. She said, "my attitude toward math is based on my understanding of math...it’s kind of like you fear what you don’t know."75 Finally, Mike describes the positive aspects of understanding mathematics and gaining a sense of accomplishment, especially if you have worked through a difficult concept or problem. He said, "if I understand it, then I like it. But if it's hard, I still kind of like it because I like to figure it out and then once I know, 'Yes! I figured this out!’”76

\section{Relationships Among Themes}

Clearly there are many relationships among the five primary factors that were found to affect college students' attitude toward mathematics. There is obvious overlap and interplay among teachers, teaching, classrooms, assessments, and students. In fact,

\footnotetext{
${ }^{72}$ Interview with Susan

${ }^{73}$ Interview with Becky

${ }^{74}$ Interview with Jonathan

${ }^{75}$ Interview with Billie

${ }^{76}$ Interview with Mike
} 
many of the quotes above illustrate this as they could be placed under more than one of the factors. It is difficult to discuss exact relationships.

As I reflect on these five primary factors that emerged from the interviews, namely, teacher characteristics, teaching characteristics, classroom characteristics, achievement and assessments, and individual perceptions and characteristics, a key relationship emerges. The first four themes represent external conditions students feel affects their attitude toward mathematics. The last theme consists of internal beliefs and perceptions that students possess. These internal conditions are formed throughout life and can be affected and changed by some external factors. In my opinion, attitudes are an internal characteristic and are most affected by individual internal perceptions. However, these perceptions can be influenced by external conditions in a math class.

For example, consider the ideal classroom conditions that have emerged from these interviews. In terms of teacher characteristics, students want a nice, approachable devoted teacher who respects students and makes time for each student. Desired teaching characteristics include multiple classroom activities and techniques coupled with clear explanations and many examples. These examples should be challenging, interesting, and useful in real life. The assessments would be fair and frequent; while overall the classroom would be small in size with a relaxed, interactive environment. All of these conditions that educators and the education system can control are external conditions belonging to one of the first four factors discussed above. Educators should try to affect the external conditions in the hopes of affecting each individual's internal conditions. Ultimately, since the interviews are from the student perspective, I see the first four 
external themes affecting the individual, internal perceptions, which, in turn, affect student attitudes toward mathematics. Figure 4.3 illustrates this relationship:

\section{Relationship Between Factors That Affect College}

Students' Attitude Toward Mathematics

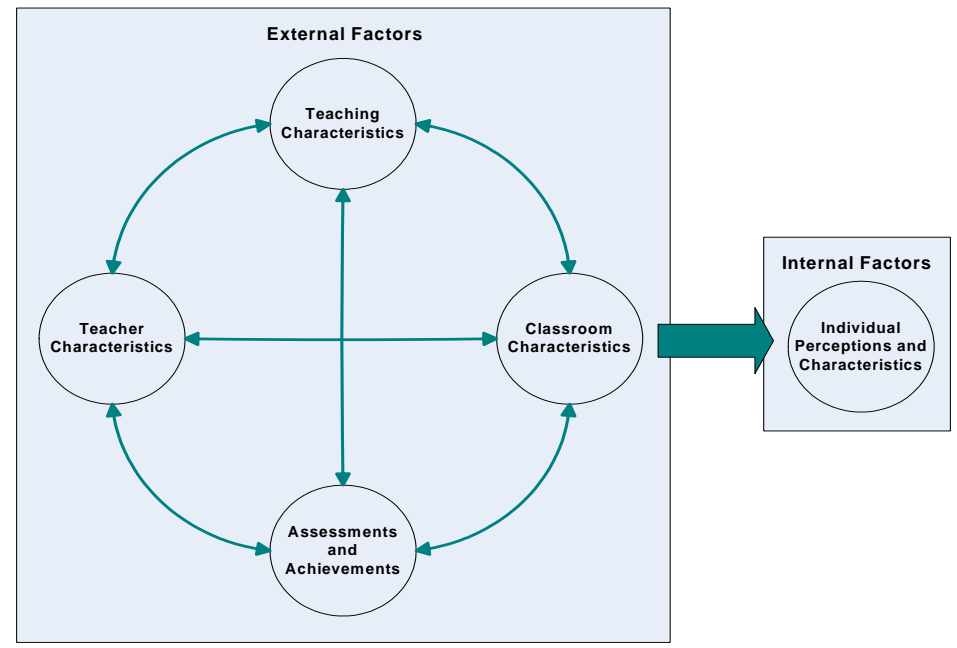

Figure 7: Relationship between Factors that Affect College Students’ Attitude toward Mathematics

After conducting and reviewing these interviews, I truly believe that students need to reach an understanding of mathematics in order to improve their attitudes toward it. Certain external factors need to occur to help with this. Teachers, teaching styles, and classrooms need to have many of the above characteristics in order to aid in student understanding. In addition, students need to have motivation to put forth effort and work with these external factors. When all of these come together, it should result in successful assessments and success in the course. Ultimately, this leads to improved student attitudes. 


\section{Chapter Summary}

This chapter presents the results from the quantitative surveys and the qualitative interviews. To summarize the results obtained from this study, each research question is revisited and answers are suggested.

1. What factors affect college algebra students' attitudes toward mathematics?

While the quantitative surveys noted the decline of the teacher's influence on student attitudes, the teacher is still one of the five primary factors that affect student attitudes. The teacher, the teaching, the classroom, the assessments and achievement, and the individual perceptions are these main factors. The first four factors comprise the external factors that can influence the internal, individual perceptions and attitude. As educators, a focus on changing and modifying characteristics of these external factors should occur that will affect student perceptions, understanding, and attitudes toward mathematics. Understanding the relationships between these factors can help us make the necessary adjustments to improve student attitudes and success.

2. Retrospectively, what were current college students' attitudes toward mathematics in primary and secondary school?

3. Currently, what are college algebra students' attitudes toward mathematics?

The quantitative surveys and subsequent grouping of students into significant grade bands and attitude trends highlights an overall idea of student attitudes over time. The groupings show the low number of students that have experienced a significant attitude experience in $3^{\text {rd }}$ through $5^{\text {th }}$ grades. It is also important to note only one student had experienced an increasing attitude trend throughout their schooling experiences. 
Every other student experienced a decrease in their attitude toward math sometime during their schooling career. In fact, many students experienced an increase and a decline in their attitude toward mathematics during various times in their lives. From interviews, it seems a decline usually occurred in the $6-8$ or $9-12$ grade band, although the most significant experiences occurred at the beginning or end of one’s schooling career.

4. What are college algebra students' perspectives concerning how to reverse or prevent poor attitudes toward mathematics at the college level?

While some students recognized the effect that personal effort and family influence may have on student attitudes, most students suggested external factors in a mathematics classroom that can work to reverse or prevent poor attitudes toward mathematics, especially at the college level. The conditions discussed concerning an ideal mathematics classroom, ideal teacher characteristics, ideal teaching techniques, and ideal assessments would all contribute to an increase in positive college student attitudes. As stated earlier, a devoted, patient teacher that moves at an appropriate pace and has time to give personal attention to each student is desired. The teacher would give good, detailed explanations and present interesting examples that show the usefulness of mathematics. This will help students make connections to the material and increase student understanding. An interactive environment would be fostered by the teacher in a small classroom with various group and collaborative activities. I believe this would increase student understanding, student success on assessments and improve student attitudes toward mathematics.

The next and final chapter discusses implications from these results, along with future research projects. 


\section{CHA P T ER 5: CONCLUSIO N}

\section{Introduction}

This chapter takes a deeper look at the results from chapter four, proposes implications of these results as they pertain to $\mathrm{K}-12$ and higher education institutions, and suggests future research endeavors. First, the five factors found in this study are compared with the factors from previous literature. The primary relationship between external and internal factors in this study and previous literature are also discussed in detail. Next, implications from this study are offered, leading to recommendations for education at all levels. Finally, ideas for future research to gain more depth to this topic are suggested.

\section{Comparisons with Previous Literature}

As seen in chapter two, previous studies have found various factors that affect student attitudes toward mathematics. I condensed these studies into six categories: instructor attitudes and beliefs, instructor style and behavior, instructional technique, assessments, parent attitudes and beliefs, and achievement. In this study, five factors were found that affect college student attitudes toward mathematics: 1) teacher characteristics, 2) teaching characteristics, 3) classroom characteristics, 4) assessments and achievement, and 5) individual perceptions and characteristics. In comparing the factors from this study to the factors from previous studies, there are plenty of similarities, along with a few differences. 


\section{Teacher Characteristics and Teaching Characteristics vs. Instructional Style and}

\section{Behavior}

Many studies highlighted the importance of instructional style and behavior which parallels numerous comments about teacher and teaching characteristics that are desired by students in this study. In terms of teacher characteristics, this study found students desire a patient, supportive teacher who respects and interacts with students. Studies by Thompson and Thompson (1989) and Midgely et al. (1989) also suggest the perceived level of patience and support of teachers affects student attitudes. While this does not seem to be a surprising result, it is an important one. College life is a big transition for students and it is important that they feel respect and support from their teachers. Even though these students are now adults, it is still possible to affect their attitudes, feelings, and level of understanding in the class. In fact, interaction and help from the teacher may even be more necessary at the college level due to the lack of community in an introductory mathematics college classroom. Most students do not know each other prior to the class and most do not share other courses with these students, especially at a large university.

Teachers need to be the glue that holds the large group of students together. One way to make a classroom more cohesive is the relationship between the teacher and the students. Students need to feel as if their teacher supports them both academically and even emotionally. Teachers can foster academic support by being willing to help students and truly caring if students understand the material. They should make office hours available, remind students of their willingness to meet with them individually, and repeatedly ask for student feedback during class. Teachers can foster emotional support 
during this time of transition just by being genuinely concerned with how students are adapting to college life, as well as empathizing with students’ journey to find balance and responsibility in their adult life. Teachers should take opportunities to offer tips and advice for adjusting to college life, especially when meeting students individually. If students feel they have support from their teacher, the overall environment in the classroom improves and students will be more willing to seek help from the teacher in and out of the classroom.

Students in this study felt the ideal teaching characteristics would be classroom activities, cooperative learning, and clear explanations with many examples. Students interviewed mentioned the positive aspects of the group laboratory component in their current mathematics class, as well as classroom activities from past mathematics classes. Students appreciated activities relating to real-life, such as simulating a grocery store or games played in class to help with concepts. Most research on collaborative learning does not focus on the collegiate level. Yet, Stanley (2002) found students tended to enjoy mathematics and appreciate its usefulness when she implemented a problem based learning (PBL) approach in her undergraduate precalculus course. However, since the assessments in the course were still standardized, the achievement of the students was lower than the author's precalculus course that did not incorporate PBL. This highlights the importance of assessments that match the learning outcomes as a result of modified teaching teachniques. It is important to note that this precalculus course only had 30 students enrolled. Larger college courses present challenges in implementing PBL or any other collaborative activities. However, if the large classes can be split into smaller subsets one day per week, as is the case with the course in the study, I believe PBL could 
be paired with some traditional lecture to enhance student understanding. This gives each student in the class a chance to work with others and more access to the teacher during the smaller class size days. Additionally, when the entire class is together, instructors can give less involved questions and problems for students to complete in a short amount of time. Just allotting thirty seconds to a few minutes for shorter questions can make a difference. Techniques like “think-pair-share”, where students complete a problem then pair with another student to compare and discuss answers can infuse small pieces of collaborative learning in a large classroom and can also stimulate more questions by students (Felder, 1997). With regards to the importance of clarity, Cheeseboro (2003) found that instructor clarity played a part in influencing student attitudes toward the course. Clear instruction will most often increase understanding, which we have seen increases student positive attitudes.

\section{Teaching Characteristics vs. Instructional Techniques}

Some of the ideal teaching characteristics from this study, particularly classroom activities, collaborative learning, and useful examples seem to align more with the instructional technique category from previous studies. Townsend et al. (1998) found that the implementation of cooperative learning activities in a college mathematics classroom increased student self-concept in mathematics. As stated above, since many students do not know others prior to the course, appropriate cooperative learning activities will increase student interaction and help foster a cohesive classroom. In addition, when students work in groups, they have an opportunity to learn from each other. This can be extremely beneficial if a student is having trouble understanding the 
teacher or needs additional explanations. It is a way to gain multiple perspectives concerning the same topic or concept.

However, some cooperative learning activities are not as successful as others. This can be due to inappropriate tasks or incorrect student implementation. The primary goal should be that students work together and learn from each other. From personal experience, I have noticed some students like group work while others do not. Most of their schooling career has been centered on individual work and many students do not know how to properly work in groups. This often results in students simply splitting the work up in the group, working on individual parts separately, and then compiling the individual pieces together to form the whole assignment. It is important that group tasks challenge students and stimulate conversation among group members. I believe an appropriate example would be giving students a central application problem to solve that requires collaboration and thought. Instructors need to be available to the groups, especially in the initial stages of the activity, to guide them into conversations and collaboration.

In terms of the usefulness of mathematics, a study by Higgins (1997) proposes that using a problem solving teaching approach increased the perceived usefulness of mathematics among students, which also increased student attitudes toward mathematics. This approach also saw an increase in student perseverance when doing mathematics. Highlighting the usefulness of mathematics gives students an opportunity to make deeper connections with mathematics. If they cannot relate to a topic or word problem, then it becomes more difficult for them to understand the concept deeply. If we can change the context in which the topic is presented and taught, I believe students can not only relate 
to the usefulness of the mathematics, but they can relate to mathematics itself since a stronger connection will be made. For example, one of the students interviewed explained his like for geometry based on its usefulness. His teacher related concepts to carpeting a house or building a structure. This caused a deeper connection and, therefore, a deeper understanding of the mathematics. I believe this can also hold implications for the number of students entering into mathematical careers. As Betz and Hackett (1983) and O’Brien, Kopala, and Martinez-Pons (1999) found, a person’s self-efficacy toward mathematics has a strong correlation to their choice of mathematics courses and their participation in math-related activities. Specifically, a student who has negative selfefficacy is less likely to enroll in higher level mathematics courses and therefore is more likely to choose a profession that does not require a strong background in mathematics. Therefore, we need to address the notion of improving self-efficacy among college students in order to promote interest in mathematical careers among a wide range of students. If students can see the usefulness of mathematics and/or if a topic can strike an interest in them, more students may continue to pursue mathematics courses and careers. However, getting students to see the usefulness and applicability of mathematics may be a simple statement, but it is not an easy task. I do not believe it is enough to increase the amount of word problems presented by a textbook. To me, it is more about relating mathematics to everyday topics. A great place to start is money and finances. An example would be housing, school or car loans. This is a perfect scenario to highlight the importance of exponential functions. Also, it is not enough to just solve equations based in a real-world context, although it can be the jumping off point. There also needs to be interpretation and gray areas. Students should become accustomed with the idea that life 
is not black and white. They can be presented with a general problem that they research and work through. This will help them to connect to the topic and mathematical concepts more deeply. Of course, this leaves less time for lecture and less time to cover a wide array of topics. It is a focus on depth rather than breadth.

\section{Assessments and Achievement vs. Assessments and Achievement}

The assessments and achievement in a course were found to affect student attitudes toward mathematics in this study. Similarly, previous literature has suggested that the type of assessments and student achievement are two factors that affect student attitudes toward mathematics. Through the course of the interviews, student felt their attitude toward mathematics is influenced by the grades they earn in the class. Since all of the interviews were from the students' perspective, this suggests that grades affect attitude. Likewise, level of achievement was found to affect motivation and enjoyment in mathematics for students from seventh to twelfth grade in a study by Tapia and Marsh (2001). Lopez et al. (1997) focused on self-efficacy and found that prior performance in mathematics affects self-efficacy. In terms of assessments, the students interviewed found low-risk, fair, frequent assessments increased their ability to achieve in the course. I believe this is partly because less material is covered per assessment and since the stakes are not as high, students' level of anxiety is lower. However, as stated in chapter four, Sabini and Monterosso (2003) found that students felt strong effort should be rewarded on assessments. This makes me wonder if students prefer low-risk assessments because effort is more rewarded.

Most students have been academically measured by grades throughout their entire schooling career. Scores are often the reason a student passes or fails a class. Based off 
of these facts, it is no surprise that a student's attitude is closely linked with their grades on assessments in the class. I do believe it is important to be sure students understand material in order to pass a class. However, I think the strong emphasis on numeric grades may send the wrong message to students. Many tend to sacrifice taking time to understand for using any means to achieve passing scores within the allotted time frame. This often results in students just wanting to be told how to do something and not caring why they are doing it. As Sabini and Monterosso (2003) also point out, college students recognize the power and importance that college grades have on admissions into graduate schools and subsequent employment. In fact, the educational system has reinforced this idea throughout most students’ lives, as grades have been the primary requirement for passing a course. I believe this is one of the primary reasons that students are more concerned with scores on assessments rather than taking time to deeply understand the concepts. Furthermore, since mathematics tests tend to focus on algorithms and procedures, students learn that as long as they can reproduce the algorithms, they can pass the class. A study by Schoenfeld (1985) highlights the contradiction that students see between what mathematics instructors say is important (to deeply understand mathematics) and what techniques students find is most helpful in succeeding on assessments (memorization). Unfortunately, the result is often surface level understanding that does not have staying power. I believe this is why many concepts are re-taught with dismal results.

\section{Classroom Characteristics vs. Instructional Style and Behavior}

Certain classroom characteristics are believed to influence student attitudes toward the class. Many students felt small classes with a relaxed atmosphere were ideal 
conditions for learning. The importance of the classroom environment that the teacher creates is recognized in a study by Thompson and Thompson (1989). A teacher's overall presence in the classroom and acceptance of student ideas contributed to a supportive environment and influenced student attitudes in a positive way. There were no studies in chapter two that specifically dealt with class size and its effect on student attitudes. I believe this is mostly due to the lack of studies focusing on large lecture courses. Most studies that investigate`attitudes were conducted in smaller classrooms, so class size did not emerge as an issue. However, it is clear that class size affects many of the other external factors that influence student attitudes toward mathematics. Ideal teacher, teaching, and assessment characteristics are easier to obtain within a smaller classroom. Smaller classrooms allow the teacher to be more available and make it easier for the teacher to take extra time to help students on an individual basis. In addition, students felt this allows the teacher to know the students better so that the teacher would be more likely to teach at the pace of the students. It is also possible to give feedback on more low-risk assessments and to create an interactive environment. However, a smaller classroom alone will not improve student attitudes. It only makes these ideal conditions easier to obtain. Without teachers and an educational system determined to implement these ideal conditions, student attitudes will most likely not improve.

Ultimately, smaller classes would be ideal, but, in reality, this is often not possible. In this case, I believe using the idea of schools within a school can help make a large classroom seem small. Splitting these larger classes into smaller groups can give the feeling of a smaller classroom. In the college algebra class that I currently teach, the classes are split into groups of 80 to work on exploratory graphing laboratories for one 50 
minute class meeting per week. Among each group of 80, groups of 2 to 3 students work on labs together. The idea is to break the large class of 200 down so that each student can get to know a couple students in their class. It also promotes collaborative learning and gives students feedback on low-risk assessments since these labs are graded by hand. I believe this is a step in the right direction, but needs to be expanded upon and used more frequently.

\section{Differences}

While there are many similarities in previous research findings and the findings of this study, there are some differences. Some of the previous literature suggested a connection between beliefs and attitudes of teachers and student attitudes toward mathematics (Uusimaki \& Nason, 2004; Beswick, 2006). There is not a similar result in this study primarily because teachers were not interviewed. Of course, this does not mean that teacher beliefs do not affect student attitudes. As a teacher, I do believe my attitude toward and beliefs about mathematics affect the way that I teach and the environment I create in the classroom. For example, when I enjoy or feel confident about a specific topic, I usually feel I do a better job explaining that concept rather than one I enjoy less. I also feel it is easier for me to explain a topic when I have struggled to understand the topic myself. I think this is because I have worked through frustration and made a meaningful connection to the concept. Ultimately, this struggle enhances my teaching. However, since only students were interviewed and polled in this study, the teacher's point of view was not investigated. Hence, without speaking with teachers concerning their views, it would be difficult to determine if and how teacher beliefs affect 
student attitudes. I believe examining teacher attitudes and beliefs would be interesting for future research.

In addition, since the student perspective was the main concentration in this study, individual perceptions and characteristics was a large part of factors found to affect college student attitudes toward mathematics. Student background was a small portion of individual characteristics in this study and is covered in previous literature when considering the role parental attitudes and beliefs play in student attitudes. A number of students reflect on experiences with their parents and families when explaining what factors affect their attitude toward mathematics. Family influence can have a positive effect on student attitudes, like the student who remembers solving puzzles with her dad, or a negative effect, similar to the student who felt the pressure of her math teacher mother. This is yet another reminder of the background internal characteristics, beliefs, and attitudes that students have formed over their entire lives when they walk into a college mathematics classroom. Educators at the college level need to understand the preconceived ideas that each student possesses, but not be discouraged or overwhelmed by them. Of course, this becomes easier in a small classroom where each student can be treated as an individual. Understanding students' background and perspective helps educators to make a positive, meaningful impact on students' attitudes. This task is becomes increasingly difficult at the college level. Typically, instructors only see each student three to fours hours per week, especially at a large university. The combination of teacher and students is usually unique to each class, each semester. One way to get to know students in an introductory math course, even in a large lecture format, is to have students write a paragraph about themselves at the beginning of the semester. In a 
smaller classroom these paragraphs can serve as the first contact with the students and continue to be built upon throughout the semester. In a large classroom, it gives an initial idea of the diversity of students and also makes students feel connected to the teacher and the class. If the larger classrooms are split into smaller groups certain times during the semester, the relationship between each student and teacher can grow. Students have more access to the teacher on an individual basis and teachers can work to understand each student's perspective. These suggestions only begin this difficult process that should be viewed as a challenge and opportunity, rather than an obstacle.

\section{External and Internal Factors}

The primary relationship between the factors found to affect college students' attitudes toward mathematics in this study was the influence that external factors have on individual internal factors. While there are not many studies that focus on these internal factors, possibly because of the difficulty in investigating these complex ideas, some studies have alluded to the importance of external factors and the effect they can have on individual, internal factors like motivation and frustration. Harkness et al. (2006) found that students believed that their instructor's support and patience was one of the many factors that motivated them to work through the struggle of problem solving in their mathematics class. Schweinle et al. (2006) conducted a study of the relationship between motivation and affect. Overall, they found that teacher support and finding the right balance between challenge and skill for students can aid in increased motivation and student affect.

I believe balancing challenge and frustration will increase true understanding, achievement, and student motivation. Many of these factors are so closely related that a 
decrease in one factor, such as motivation, can create a domino effect where many other factors are also affected. I think educators should focus on modifying the external factors over which we have control. This will lead to a change in internal factors. For example, being supportive, patient, interactive, and respectful of students can affect the teaching style, and the classroom environment. This can lead to students asking more questions and gaining a better understanding and motivation in the class. Overall, this will improve student attitudes. It is important to remember that in real life everything is connected. If we could just change one factor and student attitudes would improve, this would not be a challenging topic. Changing student attitudes will come from a myriad of techniques and ideas. It will be different for each student since each has unique internal factors and past experiences that have influenced and molded their attitude throughout their lives.

\section{Implications and Suggestions}

The five factors found to influence college students' attitudes toward mathematics create implications for schools at every level. I found through these interviews that most students really do want to understand mathematics. A lack of understanding seems to promote the decline of student attitudes toward mathematics. However, there can be differences in student definitions of understanding and teacher definitions of understanding. How do students gauge their level of understanding? Do they think understanding means being able to manipulate and apply algorithms or are they genuinely concerned with understanding the deeper concepts and connections? These clarification questions were not asked in the interviews, although upon reflecting on the interviews, I suspect the definition is different for different students. There were a few students whose definitions of understanding were similar to mine. But I am sure there were some who 
were not on the same page as I. I believe true understanding needs to be emphasized more in every grade, rather than memorization and procedures. It is more important for students to truly understand and make connections among concepts in mathematics, even if this means covering fewer topics per school year. Students need depth more than breadth. The reality is many topics get covered so quickly and poorly that students often are forced to relearn material over and over again. If each topic were concentrated on and taught for understanding the first time, I believe we would have less students needing repeated remediation and would have more positive attitudes toward mathematics. As I said earlier, one way to accomplish this is to limit the number of concepts covered per year, as well as overhauling the methods used to teach the concepts. Also, some standardized tests now in the $\mathrm{K}-12$ school system have been undergoing changes. These changes need to continue to occur and focus on testing for understanding rather than purely skill. This is not to say that skills should not be covered. However, in my opinion, skills can serve as the foundation for higher level thinking, deeper understanding and stronger connections.

In order to ensure students are able to obtain a deeper understanding and increased motivation, a proper balance between challenge and frustration needs to be available to all students. This cannot occur without appropriate placing and pacing. Great care in all grades and levels needs to occur to properly place students according to their ability level. Students need to be evaluated and constantly re-evaluated in order to ensure they are not falling too far behind or becoming bored by being too far ahead. Tests can help with this, but should mostly come from instructors knowing their students and their abilities. I believe it is also important to listen to students and their evaluation 
of their own abilities. However, caution should be used when placing students, especially at a young age. As seen in the interviews, placement can lead to students labeling themselves as proficient or deficient in mathematics for the rest of their schooling career. This internal labeling can affect self-efficacy, student motivation, and student attitudes for life. This is one of the primary reasons that students should be constantly challenged and re-evaluated in every math class. Many universities use standardized test scores, high school mathematics classes and grades, and placement tests given by the university in order to place students into mathematics classes. If standardized tests need to be used, I feel it is important to require each student to take the placement test to measure their current mathematics knowledge. Using past standardized test scores and grades does not always indicate the level of current understanding and comprehension. Many students entering college have not had mathematics classes for one year or more. These placement exams should be re-evaluated as courses are changed and modified. Instructors of the college courses should also be consulted on the development of the placement tests. Placement tests should not be the sole measure of placement. Individual discussions with the student, possibly reviewing their placement exam would shed more light on the preparedness and level of understanding of each student and could be an even better indicator of appropriate placement. Once placement is addressed, appropriate pacing becomes an easier task. However, teachers still need to focus on depth rather than breadth, which will ensure classes move at a slower pace and focus on understanding. This also requires teachers evaluating students for understanding so the pace can be slowed when understanding is occurring more slowly and sped up when the topics are understood more readily. Evaluation is not always about summative assessments. 
Teachers should constantly assess in their classroom. I find it very helpful to survey student facial expressions and body language. Often, I can get a sense if students are lost just by being aware of students’ nonverbal reactions. Once I catch this, I tend to increase my questions. I find it is always helpful to engage students not just by asking questions, but also by having them try problems in class, usually working with one or two other students near them. Often, this will raise additional questions from students and highlight areas of confusion. Asking multiple and various open-ended questions when teaching is another way to gauge student understanding. I tend to ask 'why' a lot. It is important that students know how to do something, but if they don't know why or for what purpose, I am not convinced that they have actually learned anything. Through this type of evaluation, teachers can modify their instructional approaches when they notice students are having difficulty.

This leads us to the importance of teacher devotion. Students that were interviewed want teachers who are invested in their learning and truly care if their students understand the material. An increase of devoted teachers whose primary purpose and reason for being in the education field is to teach students will definitely increase student understanding and attitudes. I believe there are educators, particularly in higher education, who view teaching merely as a requirement of their job and are often more interested in conducting research. This is usually sensed by students and can affect students' attitudes. Institutions should address these matters when they arise. It is important that teachers in a college classroom are positive and really care about their students. It is also crucial that educators can actually teach at the students' level and are willing to take the time to explain concepts to those who are less inclined to understand 
immediately. There is a difference between a brilliant mathematician and a brilliant mathematics educator. They can exist in the same person, but this joint existence is not guaranteed. This also needs to be recognized by institutions and professors should be evaluated on both skill sets. Too often, it seems college professors are regularly evaluated on the research they produce, but not as often on teaching. Teaching is, in my opinion, sometimes considered a taken for granted skill, rather than a talent that should be honed throughout life. One way to evaluate a professor's teaching for undergraduate college mathematics course is to critically review student evaluations. However, as we have seen from this study, opinions and attitudes can be influenced by many factors. Hence, it is important that this is not the only method for evaluation. Informal conversations with past and present students can also help to evaluate teaching. Scheduled and unscheduled visits to classrooms should also occur to not only evaluate teaching but also to create conversations and collaborations among colleagues. Extra efforts by everyone in the department will emphasize the importance of teaching in higher education. Increased professional development sessions for professors would also increase conversations and could improve pedagogical practices. Similarly, students will speak of their high school or middle school teachers who were aging and seemed to not care if students liked mathematics. There needs to be a way to monitor 'burn-out' in the teaching profession and it should be dealt with accordingly. Devoted teachers will take the time to teach for understanding and will get to know each student's ability.

Most of the implications and suggestions become attainable with smaller classes. Students overwhelmingly preferred smaller classes, as long as they are given more attention and, therefore, are able to understand mathematics more readily. It also 
prevents an overwhelming environment and reduces the occurrence of standardized testing. Everyone is treated more like an individual rather than a very small part of a large whole. Once again, smaller classes do not guarantee increased individual attention; it merely becomes easier to do if teachers and the educational system believe this is important and are willing to follow through. In my opinion, all mathematics classes should be smaller, especially classes with students who need the most help. In higher education, these are typically entry level mathematics courses. I do recognize that financially, smaller classes are not always possible. In these cases, I believe more effort needs to be made to make a large classroom seem small. This can be accomplished by breaking the large class into smaller subsections. Graduate assistants or teacher's aides can assist in providing personal attention to all students.

Finally, with declining student attitudes and the students' desire for mathematics to be applicable to their lives and careers, I am concerned about the implications this study holds for the future of entry level mathematics courses. The institution where the study was held already offers a calculus course for business majors and a calculus course for engineering majors in an attempt to make math more useful for students of particular majors. If other departments and students continue to fail to see the usefulness of a basic algebra course, individual departments may begin to offer their own math courses tailored for students in their department. If mathematics departments want to keep introductory mathematics courses, I believe applications in entry level math courses need to be covered more often and attempt to reach more students' interests, future careers, and daily lives. This does raise the question: where is the best place for introductory mathematics courses? After this study, it may seem that students would connect more to 
mathematics classes that relate directly to their major. However, I believe that it is important for students to not only see the applicability of mathematics in their future careers, but also in other areas and life. I think it would be too extreme to separate all the mathematics classes into various majors and disciplines. This could result in students becoming more convinced that mathematics is not a part of daily life. In addition, students changing majors present logistical complications.

\section{Future Research}

There are various topics that have emerged as a result of this study that I would love to study in more detail. First, since this study focused only on the students' perspective concerning factors that affect college students, the relationships we found among the factors were largely unidirectional. That is, we see external factors affecting internal student perceptions and attitudes. This does not mean that internal student perceptions and attitudes do not affect external factors. Hence, I would like to interview college algebra instructors in order to investigate what they feel affects their attitude toward mathematics as well as their students' attitudes toward mathematics. I may find that student attitudes influence teacher beliefs and attitudes toward particular classes. This would give a more complete picture of the topic and possibly highlight varying relationships among the data. It may also bring to light new factors and relationships that may affect student attitudes. Comparing student and teacher perspectives would emphasize the similarities and differences in the two perspectives.

I found a result from the quantitative study particularly interesting. The influence the teacher seems to have on student attitudes experienced a large decline from the high 
school era to the time after high school. I would like to investigate this idea further. I would like to speak with students in detail concerning the role they felt or feel their teacher plays in affecting their attitude throughout their schooling career. If the role of the teacher is not as large in higher education, I would like to discuss why this occurs and what factors replace teacher influence. I believe this may give me more insight to the relationship among teachers and students in higher education.

I have also become interested in many of the internal student perceptions affecting student attitudes that emerged from the interviews. Particularly, I find the idea of challenge and frustration a fascinating concept. Even though it is very complex issue, I think finding an appropriate balance between challenge and frustration may be one of the primary solutions for increasing student motivation, a sense of accomplishment, selfefficacy, and, of course, student attitudes toward mathematics.

Lastly, one of the primary limitations of this study was the retrospective nature of the survey and some interview questions. Asking students to report their attitudes concerning mathematics from memory alone does not give the most precise data. In order to gain a better, more accurate understanding of student attitudes throughout their entire lives, I would be highly interested in conducting a long term longitudinal study that follows a group of students from elementary through the beginning of college. Of course, this would be complicated and take a lot time, but I think the depth of understanding that we could obtain would be well worth the time. I could also conduct a multi-cohort longitudinal study where I would interview equivalent groups of students from each grade level in one school year to compare student attitudes toward mathematics in 
various grades. Overall, I truly believe that student attitudes are strongly linked with student achievement and merit extensive time and research.

\section{Summary}

This chapter began with a comparison of the results of this study and the results of previous literature concerning factors that affect student attitudes. Following this was a discussion of the implications of these results in the $\mathrm{K}-12$ schooling system, the higher education system, and for teaching practices. Finally, future research ideas are suggested.

A summary of the study includes revisiting the research questions:

1. What factors affect college algebra students' attitudes toward mathematics?

Five factors were found that affect college student's attitudes toward mathematics: the teacher, the teaching, the classroom, the assessments and achievement, and the individual perceptions. The first four factors comprise the external factors that can influence the internal, individual perceptions and attitude. Understanding the relationships between these factors can help us make the necessary adjustments to improve student attitudes and success.

2. Retrospectively, what were current college students' attitudes toward mathematics in primary and secondary school?

3. Currently, what are college algebra students' attitudes toward mathematics?

The quantitative surveys and subsequent grouping of students into significant grade bands and attitude trends highlights an overall idea of student attitudes over time. 
Nearly every student experienced a decrease in their attitude toward math sometime during their schooling career. However, since many students also experienced an increase in their attitude, it seems as though it is possible to influence and improve student attitudes at all levels. From interviews, a decline usually occurred in the $6-8$ or 9 - 12 grade band, although the most significant experiences occurred at the beginning or end of one's schooling career.

4. What are college algebra students' perspectives concerning how to reverse or prevent poor attitudes toward mathematics at the college level?

Most students suggested external factors in a mathematics classroom that can work to reverse or prevent poor attitudes toward mathematics, especially at the college level. The conditions discussed concerning an ideal mathematics classroom, ideal teacher characteristics, ideal teaching techniques, and ideal assessments would all contribute to an increase in positive college student attitudes. I believe considering these ideal characteristics would increase student understanding, student success on assessments and improve student attitudes toward mathematics.

Ultimately, this study found that college student attitudes toward mathematics are affected by a mixture of external characteristics like teachers, teaching style, classroom environments, and assessments, as well as internal characteristics like student background, level of understanding, challenge, and motivation. Many external factors can affect the internal, individual factors that ultimately influence a person's attitude. It is important that we consider the student's point of view so that we can alter these external factors to improve student attitudes. 


\section{R E F E R E N C E S}

Adams, T. (1997). Technology makes a difference in community college mathematics teaching. Community College Journal of Research \& Practice, 21(5), 481.

Adams, V.M. (1989). Affective issues in teaching problem solving: a teacher's perspective. In McLeod, D. \& Adams, V. (eds.) Affect and Mathematical Problem Solving, 193-201.

Alkhateeb, H., \& Hammoudi, L. (2006). Attitudes toward and approaches to learning first-year university mathematics. Perceptual \& Motor Skills, 103(1), 115-120.

Anderson, J. (2005). The relationship between student perceptions of team dynamics and simulation game outcomes: an individual-level analysis. Journal of Education for Business, Nov/Dec, 85-90.

Banks, H.F. (n.d.). World of quotes. Retrieved July 6, 2006 from http://www.worldofquotes.com/author/Harry-F.-Banks/1/index.html

Barclay, C. R. (1993). Remembering ourselves. In G. M. Davies and R. H. Logie (Eds.), Memory in Everyday Life: Advances in Psychology, 100, 289-309, Amsterdam: North Holland.

Berenson, S., Dawkins, K., Blanton, M., Coulombe, W., Kolb, J., Norwood, K., et al. (1999). Proceedings of the Annual Meeting of the North American Chapter of the International Group for the Psychology of Mathematics Education (20th, Raleigh, NC, October 31-November 3, 1998). Volume 2.

Berry, L. (2003). Bridging the gap: a community college and area high schools collaborate to improve student success in college. Community College Journal of Research \& Practice, 27(5), 393. 
Beswick, K. (2006). Changes in pre-service teachers' attitudes and beliefs: the net impact of two mathematics education units and intervening experiences. School Science and Mathematics, 106(1), 36-47.

Beswick, K. (2007). Teachers' beliefs that matter in secondary mathematics classrooms. Educational Studies in Mathematics, 65(1), 95.

Betz, N.E., \& Hackett, G. (1983). The relationship of mathematics self-efficacy expectations to the selection of science-based college majors. Journal of Vocational Behavior, 23, 329-345.

Birenbaum, M. \& Nasser, F. (2006). Ethnic and gender differences in mathematics achievement and in dispositions toward the study of mathematics. Learning and Instruction, 16(1), 26.

Brady, P., \& Bowd, A. (2005). Mathematics anxiety, prior experience and confidence to teach mathematics among pre-service education students. Teachers and Teaching: Theory and Practice, 11(1), 37-46.

Bressoud, D. (2001). What's been happening to undergraduate mathematics. Journal of Chemical Education, 78(5), 578.

Brewer, W. F. (1988). Memory for randomly sampled autobiographical events. In U. Niesser and E. Winograd (Eds.), Remembering Reconsidered. Cambridge: Cambridge University Press.

Bookman, J., \& Friedman, C. (1998). Student attitudes and calculus reform. School Science \& Mathematics, 98(3), 117. 
Cain-Caston, M. (1993). Parent and student attitudes toward mathematics as they relate to third grade mathematics achievement. Journal of Instructional Psychology, 20(2), 96-101.

Carlson, M. (1997). Obstacles for college algebra students in understanding functions: what do high-performing students really know?. AMATYC Review, 19(1), 48.

Carroll, C. (2004). ACT scores show a slight increase. Education Week, 24(1), 16-16.

Casa, T., McGivney-Burelle, J., \& DeFranco, T. (2007). The development of an instrument to measure preservice teachers' attitudes about discourse in the mathematics classroom. School Science \& Mathematics, 107(2), 70-80.

Chappell, K., \& Hardy, D. (1999). College algebra reform: documenting student attitudes and performance. Part of collected works, Rocky Mountain Teacher Education Collaborative, Colorado State University, 15-30.

Cheseboro, J. (2003). Effects of teacher clarity and nonverbal immediacy on student learning, receiver apprehension, and affect. Communication Education, 52(2), $135-147$.

Cipra, B. (1996). Calculus reform sparks a backlash. Science, 271(5251), 901.

Cipra, B. (1993). At state schools, calculus reform goes mainstream. Science, 260(5107), 484.

Cipra, B. (1988). Calculus: crisis looms in mathematics' future. Science, 239(4847), 1491.

Conway, M. A. (1990). On bias in autobiographical recall: retrospective adjustments following disconfirmed expectations. The Journal of Social Psychology, 130, 183-189. 
D’Andrade, R. G. (1981). The cultural part of cognition. Cognitive Science, 5, 179-195.

DeBellis, V., \& Goldin, G. (2006). Affect and meta-affect in mathematical problem solving: a representational perspective. Educational Studies in Mathematics, 63(2), 131-147.

Eccles, J.S. \& Wigfield, A. (2002). Motivational beliefs, values, and goals. Annual Review of Psychology, 53, 109-132.

Edwards, A. \& Ruthven, K. (2003). Young people’s perceptions of the mathematics involved in everyday activities. Educational Research, 45(3), 249-260.

Elliott, B., Oty, K., McArthur, J., \& Clark, B. (2001, November). The effect of an interdisciplinary algebra/science course on students' problem solving skills, critical thinking skills and attitudes toward mathematics. International Journal of Mathematical Education in Science \& Technology, 32(6), 811-816.

Felder, R. (1997, June). Beating the numbers game: effective teaching in large classes. Retrieved March 11, 2008, from http://www4.ncsu.edu/unity/lockers/users/f/felder/public/Papers/Largeclasses.htm

Fox, W. P. \& West, R.D. (2001). College algebra: drills or applications? PRIMUS, 11(1), 89-96.

Gasiorowski, J.H. (1998). The relationship between student characteristics and mathematics achievement, Doctoral Dissertation, Morgantown, WV.

Glaser, B. \& Strauss, A. (1967). The discovery of grounded theory: strategies for qualitative research. Chicago: Aldine. 
Grouws, D. \& Cramer, K. (1989). Teaching practices and student affect in problemsolving lessons of select junior-high mathematics teachers. In McLeod, D. \& Adams, V. (eds.) Affect and Mathematical Problem Solving, 149-161.

Hallam, S. \& Deathe, K. (2002). Ability grouping: year group differences in selfconcept and attitudes of secondary school pupils. Westminster Studies in Education, 25(1), 7-17.

Hannula, M. (2002). Attitude toward mathematics: emotions, expectations, and values. Educational Studies in Mathematics, 49, 25-46.

Hannula, M. (2006). Motivation in mathematics: goals reflected in emotions. Educational Studies in Mathematics, 63(2), 165-178.

Harkness, S., D'ambrosio, B., \& Morrone, A. (2007). Preservice elementary teachers' voices describe how their teacher motivated them to do mathematics. Educational Studies in Mathematics, 65(2), 235.

Harper, N.W., \& Daane, C.J. (1998). Causes and reduction of math anxiety in preservice elementary teachers. Actions in Teacher Education, 19(4), 29-38.

Harry, B., Sturges, K.M., \& Klingner, J.K. (2005). Mapping the process: an exemplar of process and challenge in grounded theory analysis. Educational Researcher, 34(2), $3-13$.

Hart, L. (1989). Describing the affective domain: saying what we mean. In McLeod, D. \& Adams, V. (eds.) Affect and Mathematical Problem Solving, 37-45.

Herman, M. (2007). What students choose to do and have to say about use of multiple representations in college algebra. Journal of Computers in Mathematics and Science Teaching, 26(1), 27. 
Higbee, J.L., \& Thomas, P.V. (1999). Affective and cognitive factors related to mathematics achievement. Journal of Developmental Education, 23(1), 1-15.

Higgins, K. (1997). The effect of year-long instruction in mathematical problem solving on middle-school students' attitudes, beliefs, and abilities. Journal of Experimental Education, 66(1), 5-29.

Hobson-Panico, S., Hoard, B., \& Romero, C. (1999). Math and science education reform: a community college perspective. Part of collected works, Rocky Mountain Teacher Education Collaborative, Colorado State University, 43-52.

House, J. (1995). The predictive relationship between academic self-concept, achievement expectancies, and grade performance in college calculus. Journal of Social Psychology, 135(1), 111-112.

House, J. (1993). Achievement-related expectancies, academic self-concept, and mathematics performance of academically underprepared adolescent students. The Journal of Genetic Psychology, 154, 61-71.

Hurley, J., \& Koehn, U. (1999). Effects of calculus reform: local and national. American Mathematical Monthly, 106(9), 800.

Kinney, D. (2001). A comparison of computer-mediated and lecture classes in developmental mathematics. Research and Teaching in Developmental Mathematics, 18(1), 32-40.

Koller, O., Baumert, J., \& Schnabel, K. (2001). Does interest matter? The relationship between academic interest and achievement in mathematics. Journal for Research in Mathematics Education, 32(5), 448-470. 
Liljedahl, P. (2005). Mathematical discovery and affect: the effect of AHA! Experiences on undergraduate mathematics students. International Journal of Mathematical Education in Science and Technology, 36(2-3), 219-234.

Lopez, F., Lent, R., Brown, S., \& Gore, P. (1997). Role of socio-cognitive expectations in high school students' mathematics-related interest and performance. Journal of Counseling Psychology, 44(1), 44-52.

Malmivouri, M. (2006). Affect and self-regulation. Educational Studies in Mathematics, 63, 149-164.

Marsh, H.W. (1986). Verbal and math self-concepts: an internal/external frame of reference model. American Educational Research Journal, 23, 129-149.

McLeod, D. (1988). Affective issues in mathematical problem solving: some theoretical considerations. Journal for Research in Mathematics Education, 19(2), 134-141.

McLeod, D. (1994). Research on affect and mathematics learning in the JRME: 1970 to the present. Journal for Research in Mathematics Education, 25(6), 637-647.

McLeod, D. (1992). Research on affect in mathematics education: a reconceptualization. Handbook of Research on Mathematics Teaching and Learning, 575-596.

Merriam, S. \& Associates (2002). Qualitative Research in Practice

Midgley, C., Feldlauder, H., \& Eccles, J. (1989). Student/teacher relations and attitudes toward mathematics before and after the transition to junior high school. Child Development, 60, 981-992.

Mitchell, T. (1999). Changing student attitudes toward mathematics. Primary Educator, 5(4), 2-9. 
Muzzatti, B., \& Agnoli, F. (2007). Gender and mathematics: attitudes and stereotype threat susceptibility in Italian children. Developmental Psychology, 43(3), 747759.

Narasimhan, C.C. (1993). Calculus reform for the non-science client disciplines. PRIMUS, 3(3), 254-262.

National Council of Teachers of Mathematics. (2000). Principles and standards for school mathematics. Reston, VA: Author.

National Council of Teachers of Mathematics. (1989). Professional standards for teaching mathematics. Reston, VA: Author.

O’Brien, V., Kopala, M., \& Martinez-Pons, M. (1999). Mathematics self-efficacy, ethnic identity, gender, and career interests related to mathematics and science. The Journal of Educational Research, 92(4), 231-235.

Orhun, N. (2007). An investigation into the mathematics achievement and attitude toward mathematics with respect to learning style according to gender. International Journal of Mathematical Education in Science \& Technology, 38(3), 321-333.

Papanastasiou, C. (2002). Effects of background and school factors on the mathematics achievement. Educational Research and Evaluation, 8(1), 55-70.

Parker, M. (2005). Placement, retention, and success: a longitudinal study of mathematics and retention. JGE: The Journal of General Education, 54(1), 22-40.

Patton M. Q. (2002). Qualitative Research \& Evaluation Methods, $3^{\text {rd }}$ Edition, Sage Publications. 
Pearce, K., Lungren, M., \& Wince, A. (1999). The effects of curriculum practices on first graders’ attitudes, activity preference, and achievements in mathematics. Education, 119(1), 82-90.

Pernot-Marion, E., Danion, J., \& Hedelin, G. (2004). Relations between emotion and conscious recollection of true and false autobiographical memories: an investigation using lorazepam as a pharmacological tool. Psychopharmacology, $175,60-67$.

Peterson, I. (1987, November 14). Calculus reform: catching the wave?. Science News, 132(20), 317-317.

Popham, W. (2005). Students’ attitudes count. Educational Leadership, Feb., 84-85.

Raymond, A., \& Leinenbach, M. (2000). Collaborative action research on the learning and teaching of algebra: a story of one mathematics teacher's development. Educational Studies in Mathematics, 41(3), 283-307.

Reyes, L.H. (1984). Affective variables and math education. The Elementary School Journal, 84(5), 558-581.

Roddick, C. (2001). Differences in learning outcomes: calculus and mathematica vs. traditional calculus. Primus, 11(1), 161.

Royster, D., Harris, M., \& Schoeps, N. (1999). Dispositions of college mathematics students. International Journal of Mathematical Education in Science and Technology, 30(3), 317-333.

Sabini, J. \& Monterosso, J. (2003). Moralization of college grading: performance, effort and moral worth. Basic and Applied Social Psychology, 25(3), 189-203. 
Schoenfeld, A. (1985). Students' beliefs about mathematics and their effects on mathematical performance: a questionnaire analysis. Paper presented at the Annual Meeting of the American Educational Research Association, 1-39.

Schweinle, A., Meyer, D., \& Turner, J. (2006). Striking the right balance: students' motivation and affect in elementary mathematics. Journal of Educational Research, 99(5), 271-293.

Shernoff, D.J., Csikszentmihalyi, M., Schneider, B., \& Shernoff, E.S. (2003). Student engagement in high school classrooms from the perspective of flow theory. School Psychology Quarterly, 18(2), 158-176.

Signer, B. \& Saldana, D. (2001). Educational and career aspirations of high school students and race, gender, class differences. Race, Gender \& Class, 8(1), 22.

Smith III, J., \& Star, J. (2007). Expanding the notion of imp act of K—12 standardsbased mathematics and reform calculus programs. Journal for Research in Mathematics Education, 38(1), 3-34.

Stage, F. K. (2000). Making a difference in the classroom. About Campus, July/August, $29-31$.

Stanley, S. (2002). Revitalizing precalculus with problem-based learning. The Journal of General Education, 51(4), 306-315.

Swan, M., Bell, A., Phillips, R., \& Shannon, A. (2000). The purpose of mathematical activities and pupils' perceptions of them. Research in Education, 63, 11-20.

Tapia, M. \& Marsh, G. E. (2001). Effect of gender, achievement in mathematics, and grade level on attitudes toward mathematics. Paper presented at the Annual 
Meeting of the Mid-South Educational Research Association. Science, Mathematics, and Environmental Education, 1-20.

Thomas, D.L., \& Diener, E. (1990). Memory accuracy in the recall of emotions. Journal of Personality and Social Psychology, 59(2), 291-297.

Thompson, A.G., \& Thompson, P.W. (1989). Affect and problem solving in an elementary school mathematics classroom. In McLeod, D. \& Adams, V. (eds.) Affect and Mathematical Problem Solving, 162-176.

Townsend, M., Moore, D., Tuck, B., \& Wilton, K. (1998). Self-concept and anxiety in university students studying social science statistics within a cooperative learning structure. Educational Psychology, 18(1), 1-14.

Tsao, Y. (2004) A comparison of American and Taiwanese students: their math perception. Journal of Instructional Psychology, 31(3), 206-213.

Uusimaki, L. \& Nason, R. (2004). Causes underlying pre-service teachers’ negative beliefs and anxieties about mathematics. Proceedings of the $28^{\text {th }}$ Conference of the International Group for the Psychology of Mathematics Education, 4, 369376.

Wanzer, M. \& McCroskey, J. (1998). Teacher socio-communicative style as a correlate of student affect toward teacher and course material. Communication Education, 47, 43-52.

Whitin, P. (2007). The mathematics survey: a tool for assessing attitudes and dispositions. Teaching Children Mathematics, 13(8), 426-432.

Wilkins, J. \& Ma, X. (2003). Modeling changes in student attitude toward and beliefs about mathematics. The Journal of Educational Research, 97(1), 52-63. 
Wilkins, J. \& Brand, B. (2004). Change in preservice teachers' beliefs: an evaluation of a mathematics methods course. School Science and Mathematics, 104(5), 226232.

Williams, T., Williams, K., Kastberg, D., \& Jocelyn, L. (2005). Achievement and affect in OECD nations. Oxford Review of Education, 31(4), 517-545.

Wilson, R. (2000). The remaking of math. Chronicle of Higher Education, 46(18), 1-6.

Yarborough, H. (1999). Algebra with a Discovery Approach.

Yerushalmy, M., \& Schwartz, J. (1999). A procedural approach to explorations in calculus. International Journal of Mathematical Education in Science \& Technology, 30(6), 903-914.

Yusof, Y.M., \& Tall, D. (1999). Changing attitudes to University mathematics through problem solving. Educational Studies in Mathematics, 37, 67-82.

Zan, R., Brown, L., Evans, J., \& Hannula, M. (2006). Affect in mathematics education: an introduction. Educational Studies in Mathematics, 63, 113-121. 


\section{A P P E N D I X 1: Q U A N T I T A T I V E S UR V E Y}

Please respond to each question as honestly as you can recall while you were a student in each of the grade bands below. If you attended more than one school, please answer according to the most memorable experience: If you had a strong experience in one of the grades in a grade band, please focus on that grade when answering the questions. Use the scale below to circle the appropriate answer for every the question for each grade band:

For the first set of questions, I would like you to think about your experiences and feelings with mathematics and mathematics classes from Kindergarten through Second Grade. Do you remember a strong experience in any of these three grades?

$$
\text { Yes } \quad \text { No }
$$

If Yes, which grade?

$$
\text { Kindergarten } \quad \text { First Second }
$$

Answer as honestly as you can recall.

1. In general, how would you classify your attitude toward mathematics?
Poor
Fair
Average
Good
Very Good

2. In general, how would you classify your achievement level?
Poor
Fair
Average
Good
Very Good

3. In general, how would you classify your mathematics teacher's overall personality?
Poor
Fair
Average
Good
Very Good

4. In general, how would you classify your mathematics teacher's overall teaching style?
Poor
Fair
Average
Good
Very Good

5. In general, I enjoy/enjoyed solving/doing mathematics problems.

Strongly Disagree Disagree Neutral Agree Strongly Agree


For the second set of questions, I would like you to think about your experiences and feelings with mathematics and mathematics classes from $\underline{\text { Third Grade through Fifth }}$ Grade.

Do you remember a strong experience in any of these three grades?

Yes No
If Yes, which grade?

Third Fourth Fifth

Answer as honestly as you can recall.

1. In general, how would you classify your attitude toward mathematics?

Poor Fair Average Good Very Good

2. In general, how would you classify your achievement level?

$\begin{array}{llll}\text { Poor } & \text { Fair } & \text { Average } & \text { Good }\end{array}$

3. In general, how would you classify your mathematics teacher's overall personality?

Poor Fair $\quad$ Average Good $\quad$ Very Good

4. In general, how would you classify your mathematics teacher's overall teaching style?

$\begin{array}{llll}\text { Poor } & \text { Fair } & \text { Average } & \text { Good }\end{array}$

5. In general, how would you classify your mathematics teacher's overall level of patience and support of students?

$\begin{array}{llll}\text { Poor } & \text { Fair } & \text { Average } & \text { Good }\end{array}$

6. In general, how would you classify your mathematics teacher's overall clarity when teaching?

Poor Fair Average Good Very Good

7. In general, how would you classify your mathematics teacher's overall relationship with the students? 
Poor Fair $\quad$ Average Good Very Good

8. In general, how would you classify your parents’ or guardians' attitude toward mathematics?
Poor
Fair
Average
Good
Very Good

9. In general, how would you classify your attitude toward the assessments in these math classes?
Poor
Fair
Average
Good
Very Good

10. In general, I do not enjoy/enjoyed solving/doing mathematics problems.

Strongly Disagree Disagree Neutral Agree Strongly Agree

11. In general, I am/have been curious about topics in my mathematics classes.

Strongly Disagree Disagree Neutral Agree Strongly Agree

12. In general, I am usually bored in math class.

Strongly Disagree Disagree Neutral Agree Strongly Agree

13. In general, I not feel motivated to try to learn and understand more about mathematics.

Strongly Disagree Disagree Neutral Agree Strongly Agree

14. In general, I have felt/feel competent in my ability to learn and understand mathematics.

Strongly Disagree Disagree Neutral Agree Strongly Agree

15. In general, I have felt/feel tense and/or anxious when attempting to solve a mathematics problem or when taking a mathematics test.

Strongly Disagree Disagree Neutral Agree Strongly Agree

16. Which of the following do you think most influenced your attitude toward Mathematics during this time?

Content(Type of math class)

Teacher 
Tests

Classroom Environment

Other (please specify)

For the third set of questions, I would like you to think about your experiences and feelings with mathematics and mathematics classes from Sixth Grade through Eighth Grade.

Do you remember a strong experience in any of these three grades?

Yes No

If Yes, which grade?

Sixth Seventh Eighth

Answer as honestly as you can recall.

1. In general, how would you classify your attitude toward mathematics?

Poor Fair Average Good Gery Good

2. In general, how would you classify your achievement level?

Poor Fair $\quad$ Average Good Very Good

3. In general, how would you classify your mathematics teacher's overall personality?

Poor Fair Average Good Gery Good

4. In general, how would you classify your mathematics teacher's overall teaching style?

$\begin{array}{llll}\text { Poor } & \text { Fair } & \text { Average } & \text { Good }\end{array}$

5. In general, how would you classify your mathematics teacher's overall level of patience and support of students?

Poor Fair Average Good Very Good

6. In general, how would you classify your mathematics teacher's overall clarity when teaching?

Poor Fair Average Good Very Good 
7. In general, how would you classify your mathematics teacher's overall relationship with the students?
Poor
Fair
Average
Good
Very Good

8. In general, how would you classify your parents' or guardians' attitude toward mathematics?
Poor
Fair
Average
Good
Very Good

9. In general, how would you classify your attitude toward the assessments in these math classes?
Poor
Fair
Average
Good
Very Good

10. In general, I do not enjoy/enjoyed solving/doing mathematics problems. Strongly Disagree Disagree Neutral Agree Strongly Agree

11. In general, I am/have been curious about topics in my mathematics classes.
Strongly Disagree
Disagree
Neutral
Agree
Strongly Agree

12. In general, I am usually bored in math class.

Strongly Disagree Disagree Neutral Agree Strongly Agree

13. In general, I not feel motivated to try to learn and understand more about mathematics.

Strongly Disagree Disagree Neutral Agree $\quad$ Strongly Agree

14. In general, I have felt/feel competent in my ability to learn and understand mathematics.

Strongly Disagree Disagree Neutral Agree Strongly Agree

15. In general, I have felt/feel tense and/or anxious when attempting to solve a mathematics problem or when taking a mathematics test.

Strongly Disagree Disagree Neutral Agree Strongly Agree

16. Which of the following do you think most influenced your attitude toward Mathematics during this time? 
Content(Type of math class)

Teacher

Tests

Classroom Environment

Other (please specify)

For the fourth set of questions, I would like you to think about your experiences and feelings with mathematics and mathematics classes from Ninth Grade through Twelfth Grade.

Do you remember a strong experience in any of these three grades?

$$
\text { Yes No }
$$

If Yes, which grade?

Ninth Tenth Eleventh Twelfth

Answer as honestly as you can recall.

1. In general, how would you classify your attitude toward mathematics?
Poor
Fair
Average
Good
Very Good

2. In general, how would you classify your achievement level?

Poor Fair Average Good Very Good

3. In general, how would you classify your mathematics teacher's overall personality?
Poor
Fair
Average
Good
Very Good

4. In general, how would you classify your mathematics teacher's overall teaching style?
Poor
Fair
Average
Good
Very Good

5. In general, how would you classify your mathematics teacher's overall level of patience and support of students?
Poor
Fair
Average
Good
Very Good

6. In general, how would you classify your mathematics teacher's overall clarity when teaching? 
$\begin{array}{llll}\text { Poor } & \text { Fair } & \text { Average } & \text { Good }\end{array}$

7. In general, how would you classify your mathematics teacher's overall relationship with the students?

Poor Fair Average Good Very Good

8. In general, how would you classify your parents’ or guardians' attitude toward mathematics?

$\begin{array}{llll}\text { Poor } & \text { Fair } & \text { Average } & \text { Good }\end{array}$

9. In general, how would you classify your attitude toward the assessments in these math classes?

Poor Fair Average Good Gery Good

10. In general, I do not enjoy/enjoyed solving/doing mathematics problems.

Strongly Disagree Disagree Neutral Agree Strongly Agree

11. In general, I am/have been curious about topics in my mathematics classes.

Strongly Disagree Disagree Neutral Agree Strongly Agree

12. In general, I am usually bored in math class.

Strongly Disagree Disagree Neutral Agree Strongly Agree

13. In general, I not feel motivated to try to learn and understand more about mathematics.

Strongly Disagree Disagree Neutral Agree Strongly Agree

14. In general, I have felt/feel competent in my ability to learn and understand mathematics.

Strongly Disagree Disagree Neutral Agree Strongly Agree

15. In general, I have felt/feel tense and/or anxious when attempting to solve a mathematics problem or when taking a mathematics test.

Strongly Disagree Disagree Neutral Agree Strongly Agree

16. Which of the following do you think most influenced your attitude toward Mathematics during this time? 
Content(Type of math class)

Teacher

Tests

Classroom Environment

Other (please specify)

For the last set of questions, I would like you to think about your experiences and feelings with mathematics and mathematics classes after high school until now. Do you remember a strong experience during any of these times?

Yes

No

If Yes, which course or time in your life?

Answer as honestly as you can recall.

1. In general, how would you classify your attitude toward mathematics?

Poor Fair Average Good Very Good

2. In general, how would you classify your achievement level?
Poor
Fair
Average
Good
Very Good

3. In general, how would you classify your mathematics teacher's overall personality?

Poor Fair Average Good $\quad$ Very Good

4. In general, how would you classify your mathematics teacher's overall teaching style?

Poor Fair Average Good Gery Good

5. In general, how would you classify your mathematics teacher's overall level of patience and support of students?

Poor Fair Average Good Gery Good 
6. In general, how would you classify your mathematics teacher's overall clarity when teaching?
Poor
Fair
Average
Good
Very Good

7. In general, how would you classify your mathematics teacher's overall relationship with the students?
Poor
Fair
Average
Good
Very Good

8. In general, how would you classify your parents' or guardians' attitude toward mathematics?
Poor
Fair
Average
Good
Very Good

9. In general, how would you classify your attitude toward the assessments in these math classes?
Poor
Fair
Average
Good
Very Good

10. In general, I do not enjoy/enjoyed solving/doing mathematics problems.
Strongly Disagree
Disagree
Neutral
Agree
Strongly Agree

11. In general, I am/have been curious about topics in my mathematics classes.
Strongly Disagree
Disagree
Neutral
Agree
Strongly Agree

12. In general, I am usually bored in math class.

Strongly Disagree Disagree Neutral Agree Strongly Agree

13. In general, I not feel motivated to try to learn and understand more about mathematics.

Strongly Disagree Disagree Neutral Agree Strongly Agree

14. In general, I have felt/feel competent in my ability to learn and understand mathematics.

Strongly Disagree Disagree Neutral Agree Strongly Agree

15. In general, I have felt/feel tense and/or anxious when attempting to solve a mathematics problem or when taking a mathematics test. 
Strongly Disagree Disagree Neutral Agree Strongly Agree 16. Which of the following do you think most influenced your attitude toward Mathematics during this time?

Content(Type of math class)

Teacher

Tests

Classroom Environment

Other (please specify)

General beliefs about math and teaching math

1. In general I saw/see the usefulness of mathematics in my life outside of the classroom.

Strongly Disagree Disagree Neutral Agree Strongly Agree

2. In general, I believe the best way to teach mathematics is to refrain from giving students the rules and procedures right away.

Strongly Disagree Disagree Neutral Agree Strongly Agree

3. In general, I believe the best way to teach mathematics is to let students struggle with some of the concepts and let them discover the reasons behind mathematics.

Strongly Disagree Disagree Neutral Agree Strongly Agree

4. Overall, what factors do you think most contributes to your attitude towards mathematics? Why? 


\section{APPENDIX 2: INTERVIEW PROTOCOL}

- How would you describe your current attitude toward math?

- Give a general description, from your earliest memory to your current memories, of your level of mathematics learning and your attitude toward learning mathematics./ How would your math story read? Names of chapters?

- Describe a positive memory you had in a mathematics class.

o Grade?

o Factors?

- Describe a negative memory you had in a mathematics class

o Grade?

o Factors?

- In general, what factors do you feel best supported your learning in mathematics courses?

o Content

o Teacher

o Tests

o Activities

o Overall Environment

- In general, what factors do you feel least supported your learning in mathematics courses?

o Content

o Teacher

o Tests

o Activities

o Overall Environment

- What do you think influences your attitude toward mathematics? Why?

o Content

o Teacher

o Tests

o Activities

o Overall Environment

- What kind of impact did your teacher have on your attitude toward the class?

- What, if anything, do you think could be done for you now to improve your mathematics learning?

o Content

o Teacher

o Tests

o Activities

o Overall Environment

- What, if anything, do you think could be done for you now to improve your attitude toward mathematics?

o Content

o Teacher 
o Tests

o Activities

o Overall Environment

- If you could give mathematics teachers advice to improve math learning, what would it be?

- If you could give mathematics teachers advice to improve attitudes in their classroom, what would it be?

- Describe your ideal mathematics class.
o Content
o Teacher
o Tests
o Activities
o Overall Environment 


\section{A P P E N D I X 3: O P E N-C ODE D M A T R I X}

\begin{tabular}{|c|c|c|c|c|c|c|c|}
\hline Student & $\begin{array}{l}\text { Age, } \\
\text { Major }\end{array}$ & $\begin{array}{l}\text { How would you } \\
\text { describe your } \\
\text { current attitude } \\
\text { toward math? }\end{array}$ & $\begin{array}{l}\text { Give a general } \\
\text { description, from your } \\
\text { earliest memory to your } \\
\text { current memories, of } \\
\text { your level of } \\
\text { mathematics learning } \\
\text { and your attitude } \\
\text { toward learning }\end{array}$ & $\begin{array}{l}\text { Describe a positive } \\
\text { memory you had in a } \\
\text { mathematics class. }\end{array}$ & $\begin{array}{l}\text { Describe a negative } \\
\text { memory you had in } \\
\text { a mathematics } \\
\text { class }\end{array}$ & $\begin{array}{l}\text { In general, what } \\
\text { factors do you feel } \\
\text { best supported your } \\
\text { learning in } \\
\text { mathematics courses? }\end{array}$ & $\begin{array}{l}\text { In general, what } \\
\text { factors do you } \\
\text { feel least } \\
\text { supported your } \\
\text { learning in } \\
\text { mathematics } \\
\text { courses? }\end{array}$ \\
\hline 64 & $\begin{array}{l}\text { ?, } \\
\text { Business }\end{array}$ & Decent, neutral & $\begin{array}{l}\text { Positive grade school } \\
\text { Middle school fell } \\
\text { behind } \\
\text { High school attitude } \\
\text { improved based on } \\
\text { teacher }\end{array}$ & $\begin{array}{l}\text { Geometry } \\
\text { Visual } \\
\text { Fun teacher } \\
\text { Teacher made time } \\
\text { for each }\end{array}$ & $\begin{array}{l}\text { Poor achievement } \\
\text { Lack of } \\
\text { understanding }\end{array}$ & $\begin{array}{l}\text { Manipulatives } \\
\text { Repetition } \\
\text { Practice } \\
\text { Homework }\end{array}$ & Poor teacher \\
\hline 58 & $18, ?$ & $\begin{array}{l}\text { Pretty good, } \\
\text { dependent on } \\
\text { content }\end{array}$ & $\begin{array}{l}\text { Good understanding } \\
\text { Improved in algebra- } \\
\text { challenge and teacher } \\
\text { Declined in geometry, } \\
\text { didn't understand }\end{array}$ & Solving equations & Not understanding & $\begin{array}{l}\text { Relaxed teacher } \\
\text { Relaxed atmosphere } \\
\text { Interactive teacher }\end{array}$ & $\begin{array}{l}\text { Large classes } \\
\text { Lack of one-on- } \\
\text { one }\end{array}$ \\
\hline 27 & $\begin{array}{l}\text { 18, } \\
\text { engineerin } \\
g\end{array}$ & Neutral & $\begin{array}{l}\text { Neutral } \\
\text { Algebra was interesting } \\
\text { Liked visual geometry } \\
\text { Disliked trig }\end{array}$ & $\begin{array}{l}\text { Pre-cal } \\
\text { Favorite teacher } \\
\text { Easy-going teacher } \\
\text { Made math fun }\end{array}$ & $\begin{array}{l}\text { Trig } \\
\text { Teacher poor } \\
\text { explanations } \\
\text { Memorization } \\
\text { Fast pace }\end{array}$ & $\begin{array}{l}\text { Usefulness } \\
\text { Real-world apps }\end{array}$ & $\begin{array}{l}\text { Too much book } \\
\text { work } \\
\text { Busy work }\end{array}$ \\
\hline 92 & 29, MDS & $\begin{array}{l}\text { Improved } \\
\text { Renewed } \\
\text { appreciation }\end{array}$ & $\begin{array}{l}\text { Early struggle } \\
\text { Impatient parent help } \\
\text { Late elem. school, } \\
\text { influence from friends } \\
\text { improved } \\
\text { Improved, teacher in } \\
\text { MS } \\
\text { High school decline, }\end{array}$ & $\begin{array}{l}\text { Self-pace } \\
\text { Promoted to ‘smart } \\
\text { class' }\end{array}$ & $\begin{array}{l}\text { Misplaced } \\
\text { Too difficult } \\
\text { Belittled and } \\
\text { embarrassed by } \\
\text { teacher }\end{array}$ & $\begin{array}{l}\text { Good presentation } \\
\text { Teacher personality } \\
\text { Entertaining teacher }\end{array}$ & $\begin{array}{l}\text { Peers } \\
\text { Stereotypes } \\
\text { Not cool }\end{array}$ \\
\hline
\end{tabular}




\begin{tabular}{|c|c|c|c|c|c|c|c|}
\hline & & & $\begin{array}{l}\text { not interesting, poor } \\
\text { presentation } \\
\text { College continued } \\
\text { decline, sink or swim }\end{array}$ & & & & \\
\hline 25 & $\begin{array}{l}\text { 18,psycho } \\
\text { logy }\end{array}$ & Negative & $\begin{array}{l}\text { ES positive, good } \\
\text { grades and hard work } \\
\text { HS decline, test anxiety } \\
\text { and assessments }\end{array}$ & $\begin{array}{l}\text { HS geometry, } \\
\text { achievement, hard } \\
\text { work, parental } \\
\text { support }\end{array}$ & $\begin{array}{l}\text { College, } \\
\text { achievement }\end{array}$ & $\begin{array}{l}\text { Repetition } \\
\text { Simple language }\end{array}$ & Not sure \\
\hline 23 & $\begin{array}{l}\text { ?,medical } \\
\text { technolog } \\
\mathrm{y}\end{array}$ & $\begin{array}{l}\text { Positive } \\
\text { Easy } \\
\text { Fun } \\
\text { Good } \\
\text { achievement }\end{array}$ & $\begin{array}{l}\text { Mostly good memories } \\
\text { Teacher affected } \\
\text { attitude } \\
\text { HS decline, fast pace }\end{array}$ & Rewards & $\begin{array}{l}\text { Fractions } \\
\text { Multiplication } \\
\text { tables } \\
\text { Difficult concept }\end{array}$ & $\begin{array}{l}\text { One-on-one attn. } \\
\text { Appropriate pace } \\
\text { Usefulness }\end{array}$ & $\begin{array}{l}\text { Difficult teacher } \\
\text { Telling, not } \\
\text { explaining }\end{array}$ \\
\hline 46 & $\begin{array}{l}18, \\
\text { Occupatio } \\
\text { nal } \\
\text { Therapy }\end{array}$ & $\begin{array}{l}\text { Pretty good } \\
\text { Enjoys } \\
\text { procedural }\end{array}$ & $\begin{array}{l}\text { Good early memories } \\
\text { MS good teacher } \\
\text { HS decline, geometry } \\
\text { Content, teacher, ability }\end{array}$ & $\begin{array}{l}\text { Accomplishment } \\
\text { "figuring out" }\end{array}$ & $\begin{array}{l}\text { Not understanding } \\
\text { Giving up } \\
\text { Not learning }\end{array}$ & $\begin{array}{l}\text { Good teaching style } \\
\text { Enjoyable content }\end{array}$ & $\begin{array}{l}\text { Distractions } \\
\text { from other } \\
\text { students }\end{array}$ \\
\hline 93 & $\begin{array}{l}\text { 19, social } \\
\text { studies- } \\
\text { secondary } \\
\text { ed. }\end{array}$ & $\begin{array}{l}\text { Don't like it } \\
\text { School math not } \\
\text { related to real } \\
\text { life }\end{array}$ & $\begin{array}{l}\text { ES, positive, visual, } \\
\text { easy } \\
\text { MS/HS, decline, fell } \\
\text { behind }\end{array}$ & $\begin{array}{l}\text { Usefulness } \\
\text { Real-life }\end{array}$ & $\begin{array}{l}\text { Teacher didn't } \\
\text { want to be there } \\
\text { Delayed feedback }\end{array}$ & $\begin{array}{l}\text { Hands-on } \\
\text { Usefulness in real- } \\
\text { world }\end{array}$ & $\begin{array}{l}\text { Peer teaching } \\
\text { Overwhelming } \\
\text { High pressure }\end{array}$ \\
\hline 14 & $\begin{array}{l}25, \\
\text { master's } \\
\text { in } \\
\text { elementar } \\
\text { y } \\
\text { education }\end{array}$ & $\begin{array}{l}\text { Apathetic } \\
\text { Indifferent }\end{array}$ & $\begin{array}{l}\text { Dislikes difficult things } \\
\text { Parental influence, } \\
\text { math teacher mother } \\
\text { MS, decline, misplaced, } \\
\text { unsympathetic teacher, } \\
\text { fell behind } \\
\text { Insecurities } \\
\text { HS, roller coaster, } \\
\text { content related }\end{array}$ & & $\begin{array}{l}\text { Impatient teacher } \\
\text { Misplaced } \\
\text { Fell behind }\end{array}$ & $\begin{array}{l}\text { Understanding the } \\
\text { ‘why' } \\
\text { Historical basis }\end{array}$ & $\begin{array}{l}\text { Skipping the } \\
\text { 'why' }\end{array}$ \\
\hline 71 & $\begin{array}{l}\text { 18, } \\
\text { general } \\
\text { studies }\end{array}$ & $\begin{array}{l}\text { Positive } \\
\text { Enjoys math } \\
\text { Favorite subject }\end{array}$ & $\begin{array}{l}\text { Always good attitude } \\
\text { Good achievement } \\
\text { One-on-one }\end{array}$ & $\begin{array}{l}\text { HS, enthusiastic } \\
\text { teacher } \\
\text { Fun learning } \\
\text { environment }\end{array}$ & $\begin{array}{l}\text { Misplaced } \\
\text { Bored }\end{array}$ & $\begin{array}{l}\text { Examples } \\
\text { Practice } \\
\text { Small classes } \\
\text { Interactive } \\
\text { One-on-one }\end{array}$ & lecture \\
\hline 65 & 20 , & Resentful & ES, MS, positive, & Self-paced & Test taking & Study guides & Assumption of \\
\hline
\end{tabular}




\begin{tabular}{|c|c|c|c|c|c|c|c|}
\hline & $\begin{array}{l}\text { business } \\
\text { managem } \\
\text { ent }\end{array}$ & Poor attitude & $\begin{array}{l}\text { advanced classes } \\
\text { HS, decline, passed } \\
\text { through, not motivated } \\
\text { College, poor }\end{array}$ & $\begin{array}{l}\text { Achievement } \\
\text { Motivation }\end{array}$ & $\begin{array}{l}\text { (anxiety), } \\
\text { overwhelming, } \\
\text { technology, } \\
\text { environment } \\
\text { Fear of } \\
\text { embarrassment }\end{array}$ & $\begin{array}{l}\text { Organization } \\
\text { Frequent, low-risk } \\
\text { assessments } \\
\text { Approachable teacher } \\
\text { Pacing } \\
\text { Simple explanation }\end{array}$ & knowledge \\
\hline 4 & $\begin{array}{l}\text { 18, } \\
\text { exercise } \\
\text { physiolog } \\
\text { y }\end{array}$ & $\begin{array}{l}\text { Positive, good } \\
\text { attitude } \\
\text { Enjoyed class }\end{array}$ & $\begin{array}{l}\text { Always excelled } \\
\text { Usually liked math } \\
\text { Poor } 9^{\text {th }} \text { grade teacher }\end{array}$ & $\begin{array}{l}\text { Upbeat teacher } \\
\text { Interactive with } \\
\text { students }\end{array}$ & $\begin{array}{l}\text { Trouble } \\
\text { understanding } \\
\text { Negative peers }\end{array}$ & $\begin{array}{l}\text { Homework } \\
\text { Going over problem } \\
\text { with teacher } \\
\text { Outside work }\end{array}$ & $\begin{array}{l}\text { Lecture without } \\
\text { help }\end{array}$ \\
\hline 20 & $\begin{array}{l}18, \\
\text { communic } \\
\text { ations }\end{array}$ & OK attitude & $\begin{array}{l}\text { Parental influence } \\
\text { young, fun } \\
\text { ES, positive, self-paced } \\
\text { MS, accelerated } \\
\text { HS, decline, no calculus } \\
\text { review } \\
\text { Pre-Ca, usefulness }\end{array}$ & $\begin{array}{l}\text { Being ahead, } \\
\text { accelerated } \\
\text { Feeling smart } \\
\text { Math field day }\end{array}$ & $\begin{array}{l}\text { Mean teacher after } \\
\text { school } \\
\text { Not approachable }\end{array}$ & $\begin{array}{l}\text { Understanding } \\
\text { Early start } \\
\text { Motivated }\end{array}$ & $\begin{array}{l}\text { Calculus teacher } \\
\text { Teaching style } \\
\text { Not ok to not } \\
\text { understand } \\
\text { Not able to ask } \\
\text { questions }\end{array}$ \\
\hline 32 & $\begin{array}{l}\text { 18, } \\
\text { psycholog } \\
\text { y, } \\
\text { journalism }\end{array}$ & OK attitude & $\begin{array}{l}\text { Positive until geometry, } \\
\text { advanced classes } \\
\text { Geometry, decline, as it } \\
\text { got more difficult }\end{array}$ & $\begin{array}{l}\text { Good, caring teachers } \\
\text { Taught well } \\
\text { Devoted } \\
\text { Made sure each knew } \\
\text { Personal attn }\end{array}$ & $\begin{array}{l}\text { Teachers who } \\
\text { couldn't teach }\end{array}$ & $\begin{array}{l}\text { Visuals } \\
\text { Knowing the 'why' }\end{array}$ & \\
\hline 33 & $\begin{array}{l}19, \\
\text { journalism }\end{array}$ & $\begin{array}{l}\text { Neutral attitude } \\
\text { Only interested } \\
\text { in personal } \\
\text { usefulness }\end{array}$ & $\begin{array}{l}\text { Young, more positive, } \\
\text { understanding, easier } \\
\text { Older, decline, harder, } \\
\text { didn't make sense, took } \\
\text { time and effort } \\
\text { Required }\end{array}$ & $\begin{array}{l}\text { Understanding, } \\
\text { preferably quick } \\
\text { Less frustration }\end{array}$ & $\begin{array}{l}\text { Embarrassment in } \\
\text { front of class }\end{array}$ & $\begin{array}{l}\text { Teacher takes time } \\
\text { Personal effort } \\
\text { Multiple reps and } \\
\text { explanation }\end{array}$ & $\begin{array}{l}\text { Lack of } \\
\text { motivation }\end{array}$ \\
\hline 52 & $\begin{array}{l}18, \\
\text { journalism }\end{array}$ & $\begin{array}{l}\text { Neutral attitude } \\
\text { Requirement }\end{array}$ & $\begin{array}{l}\text { MS, good teacher } \\
\text { Self-teaching } \\
\text { HS, turning into a joke }\end{array}$ & Good achievement & Not good grades & $\begin{array}{l}\text { Helpful teachers } \\
\text { Good examples }\end{array}$ & $\begin{array}{l}\text { Content } \\
\text { Not useful }\end{array}$ \\
\hline 43 & $\begin{array}{l}23 \text {, } \\
\text { agricultur } \\
\text { e and } \\
\text { education }\end{array}$ & $\begin{array}{l}\text { Poor attitude } \\
\text { Hated math } \\
\text { whole life }\end{array}$ & $\begin{array}{l}\text { Early, neutral, } \\
\text { understood } \\
\text { MS, hate, feel stupid, } \\
\text { placement, teachers not } \\
\text { understanding }\end{array}$ & $\begin{array}{l}\text { Frustrating a teacher } \\
\text { by not doing } \\
\text { homework }\end{array}$ & $\begin{array}{l}\text { Singled out in class } \\
\text { by teacher } \\
\text { Embarrassed }\end{array}$ & $\begin{array}{l}\text { Understanding } \\
\text { teacher } \\
\text { Interesting techniques } \\
\text { Usefulness }\end{array}$ & $\begin{array}{l}\text { Not giving a } \\
\text { reason to know }\end{array}$ \\
\hline
\end{tabular}




\begin{tabular}{|c|c|c|c|c|c|c|c|}
\hline 59 & $\begin{array}{l}\text { 18, child } \\
\text { developm } \\
\text { ent and } \\
\text { family } \\
\text { studies }\end{array}$ & $\begin{array}{l}\text { Good attitude } \\
\text { Good } \\
\text { achievement } \\
\text { Enjoys }\end{array}$ & $\begin{array}{l}\text { Always enjoyed } \\
\text { Games } \\
\text { Helpful teachers }\end{array}$ & $\begin{array}{l}\text { Games/jeopardy } \\
\text { Visualization }\end{array}$ & $\begin{array}{l}\text { Teacher that } \\
\text { wouldn't explain }\end{array}$ & $\begin{array}{l}\text { Breaking it down } \\
\text { Thorough } \\
\text { explanation }\end{array}$ & No explanation \\
\hline 54 & $\begin{array}{l}\text { 18, } \\
\text { secondary } \\
\text { ed, } \\
\text { English }\end{array}$ & $\begin{array}{l}\text { Neutral attitude } \\
\text { Requirement }\end{array}$ & $\begin{array}{l}\text { ES, hated, perfectionist } \\
\text { frustration } \\
\text { MS, HS, improved } \\
\text { Excellent achievement }\end{array}$ & $\begin{array}{l}\text { Teacher } \\
\text { Personal attention } \\
\text { Games }\end{array}$ & $\begin{array}{l}\text { Frustration } \\
\text { Inconsistent } \\
\text { teaching }\end{array}$ & $\begin{array}{l}\text { Visual } \\
\text { Manipulatives }\end{array}$ & $\begin{array}{l}\text { Too fast pace } \\
\text { Not recognizing } \\
\text { student difficulty } \\
\text { Unapproachable } \\
\text { teacher }\end{array}$ \\
\hline 40 & $\begin{array}{l}19, \\
\text { business } \\
\text { law, } \\
\text { philosoph } \\
\text { y minor }\end{array}$ & $\begin{array}{l}\text { Poor attitude } \\
\text { Confusing } \\
\text { Graphs }\end{array}$ & $\begin{array}{l}\text { ES, MS, liked } \\
\text { HS, trickier, still liked } \\
\text { College, decline, } \\
\text { required, large class }\end{array}$ & $\begin{array}{l}\text { Math field day } \\
\text { Challenge }\end{array}$ & $\begin{array}{l}\text { Not winning math } \\
\text { field day }\end{array}$ & $\begin{array}{l}\text { Teacher presentation } \\
\text { Detailed explanation } \\
\text { Visual } \\
\text { Personal attn }\end{array}$ & Large class \\
\hline
\end{tabular}




\begin{tabular}{|c|c|c|c|c|c|c|c|}
\hline $\begin{array}{l}\text { What do } \\
\text { you } \\
\text { think } \\
\text { influenc } \\
\text { es your } \\
\text { attitude } \\
\text { toward } \\
\text { mathem } \\
\text { atics? } \\
\text { Why? }\end{array}$ & $\begin{array}{l}\text { What kind } \\
\text { of impact } \\
\text { did your } \\
\text { teacher } \\
\text { have on } \\
\text { your } \\
\text { attitude } \\
\text { toward the } \\
\text { class? }\end{array}$ & $\begin{array}{l}\text { What, if } \\
\text { anything, do you } \\
\text { think could be } \\
\text { done for you } \\
\text { now to improve } \\
\text { your } \\
\text { mathematics } \\
\text { learning? }\end{array}$ & $\begin{array}{l}\text { What, if anything, do } \\
\text { you think could be done } \\
\text { for you now to improve } \\
\text { your attitude toward } \\
\text { mathematics? }\end{array}$ & $\begin{array}{l}\text { If you could give } \\
\text { mathematics teachers } \\
\text { advice to improve } \\
\text { math learning, what } \\
\text { would it be? }\end{array}$ & $\begin{array}{l}\text { If you could give } \\
\text { mathematics } \\
\text { teachers advice to } \\
\text { improve attitudes } \\
\text { in their classroom, } \\
\text { what would it be? }\end{array}$ & $\begin{array}{l}\text { Describe your ideal } \\
\text { mathematics class }\end{array}$ & $\begin{array}{l}\text { Why do you } \\
\text { think other } \\
\text { students dislike } \\
\text { math? }\end{array}$ \\
\hline $\begin{array}{l}\text { Underst } \\
\text { anding } \\
\text { Level of } \\
\text { frustrati } \\
\text { on }\end{array}$ & $\begin{array}{l}\text { Pretty big } \\
\text { Willingne } \\
\text { ss to help } \\
\text { Clear } \\
\text { explanatio } \\
\text { ns }\end{array}$ & More homework & $\begin{array}{l}\text { Upbeat teacher } \\
\text { Explains for everyone }\end{array}$ & $\begin{array}{l}\text { Variety } \\
\text { Practice }\end{array}$ & $\begin{array}{l}\text { Shortcuts } \\
\text { Easy way }\end{array}$ & $\begin{array}{l}\text { Hands-on } \\
\text { Fun } \\
\text { Teacher walking } \\
\text { around and helping }\end{array}$ & $\begin{array}{l}\text { They are not } \\
\text { 'math-inclined' }\end{array}$ \\
\hline $\begin{array}{l}\text { Appropr } \\
\text { iate } \\
\text { level of } \\
\text { challeng } \\
\text { e } \\
\text { Earning } \\
\text { the } \\
\text { grade }\end{array}$ & $\begin{array}{l}\text { Big } \\
\text { influence }\end{array}$ & Nothing & Nothing & $\begin{array}{l}\text { Repetition } \\
\text { Make sure everyone } \\
\text { understands }\end{array}$ & Work with students & $\begin{array}{l}\text { Joking } \\
\text { Relaxed } \\
\text { Lecture } \\
\text { Chalkboard }\end{array}$ & $\begin{array}{l}\text { They don't } \\
\text { understand it or } \\
\text { think it is } \\
\text { interesting }\end{array}$ \\
\hline $\begin{array}{l}\text { Level of } \\
\text { fun } \\
\text { Fun is } \\
\text { depende } \\
\text { nt on } \\
\text { usefulne } \\
\text { ss in life } \\
\text { Appropr } \\
\text { iate } \\
\text { challeng } \\
\text { e }\end{array}$ & $\begin{array}{l}\text { Greatly } \\
\text { Teacher } \\
\text { attitude }\end{array}$ & $\begin{array}{l}\text { Class } \\
\text { involvement } \\
\text { Teacher } \\
\text { interaction }\end{array}$ & Nothing & $\begin{array}{l}\text { Dynamic class } \\
\text { Interesting class }\end{array}$ & $\begin{array}{l}\text { Easy going } \\
\text { Respect student } \\
\text { ideas } \\
\text { Good relationship } \\
\text { with students }\end{array}$ & $\begin{array}{l}\text { Importance of teacher } \\
\text { presentation, not } \\
\text { content } \\
\text { Flowing class }\end{array}$ & $\begin{array}{l}\text { They struggle } \\
\text { with it }\end{array}$ \\
\hline $\begin{array}{l}\text { Doesn't } \\
\text { come }\end{array}$ & $\begin{array}{l}\text { All } \\
\text { influence }\end{array}$ & $\begin{array}{l}\text { Personal } \\
\text { attention }\end{array}$ & Nothing & $\begin{array}{l}\text { Take time } \\
\text { Respect students }\end{array}$ & $\begin{array}{l}\text { Interesting } \\
\text { presentation }\end{array}$ & $\begin{array}{l}\text { Small class } \\
\text { Teacher take time }\end{array}$ & $\begin{array}{l}\text { Math is } \\
\text { stereotypically }\end{array}$ \\
\hline
\end{tabular}




\begin{tabular}{|c|c|c|c|c|c|c|c|}
\hline $\begin{array}{l}\text { easily } \\
\text { Feeling } \\
\text { stupid } \\
\text { Ability } \\
\text { to } \\
\text { accompl } \\
\text { ish }\end{array}$ & $\begin{array}{l}\text { Teacher } \\
\text { personalit } \\
\text { y } \\
\text { Teacher } \\
\text { care }\end{array}$ & $\begin{array}{l}\text { Not being } \\
\text { embarrassed to } \\
\text { ask questions }\end{array}$ & & Correct pacing & & $\begin{array}{l}\text { Flexible schedule } \\
\text { Example problems } \\
\text { Review homework }\end{array}$ & $\begin{array}{l}\text { nerdy and not } \\
\text { exciting }\end{array}$ \\
\hline $\begin{array}{l}\text { Achieve } \\
\text { ment, } \\
\text { effort } \\
\text { matchin } \\
\text { g } \\
\text { achieve } \\
\text { ment }\end{array}$ & $\begin{array}{l}\text { No one } \\
\text { seemed to } \\
\text { care if you } \\
\text { LIKED it }\end{array}$ & $\begin{array}{l}\text { Refresh } \\
\text { Review }\end{array}$ & $\begin{array}{l}\text { Repetition } \\
\text { Make it fun } \\
\text { Ability to succeed } \\
\text { Required work }\end{array}$ & $\begin{array}{l}\text { Repetition } \\
\text { Connect math } \\
\text { language to 'real' } \\
\text { Simplify concepts }\end{array}$ & $\begin{array}{l}\text { Understanding } \\
\text { Achievement }\end{array}$ & $\begin{array}{l}\text { Teacher face to face } \\
\text { Not auditorium } \\
\text { Not overwhelming } \\
\text { environment } \\
\text { Required work }\end{array}$ & $\begin{array}{l}\text { They have to put } \\
\text { forth effort and } \\
\text { understand in } \\
\text { order to have } \\
\text { good } \\
\text { achievement }\end{array}$ \\
\hline $\begin{array}{l}\text { Parental } \\
\text { encoura } \\
\text { gement } \\
\text { Underst } \\
\text { anding } \\
\text { Appropr } \\
\text { iate } \\
\text { pace }\end{array}$ & $\begin{array}{l}\text { Big } \\
\text { impact } \\
\text { Teacher } \\
\text { attitude }\end{array}$ & $\begin{array}{l}\text { Review sheet } \\
\text { Guidelines } \\
\text { Organization } \\
\text { Memorization }\end{array}$ & $\begin{array}{l}\text { Being a 'math genius' } \\
\text { Ability }\end{array}$ & $\begin{array}{l}\text { Good attitude } \\
\text { Calm } \\
\text { Classroom } \\
\text { management } \\
\text { Excited attitude }\end{array}$ & $\begin{array}{l}\text { Give them a reason } \\
\text { 'why' they should } \\
\text { want to learn it } \\
\text { Motivation }\end{array}$ & $\begin{array}{l}\text { Interactive class } \\
\text { Activities } \\
\text { Technology } \\
\text { Puzzles/games } \\
\text { Interesting } \\
\text { Real-life topics }\end{array}$ & $\begin{array}{l}\text { They don't think } \\
\text { they need to } \\
\text { know it } \\
\text { Not useful to } \\
\text { them }\end{array}$ \\
\hline $\begin{array}{l}\text { Achieve } \\
\text { ment }\end{array}$ & $\begin{array}{l}\text { Good role } \\
\text { Teacher } \\
\text { attitude }\end{array}$ & $\begin{array}{l}\text { Tutoring } \\
\text { Personal effort } \\
\text { Complete } \\
\text { understanding }\end{array}$ & & $\begin{array}{l}\text { Make sure everyone } \\
\text { understands }\end{array}$ & $\begin{array}{l}\text { Positive attitude } \\
\text { No frustration } \\
\text { Patience }\end{array}$ & $\begin{array}{l}\text { Teacher shows } \\
\text { Students try } \\
\text { Helpful } \\
\text { Small class }\end{array}$ & $\begin{array}{l}\text { They can't so it } \\
\text { It's too } \\
\text { frustrating }\end{array}$ \\
\hline $\begin{array}{l}\text { Usefuln } \\
\text { ess }\end{array}$ & $\begin{array}{l}\text { Big } \\
\text { impact } \\
\text { Enthusias } \\
\text { m }\end{array}$ & $\begin{array}{l}\text { Basic } \\
\text { understanding } \\
\text { Review }\end{array}$ & Hands-on activities & $\begin{array}{l}\text { Don't be boring } \\
\text { Want to be there } \\
\text { Interactive material }\end{array}$ & $\begin{array}{l}\text { More personal } \\
\text { Small class } \\
\text { Build community }\end{array}$ & $\begin{array}{l}\text { Useful material } \\
\text { Group work }\end{array}$ & $\begin{array}{l}\text { They just don't } \\
\text { 'get it' }\end{array}$ \\
\hline $\begin{array}{l}\text { Persona } \\
1 \\
\text { insecuri } \\
\text { ties } \\
\text { Fear of } \\
\text { failure }\end{array}$ & $\begin{array}{l}\text { Some big, } \\
\text { some not } \\
\text { Mostly } \\
\text { small } \\
\text { Teacher } \\
\text { attitude } \\
\end{array}$ & $\begin{array}{l}\text { Personal effort } \\
\text { Mandatory work } \\
\text { Tutoring }\end{array}$ & Being finished with it & $\begin{array}{l}\text { Properly place } \\
\text { students }\end{array}$ & $\begin{array}{l}\text { One-on one } \\
\text { Personal attention } \\
\text { Small class } \\
\text { Take time }\end{array}$ & $\begin{array}{l}\text { Small class } \\
\text { Personal attn } \\
\text { Small group work } \\
\text { Good pace } \\
\text { Concrete topics }\end{array}$ & $\begin{array}{l}\text { They don't excel } \\
\text { at it }\end{array}$ \\
\hline
\end{tabular}




\begin{tabular}{|c|c|c|c|c|c|c|c|}
\hline $\begin{array}{l}\text { Ability } \\
\text { Achieve } \\
\text { ment } \\
\text { Accomp } \\
\text { lishmen } \\
\mathrm{t}\end{array}$ & $\begin{array}{l}\text { Fairly big } \\
\text { influence } \\
\text { Willingne } \\
\text { ss to help }\end{array}$ & $\begin{array}{l}\text { Less lecture } \\
\text { More examples }\end{array}$ & Nothing & $\begin{array}{l}\text { Energetic } \\
\text { Answer lots of } \\
\text { questions } \\
\text { Good attitude }\end{array}$ & $\begin{array}{l}\text { Less repetition } \\
\text { More variety } \\
\text { Activities }\end{array}$ & $\begin{array}{l}\text { Small class } \\
\text { Interactive teacher } \\
\text { Check on students } \\
\text { Activities } \\
\text { Make sure } \\
\text { understanding }\end{array}$ & $\begin{array}{l}\text { They don't do } \\
\text { well in it, their } \\
\text { effort doesn't } \\
\text { pay off in } \\
\text { assessments, and } \\
\text { they don't } \\
\text { understand }\end{array}$ \\
\hline $\begin{array}{l}\text { Falling } \\
\text { behind }\end{array}$ & $\begin{array}{l}\text { Some } \\
\text { impact } \\
\text { Didn't } \\
\text { seem to } \\
\text { care if } \\
\text { liked it }\end{array}$ & $\begin{array}{l}\text { Personal effort } \\
\text { More math } \\
\text { classes } \\
\text { Better } \\
\text { understanding }\end{array}$ & Understanding & $\begin{array}{l}\text { Show most difficult } \\
\text { examples } \\
\text { Help decipher } \\
\text { language in questions }\end{array}$ & Don't know & $\begin{array}{l}\text { Small class } \\
\text { Chalkboard } \\
\text { Less intimidating } \\
\text { environment }\end{array}$ & $\begin{array}{l}\text { They are } \\
\text { ignorant in the } \\
\text { subject, had bad } \\
\text { teachers in past } \\
\text { and it is too } \\
\text { redundant }\end{array}$ \\
\hline $\begin{array}{l}\text { Parental } \\
\text { influenc } \\
\text { e } \\
\text { Good } \\
\text { teachers }\end{array}$ & $\begin{array}{l}\text { Big effect } \\
\text { Teacher } \\
\text { attitude } \\
\text { and } \\
\text { personalit } \\
\text { y }\end{array}$ & $\begin{array}{l}\text { Smaller class } \\
\text { More time with } \\
\text { teacher } \\
\text { Personal attn }\end{array}$ & Later time in day & $\begin{array}{l}\text { Interactive with } \\
\text { students } \\
\text { More examples }\end{array}$ & $\begin{array}{l}\text { Show usefulness } \\
\text { Many examples }\end{array}$ & $\begin{array}{l}\text { Small class } \\
\text { Lots of examples } \\
\text { Challenge/accomplis } \\
\text { hment } \\
\text { Good teacher } \\
\text { personality }\end{array}$ & $\begin{array}{l}\text { They have } \\
\text { trouble with } \\
\text { numbers and } \\
\text { logical thinking }\end{array}$ \\
\hline $\begin{array}{l}\text { Underst } \\
\text { anding } \\
\text { Achieve } \\
\text { ment }\end{array}$ & $\begin{array}{l}\text { A lot of } \\
\text { impact } \\
\text { Teacher } \\
\text { personalit } \\
\text { y and } \\
\text { teaching } \\
\text { style }\end{array}$ & personal effort & Nothing & $\begin{array}{l}\text { Clear, thorough } \\
\text { explanation }\end{array}$ & $\begin{array}{l}\text { Feedback } \\
\text { Ask for student } \\
\text { input } \\
\text { Improve teaching } \\
\text { style } \\
\text { Willing to help }\end{array}$ & $\begin{array}{l}\text { Hands-on } \\
\text { Games } \\
\text { Shorter lectures } \\
\text { Small class } \\
\text { Personal attention }\end{array}$ & $\begin{array}{l}\text { They don't } \\
\text { understand it and } \\
\text { are too } \\
\text { intimidated to } \\
\text { ask for help }\end{array}$ \\
\hline $\begin{array}{l}\text { Level of } \\
\text { difficult } \\
\mathrm{y}\end{array}$ & $\begin{array}{l}\text { Big } \\
\text { impact } \\
\text { Motivatio } \\
\mathrm{n}\end{array}$ & Personal effort & Understanding & Nothing & $\begin{array}{l}\text { Rewards } \\
\text { Motivation }\end{array}$ & $\begin{array}{l}\text { Fun } \\
\text { environment/teaching } \\
\text { Laughter } \\
\text { Enthusiasm } \\
\text { Activities/games }\end{array}$ & $\begin{array}{l}\text { They don't get it } \\
\text { and it is required }\end{array}$ \\
\hline $\begin{array}{l}\text { Parents/ } \\
\text { grandm } \\
\text { a } \\
\text { Backgro } \\
\text { und }\end{array}$ & $\begin{array}{l}\text { Not much } \\
\text { Help } \\
\text { motivate } \\
\text { but not } \\
\text { like }\end{array}$ & Personal effort & Nothing & $\begin{array}{l}\text { Lots of examples } \\
\text { Multiples reps }\end{array}$ & $\begin{array}{l}\text { Appropriate pace } \\
\text { Common language }\end{array}$ & $\begin{array}{l}\text { Slow pace, plenty of } \\
\text { time } \\
\text { Many various } \\
\text { examples } \\
\text { Rewards/games, } \\
\text { activities }\end{array}$ & $\begin{array}{l}\text { It is difficult and } \\
\text { they don't use it } \\
\text { at birth }\end{array}$ \\
\hline
\end{tabular}




\begin{tabular}{|c|c|c|c|c|c|c|c|}
\hline & & & & & & Calm teacher & \\
\hline $\begin{array}{l}\text { Achieve } \\
\text { ment } \\
\text { Reward } \\
\text { s }\end{array}$ & $\begin{array}{l}\text { A lot of } \\
\text { impact }\end{array}$ & $\begin{array}{l}\text { Smaller classes } \\
\text { Personal attn }\end{array}$ & $\begin{array}{l}\text { Changing motivation } \\
\text { from grades to wanting } \\
\text { to learn }\end{array}$ & $\begin{array}{l}\text { Slow pace } \\
\text { Thorough } \\
\text { explanation } \\
\text { Thought process }\end{array}$ & Usefulness & $\begin{array}{l}\text { Small class } \\
\text { Interaction with } \\
\text { students } \\
\text { Usefulness }\end{array}$ & $\begin{array}{l}\text { It is hard, boring, } \\
\text { required and not } \\
\text { useful in } \\
\text { everyday life }\end{array}$ \\
\hline $\begin{array}{l}\text { Usefuln } \\
\text { ess } \\
\text { Relate } \\
\text { to life }\end{array}$ & $\begin{array}{l}\text { Moderate } \\
\text { impact } \\
\text { Also } \\
\text { parents } \\
\text { and peers }\end{array}$ & Nothing & $\begin{array}{l}\text { Hates the info that don't } \\
\text { need to know } \\
\text { Actual understanding } \\
\text { Connect to real life }\end{array}$ & $\begin{array}{l}\text { Make connections } \\
\text { Reason to know }\end{array}$ & $\begin{array}{l}\text { Understanding } \\
\text { students' lives and } \\
\text { backgrounds }\end{array}$ & $\begin{array}{l}\text { Hands-on } \\
\text { All students at same } \\
\text { level } \\
\text { Active, prepared } \\
\text { teachers }\end{array}$ & $\begin{array}{l}\text { They don't } \\
\text { understand it and } \\
\text { need to connect } \\
\text { math to other } \\
\text { subjects and their } \\
\text { lives }\end{array}$ \\
\hline $\begin{array}{l}\text { Underst } \\
\text { anding } \\
\text { No } \\
\text { struggle } \\
\text { (easy) }\end{array}$ & $\begin{array}{l}\text { Large role } \\
\text { Good } \\
\text { explanatio } \\
\mathrm{n}\end{array}$ & Personal effort & Time of class & $\begin{array}{l}\text { More involved and } \\
\text { interactive }\end{array}$ & $\begin{array}{l}\text { Simple } \\
\text { explanations } \\
\text { Easy route }\end{array}$ & $\begin{array}{l}\text { Small class } \\
\text { Personal attention } \\
\text { Relaxed atmosphere } \\
\text { Outgoing teacher }\end{array}$ & $\begin{array}{l}\text { They are not } \\
\text { getting good } \\
\text { grades in it }\end{array}$ \\
\hline $\begin{array}{l}\text { Achieve } \\
\text { ment } \\
\text { Effort } \\
\text { matchin } \\
\text { g grade }\end{array}$ & $\begin{array}{l}\text { Big } \\
\text { influence } \\
\text { Caring } \\
\text { teachers }\end{array}$ & $\begin{array}{l}\text { Small class } \\
\text { Comfortable } \\
\text { environment } \\
\text { Able to ask }\end{array}$ & $\begin{array}{l}\text { Understanding } \\
\text { More low risk } \\
\text { assessments collected }\end{array}$ & $\begin{array}{l}\text { Teach different ways } \\
\text { To different levels }\end{array}$ & $\begin{array}{l}\text { Show usefulness } \\
\text { Reason to } \\
\text { understand }\end{array}$ & $\begin{array}{l}\text { Small class } \\
\text { Collect homework } \\
\text { Paper tests } \\
\text { Teacher who likes } \\
\text { math } \\
\text { Teacher who takes } \\
\text { time }\end{array}$ & $\begin{array}{l}\text { If they don't } \\
\text { understand, they } \\
\text { fall behind and } \\
\text { always are trying } \\
\text { to catch up }\end{array}$ \\
\hline $\begin{array}{l}\text { Achieve } \\
\text { ment } \\
\text { Variety } \\
\text { Level of } \\
\text { learning }\end{array}$ & & $\begin{array}{l}\text { Logic class } \\
\text { More review }\end{array}$ & $\begin{array}{l}\text { Importance of personal } \\
\text { effort } \\
\text { Good teacher }\end{array}$ & $\begin{array}{l}\text { Explain 'why' } \\
\text { Multiple reps } \\
\text { Cater to all learners }\end{array}$ & $\begin{array}{l}\text { Student } \\
\text { responsibility } \\
\text { Give tools for } \\
\text { students }\end{array}$ & $\begin{array}{l}\text { Small class } \\
\text { Personal attention } \\
\text { Usefulness } \\
\text { Lecture then labs }\end{array}$ & Didn't ask \\
\hline $\begin{array}{l}\text { Usefuln } \\
\text { ess } \\
\text { Require } \\
\text { ment }\end{array}$ & $\begin{array}{l}\text { Above } \\
\text { average } \\
\text { Pacing } \\
\text { Willing to } \\
\text { help }\end{array}$ & $\begin{array}{l}\text { Study guide } \\
\text { More review } \\
\text { Summary sheet }\end{array}$ & Usefulness & $\begin{array}{l}\text { Positive } \\
\text { Willing to help } \\
\text { Connect with } \\
\text { students } \\
\text { Usefulness } \\
\text { Care }\end{array}$ & $\begin{array}{l}\text { Willing to answer } \\
\text { questions } \\
\text { Care }\end{array}$ & $\begin{array}{l}\text { Smaller class } \\
\text { Interactive } \\
\text { Usefulness } \\
\text { Labs } \\
\text { Organized notes } \\
\text { Appropriate pace } \\
\text { Multiple } \\
\text { representations for }\end{array}$ & Didn’t ask \\
\hline
\end{tabular}




\begin{tabular}{|c|c|c|c|c|c|c|c|}
\hline & & & & & & different learners & \\
\hline $\begin{array}{l}\text { Teacher } \\
\text { Way } \\
\text { course } \\
\text { is laid } \\
\text { out } \\
\text { Pace }\end{array}$ & $\begin{array}{l}\text { Big } \\
\text { impact } \\
\text { Clear } \\
\text { explanatio } \\
\mathrm{n} \\
\text { Usefulnes } \\
\mathrm{s} \\
\end{array}$ & $\begin{array}{l}\text { More group } \\
\text { work }\end{array}$ & $\begin{array}{l}\text { Relate to real-life } \\
\text { Usefulness }\end{array}$ & $\begin{array}{l}\text { Usefulness } \\
\text { Relaxed }\end{array}$ & Clear explanation & $\begin{array}{l}\text { Small class } \\
\text { Group work } \\
\text { Funny teacher }\end{array}$ & $\begin{array}{l}\text { They don't think } \\
\text { they can learn it } \\
\text { because no one } \\
\text { ever showed } \\
\text { them they could }\end{array}$ \\
\hline $\begin{array}{l}\text { Achieve } \\
\text { ment } \\
\text { Ability }\end{array}$ & $\begin{array}{l}\text { Large } \\
\text { impact } \\
\text { Personal } \\
\text { relationshi } \\
\text { p }\end{array}$ & $\begin{array}{l}\text { Personal attn } \\
\text { One-on-one help } \\
\text { Personal effort } \\
\text { Understanding }\end{array}$ & $\begin{array}{l}\text { Better understanding } \\
\text { Revisit old concepts } \\
\text { Connect }\end{array}$ & $\begin{array}{l}\text { Take time } \\
\text { Class management } \\
\text { Know where students } \\
\text { are at } \\
\text { Class management }\end{array}$ & $\begin{array}{l}\text { Make sure all } \\
\text { students understand } \\
\text { More interesting } \\
\text { examples } \\
\text { Age appealing } \\
\text { Frequent checks } \\
\end{array}$ & $\begin{array}{l}75-100 \text { people } \\
\text { Low-risk frequent } \\
\text { assessment } \\
\text { Stern, demanding } \\
\text { teacher }\end{array}$ & $\begin{array}{l}\text { They are turned } \\
\text { off by the subject } \\
\text { because it is not } \\
\text { interesting }\end{array}$ \\
\hline
\end{tabular}

